Discussion Paper No. 04-41

Evaluating the Dynamic Employment Effects of Training Programs in East Germany

\title{
Using Conditional Difference-in-Differences
}

Annette Bergemann, Bernd Fitzenberger and Stefan Speckesser

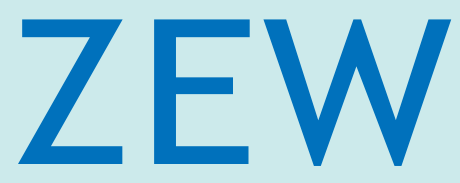

Zentrum für Europäische Wirtschaftsforschung $\mathrm{GmbH}$

Centre for European

Economic Research 
Discussion Paper No. 04-41

\title{
Evaluating the Dynamic Employment Effects of Training Programs in East Germany Using Conditional Difference-in-Differences
}

\author{
Annette Bergemann, Bernd Fitzenberger \\ and Stefan Speckesser
}

Download this ZEW Discussion Paper from our ftp server:

ftp://ftp.zew.de/pub/zew-docs/dp/dp0441.pdf

Die Discussion Papers dienen einer möglichst schnellen Verbreitung von neueren Forschungsarbeiten des ZEW. Die Beiträge liegen in alleiniger Verantwortung der Autoren und stellen nicht notwendigerweise die Meinung des ZEW dar.

Discussion Papers are intended to make results of ZEW research promptly available to other economists in order to encourage discussion and suggestions for revisions. The authors are solely responsible for the contents which do not necessarily represent the opinion of the ZEW. 


\section{Non-technical Summary}

After German unification, Active Labor Market Policies (ALMP) were implemented at a large scale in East Germany in order to prevent unemployment. These programs mainly consisted of training and temporary employment schemes. In 2002, more than a decade later, the German Federal Employment Service (Bundesanstalt für Arbeit, BA) still spent around $€ 20$ Billion $(\approx 0.9 \%$ of the GDP) for ALMP. About $50 \%$ of this budget goes to East Germany even though the labor force in East Germany is less than one sixth of Germany as a whole. Quite a significant share of the labor force in East Germany has been participating in programs of ALMP since 1990. In light of persistently high unemployment, the effectiveness of ALMP in East Germany is often questioned.

Contributing to this debate, we estimate the employment effect of public sector sponsored training programs in East Germany at the individual level for the time period 1990 to 1999. Training programs were intended to provide skills to the individuals that are in demand in a market economy but not in sufficient supply due to the former educational system. Consequently, regarding the number of participants, training was the largest ALMP program in East Germany. Our empirical analysis focusses on the group of individuals who belonged to the active labor force in 1990. This group was hit fully by the transformation shock. We use data from the Labor Market Monitor for the state of Sachsen-Anhalt (Arbeitsmarktmonitor Sachsen-Anhalt LMM-SA).

This paper first provides an overview on training programs in East Germany and develops the methodology for estimating treatment effects of training programs based on a dynamic employment model. Then, the evaluation of the program involves estimating separately the effects on the outcome variables transitions between employment and nonemployment depending on the employment status in the previous month. When evaluating the average effect of labor market policy for the treated individuals, it is important to estimate the counterfactual average nontreatment outcome for the treated individuals based on similar nontreated individuals in order to avoid a possible bias induced by the selection into the programs. We implement nonparametric kernel matching based on the estimated propensity score for treatment. This way, we intend to control for selection bias based on observed characteristics. In a second step, we take before-after differences in outcomes either using a static conditional difference-in-differences estimator (CDiD) or - as an innovation in this paper - a dynamic conditional difference-in-differences estimator in hazard rates (CDiDHR) to account for a remaining potential selection bias due to time invariant, unobserved characteristics. We therefore estimate the effect of the program on the before-after differences in outcomes without explaining their levels.

We argue that estimating CDiDHR is more appropriate since future employment chances are state dependent, i.e. the probability to be employed in the next month 
depends strongly upon whether an individual is employed in the current month. The literature using $\mathrm{CDiD}$ so far has not yet treated employment as a dynamic process.

Another aspect to address is the possibility that before the participation in a labor market program, the employment situation of the future participants deteriorates disproportionately (Ashenfelter's Dip). We take this into account by not using the situation shortly before the start of the program when doing the before-after comparison.

Furthermore, there is the possibility of multiple sequential treatments which might reflect "carousel effects" and which are quite important in the context of a European welfare state. Carousel effects denote a situation where individuals keep participating in labor market programs because the programs do not increase their employment chances but they provide transfer payments to the participants. We address this issue by first estimating the effect of training as a first treatment. Then, we estimate both the incremental effect of a second treatment, which can be another training program or a job creation program, and the combined effect of such sequences.

Important findings are: Training as a first treatment shows insignificant effects on the transition rates. The effect of program sequences and the incremental effect of a second program on the reemployment probability are insignificant. However, the incremental effect on the probability to remain employed is slightly positive. The estimated effects do depend heavily on the time the programs took place. Overall, our results are not as negative as previous results in the literature and it is unlikely that training on average reduces considerably the future employment chances of participants. Of course, this is still far from saying that training was a success! On the methodological side, our study suggests that observed characteristics in the survey data set used here are not sufficient to control completely for selection into treatment. In addition, it also shows, that the likely presence of Ashenfelter's Dip has to be addressed when implementing a difference-in-differences estimator. 


\title{
Evaluating the Dynamic Employment Effects of Training Programs in East Germany Using Conditional Difference-in-Differences*
}

\author{
Annette Bergemann ${ }^{+}$, Bernd Fitzenberger ${ }^{\S}$, Stefan Speckesser ${ }^{\&}$
}

April 2004

\begin{abstract}
This paper evaluates the effects of Public Sponsored Training in East Germany in the context of reiterated treatments. Selection bias based on observed characteristics is corrected for by applying kernel matching based on the propensity score. We control for further selection and the presence of Ashenfelter's Dip before the program with conditional difference-in-differences estimators. Training as a first treatment shows insignificant effects on the transition rates. The effect of program sequences and the incremental effect of a second program on the reemployment probability are insignificant. However, the incremental effect on the probability to remain employed is slightly positive.
\end{abstract}

Keywords: Evaluation of active labor market policy in East Germany, nonparametric matching, conditional difference-in-differences, employment dynamics, Ashenfelter's Dip, bootstrap

JEL classification: C 14, C 23, H 43, J 64, J 68

\footnotetext{
* We are grateful for numerous helpful comments received in seminars at UCL, PSI London, ECB, the Universities of Essen, Bochum, Tor Vergata, Basel, Bergen, Tübingen, Heidelberg, Bristol, Humboldt University in Berlin, Mannheim, Erfurt, and Tinbergen Institute Amsterdam. We also benefitted from the comments received at the GAAC-ZEW conference, IZA workshop, "Ausschuß für Ökonometrie", ESEM in Venice, EEA Summerschool 2003, RTN-conference on the Evaluation of European Labour market Policies 2003, and a CEPR conference on Education Policies 2003. We especially thank Gerard van den Berg and Ed Vytlacil for their very helpful comments. Thanks goes also to Thomas Ketzmerick of the ZSH for the provision and help with the data. Annette Bergemann acknowledges the support by a Marie Curie Fellowship of the European Community Programme 'EU Training and Mobility of Researcher' under contract number HPMF-CT-200202047. The usual disclaimer applies.

Corresponding Author: Bernd Fitzenberger, Department of Economics, Goethe-University, PO Box 111932 (PF 247), 60054 Frankfurt am Main, Germany, Email: fitzenberger@wiwi.unifrankfurt.de

+ University of Mannheim and Tinbergen Institute Amsterdam $\S$ Goethe-University Frankfurt, ZEW, and IFS \& University of Mannheim
} 


\section{Contents}

1 Introduction 1

2 Training in East Germany 3

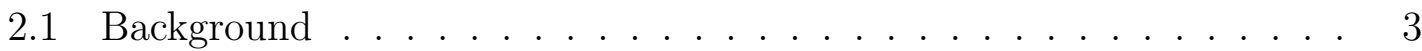

2.2 Training under the Labor Promotion Act 1990-1997 . . . . . . . . . . 4

2.3 Changes in Programs and Incentives . . . . . . . . . . . . . 5

2.4 Aggregate Participation . . . . . . . . . . . . . . . 6

$\begin{array}{lll}3 & \text { Evaluation Approach } & 6\end{array}$

3.1 Selection on Observables and Matching _ . . . . . . . . . . . 7

3.2 Employment Model and Ashenfelter's Dip . . . . . . . . . . . . . . 10

3.3 Conditional Difference-in-Differences . . . . . . . . . . . . . . . 11

3.3.1 Conditional Difference-in-Differences in Employment Rate . . 12

3.3.2 Conditional Difference-in-Differences in Hazard Rates (CDiDHR) . . . . . . . . . . . . . . . 12

3.4 Multiple Treatments and Carousel Effects . . . . . . . . . . . . . . . 14

4 Empirical Analysis $\quad 15$

4.1 Data . . . . . . . . . . . . . . . . . . . 15

4.2 Implementation of Evaluation Approach . . . . . . . . . . . . . 18

4.3 Specification of Outcome Equation . . . . . . . . . . . . . . . 20

4.4 Estimated Treatment Effects _. . . . . . . . . . . . . . . 23

4.4.1 CDiD Results . . . . . . . . . . . . . . . . 24

4.4 .2 CDiDHR Results . . . . . . . . . . . . . . . 25

$\begin{array}{lll}5 & \text { Conclusions } & 27\end{array}$

$\begin{array}{ll}\text { References } & 29\end{array}$

$\begin{array}{ll}\text { Appendix } & 32\end{array}$ 


\section{Introduction}

After the formation of the German "Social and Economic Union" in 1990, the East German economy underwent enormous changes. It had to transform from a command driven backward economy to a market economy at an unprecedented speed. The transformation process brought about high unemployment in East Germany. To increase the employment chances of the unemployed, the German government decided to provide on a high scale Active Labor Market Policies (ALMP) in East Germany. These programs mainly consisted of training and temporary employment schemes. In 2002, more than a decade after the reunification, the German Federal Employment Service (Bundesanstalt für Arbeit, BA) still spent around $€ 20$ Billion $(\approx 0.9 \%$ of the GDP) for ALMP (Bundesanstalt für Arbeit, 2003). About $50 \%$ of this budget is spent in East Germany even though the labor force in East Germany is less than one sixth of Germany as a whole. Quite a significant share of the labor force in East Germany has been participating in programs of ALMP since 1990.

Contributing to the debate on the effectiveness of ALMP, this paper estimates the employment effect of public sector sponsored training programs in East Germany at the individual level for the time period 1990 to 1999. In the early 90s, training was often considered to be the most effective among the ALMP programs. It was intended to provide skills that are in demand in a market economy but not in sufficient supply due to the former educational system. Consequently, regarding the number of participants, training was the largest ALMP program in East Germany.

In our empirical analysis we focus on the group of individuals who belonged to the active labor force in 1990. This group was hit fully by the transformation shock. We use data from the Labor Market Monitor for the state of Sachsen-Anhalt (Arbeitsmarktmonitor Sachsen-Anhalt LMM-SA), a data set allowing for monthly information on employment and program participation.

We implement a semiparametric conditional difference-in-differences estimator (CDiD) (Heckman/Ichimura/Smith/Todd, 1998). In the light of the state dependence of the employment process we extend the CDiD approach to use transition rates between different labor market states as outcome variables instead of exclusively use employment rates in levels as often done in the literature.

For the implementation of the CDiD estimator, we apply propensity score matching in the first stage and then estimate average effects of treatment-on-the-treated. The analysis matches treated individuals to nonparticipants using kernel matching to account for selection on observables. Selection on time invariant unobservable characteristics is controlled for using a conditional difference-in-differences estimator. Our inference uses a bootstrap approach taking account of the estimation error in the propensity score. We perform a sensitivity analysis on the implementation details of the evaluation approach. 
Our results indicate that modeling transition rates is more appropriate than using unconditional employment rates. Using only employment rates as success criterion could result in misleading conclusions concerning the effectiveness of ALMP programs. With regard to the transition rates, we find that the employment effects are mostly insignificant and that there are some significantly positive effects for selected start dates.

In addition, our results show the usefulness of exploiting the additional information which transition rates can provide as opposed to unconditional employment rates. With the aid of transition rates we are able to determine whether ALMP programs help to find a job and/or whether they rather stabilize employment. Our results show significant variation over time concerning these two outcomes.

We make three additional points in the methodological debate on program evaluation: First, anticipation effects regarding future participation or eligibility criteria (Ashenfelter's Dip) requiring a certain elapsed duration of unemployment for participation are likely to affect strongly the results of any difference-in-differences estimator (Heckman and Smith, 1999). Using institutional knowledge to bound the start of the Ashenfelter's Dip, we suggest a long-run difference-in-differences estimator to take account of possible effects of anticipation or participation rules. Second, we suggest a heuristic cross-validation procedure for the bandwidth choice which is well suited to the estimation of conditional expectations for counterfactual variables.

The third point relates to the fact that in East Germany individuals often participate more than once in a program during a short time period. Some observers (e.g. Hagen and Steiner, 2000) suggest that multiple program participation occurs because the participants cannot (or do not want to) find a job after the end of the first program. In order to keep their transfer income (and possibly in order to lower the level of official unemployment), these persons participate in a further program "carousel effect"). To address this issue, our study estimates the effects of participation in training as first program and of participation in a second program afterwards, be it a second training program or a job creation program. Regarding participation in a second program, we estimate both the incremental effect of the second program and the combined effect using our difference-in-differences approach. ${ }^{1}$

Former studies on the effect of ALMP in East Germany on the individual employment chances provide mainly negative though unclear evidence, see the surveys in Fitzenberger and Speckesser (2002) and Hagen and Steiner (2000). The existing studies suffer greatly from data limitations, either they are plagued by a small num-

\footnotetext{
${ }^{1}$ Some progress has been made in the methodological literature in order to extend standard static evaluation approaches to the dynamic selection issue involved here, see Lechner/Miquel (2001). The requirements on the data when applying the Lechner/Miquel approach are unlikely to be satisfied in our case (see section 3 below) and we are not aware of an actual application of this approach.
} 
ber of participants (German Socio-Economic Panel, e.g. Lechner, 1998) or the data is limited to the early 1990's and does not allow for constructing the employment history on a monthly basis (Labor Market Monitor for East Germany, e.g. Fitzenberger/Prey, 2000). ${ }^{2}$

The paper is organized as follows: Section 2 gives a short description of the institutional background for ALMP in East Germany and discusses descriptive evidence. Section 3 develops the microeconomic evaluation approach used here. The implementation of the approach is described and the empirical results of the evaluation are discussed in section 4 . Section 5 concludes. The appendix includes detailed descriptive evidence and results.

\section{Training in East Germany}

\subsection{Background}

Between 1969 and 1997, training as part of Active Labor Market Policy in Germany was regulated by the Labor Promotion Act (Arbeitsförderungsgesetz, AFG). Despite a number of changes in the regulation over this time period, the basic design of training programs remained almost unchanged until the AFG was replaced by the new Social Law Book III (SGB III) in 1998. The German Federal Labor Office (Bundesanstalt für Arbeit, BA) was in charge of implementing these programs in addition to being responsible for job placement and for paying out unemployed benefits. Training programs under the AFG rule fell into four categories: ${ }^{3}$ Further Vocational Training (Fortbildung), Re-training (Umschulung), Short-term training (Kurzzeitmaßnahmen nach $\S 41 a A F G$ ) and Integration subsidies (Einarbeitungszuschuss, $\S \S 33$ - 52 AFG). With German unification, these programs were extended to East Germany after July 1990 ( $§ 249$ AFG). Policy makers intended to foster the adjustment of the East German human capital stock to Western levels. The large and prolonged use of ALMP was also justified by equity goals (the standard of living in East Germany should converge quickly to Western levels) and by political goals (political stability after a massive transformation shock and avoiding large scale outmigration).

\footnotetext{
${ }^{2}$ Our earlier paper Bergemann et al. (2000), where the impact on employment rates is estimated for the period 1990 to 1998, is an exception. Reliable administrative data on ALMP has so far not been made available.

${ }^{3}$ We ignore German language courses which have different target groups.
} 


\subsection{Training under the Labor Promotion Act 1990-1997}

Further vocational training ( $\S 41 \mathrm{AFG}$ ) consists of the assessment, maintenance, and extension of skills. The duration of the courses depends on the characteristics of the participants. The courses regularly take between 2 and 8 months and are mainly offered by private sector training companies.

Re-training enables vocational re-orientation if no adequate employment can be found because of skill obsolescence. Re-training is supported by the BA for a period up to 2 years and aims at providing a new certified vocational training degree.

Short-term training aim at increasing the employment chances by skill assessment, orientation, and guidance. The courses are intended to increase the placement rate of the unemployed. Mostly, they do not provide occupational skills but aim at maintaining search intensity and increasing hiring chances. The courses usually last from two weeks to two months.

Integration Subsidies involve payments to employers providing employment to previously unemployed workers who need a training period. The worker earns a regular wage from the employer. This program is included in official numbers of participation in training programs. However, it is not analyzed in our empirical analysis because the data used do not allow to identify it.

Except for integration subsidies, all participants in full-time courses are granted an income maintenance payment (Unterhaltsgeld) if the conditions of entitlement are satisfied. To qualify, persons must meet the requirement of being previously employed for a minimum duration during a set period of time, i.e. at least one year in employment or receipt of unemployment benefit or subsequent unemployment assistance. The set period may be extended for individuals returning to the labor market.

The income maintenance payment amounts to the same level as unemployment benefits, i.e. to $67 \%$ (60\%) of previous net earnings for participants with (without) at least one dependent child. The income maintenance payments used to be higher in the early 1990's (see below). If a person does not fulfill the requirement of previous employment, but received unemployment assistance until the start of treatment, the income maintenance may be paid as well. Participants re-qualify for unemployment benefits providing an additional incentive for participation. The BA also covers all the direct training costs such as course fees. 


\subsection{Changes in Programs and Incentives}

During the 1990's, legislation modified the types of programs, the level of income maintenance payments, and the eligibility criteria. Short-term training programs were abolished formally in 1992 and in 1993, a new program started with the same purpose. However, participants were no longer considered as taking part in training programs and were therefore recorded as unemployed. Income maintenance payments were reduced after 1993 from 68\% (63\%) of the net earnings during previous employment for participants with (without) children to $63 \%$ (60\%).

Before 1994, participation in a training program was accessible for participants without having experienced unemployment beforehand as long as the case worker considered participation in training as "advisable". This type of training intended to prevent future unemployment, to increase the labor market prospects of the employed in the future, or to foster re-integration of individuals returning to the labor market. Starting in 1994, the access was restricted to individuals fulfilling the criteria for "necessary" training which basically restricted the program to formerly unemployed participants. However, especially in East Germany, the participation under the weak criterion of "being threatened by unemployment" was still possible.

The changes resulted in a new mix of participants in trainings programs and they somewhat shifted the focus of training. A credible evaluation strategy has to account for these changes.

The end of explicit short-term training programs made the remaining programs longer and more expensive on average. In addition, the remaining program mix was less explicitly focussed on a immediate placement of participants. The mix of programs observed after the change is more strongly focussed on providing additional skills and helping participants to signal their skills. We suspect therefore that, on the one hand, incentives to participate are stronger on average than for the program mix before the reform. This may result on average in stronger anticipation effects such that in the prospect of participation unemployed individuals decrease their search effort for a new job.

On the other hand, training programs became less attractive, especially for workers who are still employed, both due to the lower income maintenance payments and due to the focus on previously unemployed individuals. Over time, a change in the selection of the program group occurred restricting training to problem groups with a priori significantly lower employment chances. 


\subsection{Aggregate Participation}

Training programs were implemented in East Germany immediately after unification (see figure 1): 98,500 persons started to participate during the last three months of 1990. In 1991, the maximum was reached with 892,145 entries. Only in 1992, there was a similar magnitude. Afterwards the number was much lower and it went down to 166,000 in 1997. During the most recent years, participation recovered at a level slightly above 180,000 reflecting the ongoing importance of these programs in East Germany. The share of entries into re-training in percent of training in total varies between $15 \%$ in 1991 and $28 \%$ in 1993, the share for integration subsidies declines from $15 \%$ in 1991 to $8 \%$ in 1997. No separate figures are available neither for short-term training and further vocational training for the early 1990's nor for the subprograms after 1997 due to the change in the regulation.

Stocks of participants show a similar pattern (see figure 2). The maximum was reached in 1992, amounting to 492,000 participants on average. Participation has been declining afterwards (2000: 139,700, 2002: 129,000 participants). The trends for the subprograms (not reported in figure 2) are analogous.

Direct costs for participation paid by the BA (see figure 2, right axis) - income maintenance, course fees, travel costs etc. - continuously increased over time. In 1991, when short-term training programs still existed, annual costs were at $€ 8,000$ per participant. With $€ 14,600$ in 1995 and the most recent number being $€ 20,600$, the programs observed became much more expensive over time.

\section{Evaluation Approach}

Our empirical analysis is based upon the potential-outcome-approach to causality (Roy, 1951, Rubin, 1974), see the survey Heckman/LaLonde/Smith (1999). We focus on estimating the average causal effect of treatment-on-the-treated (TT) in the binary treatment case. ${ }^{4} \mathrm{TT}$ is given by

$$
E\left(Y^{1} \mid D=1\right)-E\left(Y^{0} \mid D=1\right)
$$

\footnotetext{
${ }^{4}$ The framework can be extended to allow for multiple, exclusive discrete treatments. Lechner (1999) and Imbens (2000) show how to extend standard propensity score matching estimators for this purpose and e.g. Larsson (2003) provides an application to ALMP in Sweden based on a large and quite homogeneous treatment and comparison group. Although, it would be a natural extension in our application to explicitly allow for multiple, exclusive treatments by ALMP, we do not think that our data is sufficiently rich enough for this purpose. In addition, our analysis is much more demanding since we argue that matching on observable covariates will not suffice to control for selection bias and since we model the effects on transition rates between different labor market states. Therefore, we restrict ourselves to estimating TT for training where the comparison group is the group of all individuals who either do not participate in any program or who only participate in other programs where the latter two are weighted by their sample frequencies.
} 
where the treatment outcome $Y^{1}$ and the nontreatment outcome $Y^{0}$ are the two potential outcomes and $D$ denotes the treatment dummy. Our outcome variable of interest is a dummy variable for employment, possibly conditional on employment in the previous month resulting in a transition dummy. The observed outcome $Y$ is given by $Y=D Y^{1}+(1-D) Y^{0}$. The evaluation problem consists of estimating $E\left(Y^{0} \mid D=1\right)$ since the counterfactual outcome in the nonparticipation situation is not observed for the participating individuals $(D=1)$. Thus, identifying assumptions are needed to estimate $E\left(Y^{0} \mid D=1\right)$ based on the outcomes for nonparticipants $(D=0)$.

We apply a conditional difference-in-differences (CDiD) approach which combines two widely used concepts to estimate the average nontreatment outcome for the treated $E\left(Y^{0} \mid D=1\right)$. One is to consider the situation of program participants before treatment (before-after-comparison) and the other is to consider a control group of comparable persons who did not participate. The major drawback of the before-and-after comparison lies in the assumption of a constant average nontreatment outcome over time for the treated population. This is violated, if over time labor market outcomes change irrespective of participation, i.e. formally $E\left(Y_{t 0}^{0} \mid D=1\right) \neq E\left(Y_{t 1}^{0} \mid D=1\right)$ where $t 0$ is a point of time before treatment and $t 1$ after treatment. Another issue involves participation rules and possible anticipation effects of the treatment (Ashenfelter's Dip) resulting in $Y_{t 0}^{0}$ already being affected by the treatment in the future. Regarding the selection of an appropriate control group, it is usually not warranted to assume that the average nonparticipation outcome of the participants is the same as for the nonparticipants, i.e. we have $E\left(Y^{0} \mid D=1\right) \neq E\left(Y^{0} \mid D=0\right)$. Thus, a readily available sample estimate for $E\left(Y^{0} \mid D=0\right)$ is not a consistent estimate for the counterfactual $E\left(Y^{0} \mid D=1\right)$.

\subsection{Selection on Observables and Matching}

Assuming the Conditional Mean Independence Assumption (CIA)

$$
E\left(Y^{0} \mid D=1, X\right)=E\left(Y^{0} \mid D=0, X\right)
$$

implies that the nontreatment outcome of the participants and of the nonparticipants are now comparable in expectation when conditioning on $X$. Then, to estimate the expected nonparticipation outcome for the participants with observable characteristics $X$, it suffices to take the average outcome for nonparticipants with the same $X$. This is the basis of the popular matching approach, see Heckman/Ichimura/Todd (1998), Heckman/Ichimura/Smith/Todd (1998), Heckman/LaLonde/Smith (1999), or Lechner (1998). This approach estimates the expected nontreatment outcome for a participant $i$ with characteristics $X$ by the fitted value of a nonparametric regression in the sample of nonparticipants at point $X$. The nonparametric regression can be represented by a weight function $w_{N_{0}}(i, j)$ that gives the higher a weight to 
nonparticipants $j$ the stronger his similarity to participant $i$ regarding $X$. For each $i$, these weights sum up to one over $j\left(\sum_{j \in\{D=0\}} w_{N_{0}}(i, j)=1\right)$. The estimated TT is then

$$
\frac{1}{N_{1}} \sum_{j \in\{D=1\}}\left\{Y_{i}^{1}-\sum_{j \in\{D=0\}} w_{N_{0}}(i, j) Y_{j}^{0}\right\},
$$

with $N_{0}$ the number of nonparticipants $j$ and $N_{1}$ the number of participants $i$.

Matching estimators differ with respect to the weights attached to members of the comparison group. The most popular approach in the literature is nearest neighbor matching just using the outcome for the closest nonparticipant $(j(i))$ as the comparison level for participant $i$, see Heckman/LaLonde/Smith (1999) and Lechner (1998). In this case, $w_{N_{0}}(i, j(i))=1$ for the nearest neighbor $j(i)$ and $w_{N_{0}}(i, j)=0$ for all other nonparticipants $j \neq j(i)$. Following Heckman, Ichimura, Smith, Todd (1998), we implement a different matching approach using a nonparametric local linear kernel regression to estimate the expected nonparticipation outcome of participants with certain characteristics, see also Pagan/Ullah (1999). This amounts to specifying the weight function based on a kernel function which has as its argument the distance in terms of characteristics of the individuals. ${ }^{5}$ This so called kernel matching has a number of theoretical advantages compared to nearest neighbor matching. The asymptotic properties of kernel based methods are straightforward to analyze and it has been shown that bootstrapping provides a consistent estimator of the sampling variability of the estimator in (3) even if matching is based on closeness in generated variables (this is the case with the popular method of propensity score matching which will be discussed below), see Heckman/Ichimura/Smith/Todd (1998) or Ichimura/Linton (2001) for an asymptotic analysis of kernel based treatment estimators. We are not aware of similar results for nearest neighbor matching.

It is difficult to match with respect to a high-dimensional vector of observable characteristics X ("curse-of-dimensionality"), see Pagan/Ullah (1999). Therefore, the evaluation literature uses extensively the result of Rosenbaum and Rubin (1983) that the CIA in equation (2) implies that participants and nonparticipants become comparable in expectation when conditioning on the treatment probability $P(X)$ (propensity score) as a function of the observable characteristics $X$, i.e.

$$
E\left(Y^{0} \mid D=1, P(X)\right)=E\left(Y^{0} \mid D=0, P(X)\right)
$$

provided $0<P(D=1 \mid X)<1$. This result reduces the matching problem to one dimension effectively using the "closeness" in the propensity score as the weighting scheme. However, the propensity score has to be estimated. We implement kernel matching based on the estimated propensity score. We take account of the sampling

\footnotetext{
${ }^{5}$ We also checked the sensitivity of our results by using nearest neighbor matching without and with caliper (the latter allows only for matches which are sufficiently close). For our application, it turned out that the choice of matching approach had no notable impact on the estimated treatment effects. We only report the results using kernel matching.
} 
variability in the estimated propensity score by applying a computationally quite expensive bootstrap method to construct the standard errors of the estimated treatment effects. To account for autocorrelation over time, we use the entire time path for each individual as block resampling unit. All the bootstrap results reported in this paper are based on 200 resamples.

For the local linear kernel regression in the sample of nonparticipants, we use the Gaussian kernel, see Pagan/Ullah (1999). ${ }^{6}$ Standard bandwidth choices (e.g. rules of thumb) for pointwise estimation are not advisable here since the estimation of the treatment effect is based on the average expected nonparticipation outcome for the group of participants, possibly after conditioning on some information to capture the heterogeneity of treatment effects. Since averaging pointwise estimates reduces the variance, it is clear that the asymptotically optimal bandwidth should go to zero faster than an optimal bandwidth for a pointwise estimate, see Ichimura/Linton (2001) on such results for a different estimator of treatment effects. ${ }^{7}$

To choose the bandwidth, we suggest the following heuristic leave-one-out crossvalidation procedure which mimics the estimation of the average expected nonparticipation outcome for each period. First, for each participant $i$, we identify the nearest neighbor $n n(i)$ in the sample of nonparticipants, i.e. the nonparticipant whose propensity score is closest to that of $i$. Second, we choose the bandwidth to minimize the sum of the period-wise squared prediction errors

$$
\sum_{t=1}^{T}\left[\frac{1}{N_{1, t}} \sum_{i=1}^{N_{1, t}}\left(Y_{n n(i), t}^{0}-\sum_{j \in\{D=0\} \backslash n n(i)} w_{i, j} Y_{j, t}^{0}\right)\right]^{2}
$$

where the prediction of employment status for $n n(i)$ is not based on the nearest neighbor $n n(i)$ himself and $t=1, \ldots, T$ denotes the month $(T=120$ for our data). The optimal bandwidth affecting the weights $w_{i, j}$ through the local linear regression is determined by a one-dimensional search. The resulting bandwidth is typically smaller than a rule-of-thumb value for pointwise estimation, but this is not always the case, see Ichimura/Linton (2001) for similar evidence in small samples based on simulated data. Since our method for the bandwidth choice is computationally quite expensive, it is not possible to bootstrap it. Instead, we use the bandwidth found for the sample in all resamples.

\footnotetext{
${ }^{6}$ A kernel function with unbounded support avoids some of the problems involved with local linear kernel regression, namely, that the variance can be extremely high in areas where there is not a lot of data, see Seifert/Gasser (1996) and Frölich (2001) for a critical assessment of local linear kernel regression.

${ }^{7}$ This is also the rationale for researchers using nearest neighbor matching with just the closest neighbor thus focussing on minimizing the bias.
} 


\subsection{Employment Model and Ashenfelter's Dip}

We specify the econometric model for employment in order to be clear about which treatment parameters are estimated. The dummy variable for employment $Y_{i t}$ of individual $i$ in month $t$ exhibits strong state dependence, i.e. holding everything else constant the probability to remain employed $P\left(Y_{i t}=1 \mid Y_{i, t-1}=1\right)$ given that $i$ is employed in the previous month is likely to be much higher than the reemployment probability $P\left(Y_{i t}=1 \mid Y_{i, t-1}=0\right)$ given that $i$ is not employed in the previous month. ${ }^{8}$ Therefore, the dynamic employment process for individual $i$ is specified using separate outcome equations depending on the state in the previous month as

(5) $Y_{i t}=\left\{\begin{array}{lrll}a^{e}\left(X_{i}, t\right)+\delta_{i, t, \tau}^{e} D_{i, t}(\tau)+c_{i}^{e}+u_{i, t}^{e} & \text { for } & Y_{i, t-1}=1 & \text { (employed before) } \\ a^{n}\left(X_{i}, t\right)+\delta_{i, t, \tau}^{n} D_{i, t}(\tau)+c_{i}^{n}+u_{i, t}^{n} & & Y_{i, t-1}=0 & \text { (not empl. before) }\end{array}\right.$

where $D_{i, t}(\tau)$ is a dummy variable for treatment in period $\tau, a^{e}\left(X_{i}, t\right), a^{n}\left(X_{i}, t\right)$ are functions describing the state dependent employment probabilities as a flexible function of observed time invariant characteristics $X_{i}$ and month $t, \delta_{i, t, \tau}^{e}, \delta_{i, t, \tau}^{n}$ are the individual specific, state dependent effects of treatment on the employment probabilities, $c_{i}^{e}, c_{i}^{n}$ are state dependent permanent individual specific effects, and $u_{i, t}^{e}, u_{i, t}^{n}$ are the idiosyncratic, period specific effects. To simplify the notation, we only consider the effects of treatment in one period $\tau$. Furthermore, we assume that the effect of treatment occurs after treatment, i.e. $\delta_{i, t, \tau}^{k}=0$ for $t<\tau$ and $k=e, n{ }^{9}$ We will discuss below Ashenfelter's Dip as linking treatment and the idiosyncratic error term before treatment. We allow the individual treatment effect $\delta_{i, t, \tau}^{k}(k=e, n)$ to depend upon observed characteristics $X_{i}$ and the individual specific effects $c_{i}^{k}$. They are also allowed to vary by $i, t$, and $\tau$ conditional upon $X_{i}$ and $c_{i}^{k}$. For the idiosyncratic error terms, we assume that $u_{i, t}^{e}, u_{i, t}^{n}$ are mean independent of treatment in the past.

Regarding the issue of selection bias, the evaluation approach should allow that treatment $D_{i, t}(\tau)$ is affected by the observed covariates $\left(X_{i}, t\right)$, by the treatment effects $\delta_{i, t, \tau}^{e}, \delta_{i, t, \tau}^{n}$ and by the individual specific effects $c_{i}^{e}, c_{i}^{n}$. Furthermore, we should not impose strong functional form restrictions on the specification of $a^{e}\left(X_{i}, t\right), a^{n}\left(X_{i}, t\right)$. The evaluation approach should be as nonparametric as possible relying on the smallest plausible set of assumptions.

It is often observed, that shortly before the participation in a labor market program the employment situation of the future participants deteriorates disproportionately. A similar finding termed Ashenfelter's Dip was first discovered when evaluating the treatment effects on earnings (Ashenfelter, 1978). Later research

\footnotetext{
${ }^{8}$ In this section, the index $i$ denotes any individual whereas in the remainder of the paper $i$ applies only to treated individuals.

${ }^{9}$ This assumption is similar to the timing-of-events approach in the literature using duration models to estimate treatment effects, see Abbring/Van den Berg (2003).
} 
demonstrated that the same phenomenon can also occur regarding employment, see Heckman/LaLonde/Smith (1999), Heckman/Smith (1999), and Fitzenberger/Prey (2000). We argue that in our context Ashenfelter's Dip is caused by participation rules or anticipation effects. Therefore, we allow that $D_{i, t}(\tau)$ can be correlated with $u_{i, \tau-s}^{k}(k=e, n)$ with $s=1, \ldots, a d$ and ad denotes the begin of Ashenfelter's Dip. Even though no tough participation rules were applied in East Germany in the early 1990's, it is clear that in most cases unemployment must have lasted some time before treatment could start. A reason for anticipation effects can be that unemployed workers or workers at the risk of becoming unemployed reduce their search effort if they know that participation in an active labor market program is an option in the near future. Analogously, unemployed individuals expecting to start a new job in the future are not likely to receive treatment.

It is conceivable to interpret Ashenfelter's Dip as a treatment effect thus violating our timing-of-events assumption. We stick to this assumption since both anticipation effects and participation rules have no bearing on the economic mechanisms at work during and after treatment. Therefore, we assume that these preprogram effects are not linked to the outcome variable once treatment has started, i.e. $u_{i, \tau-s}^{k}(k=e, n)$ are not correlated with $u_{i, t}^{k}$ with $s \geq 1$ and $t \geq \tau \cdot{ }^{10}$

In our empirical analysis, we allow for a maximum length of time (ad months) for Ashenfelter's Dip. ad is set according to institutional features of the programs under consideration. After inspection of the data, we set ad conservatively and we let it vary over time (see section 4.3 and 4.4 ). While it is likely that shortly after German unification the anticipation of program participation occurs only shortly before the begin of the program and participation rules were applied in a very lax way, ad increases with the rise of unemployment during the early 1990s.

\subsection{Conditional Difference-in-Differences}

While the matching approach addresses selection bias due to observed variables, selection bias due to unobserved characteristics has to be addressed differently. We allow the selection into treatment to be affected by the permanent unobserved effects in our employment model in equation (5). For instance, unobserved characteristics could be due to differences in the motivation of participants or could reflect that programs are targeted to individuals with some particular problems in the labor market. ${ }^{11}$ The difference-in-differences estimator can be used when selection effects

\footnotetext{
${ }^{10}$ This is in contrast to Heckman/Smith (1999) who model the recovery process to be expected (based on nontreatment outcomes) after the treatment being parallel to the deterioration during Ashenfelter's Dip. The state dependence in our employment process results in a recovery process which does not have to be parallel to what happens before the treatment.

${ }^{11} \mathrm{We}$ do not pursue to estimate an econometric selection model since the scarce data do not allow for credible exclusion restrictions in the participation equation, see section 4.1 .
} 
are additively separable and time invariant. Then, it is possible to use the framework in section 3.1 by merely analyzing the before-after-change in the outcome variable instead of its level. We implement a conditional difference-in-differences (CDiD) estimator using preprogram differences in the outcome variable after matching to control for remaining unobservable differences. In order to avoid the "fallacy of alignment" (Heckman/LaLonde/Smith, 1999), we have to take account of possible preprogram effects via Ashenfelter's Dip. We extend the CDiD as used in the literature to fully capture the state dependence in the employment process.

\subsubsection{Conditional Difference-in-Differences in Employment Rate}

Following the approach in Heckman/Ichimura/Smith/Todd (1998), ${ }^{12}$ we use kernel matching based on the estimated propensity score to match participants $i$ and nonparticipants $j$ in the same time period $t$ and then the simple CDiD-estimator for the treatment effect on the employment rate $^{13}$ in period $t 1$ is given by

$$
\frac{1}{N_{1}} \sum_{i=1}^{N_{1}}\left[Y_{i, t 1}^{1}-Y_{i, t 0}^{0}-\sum_{j} w_{i, j}\left(Y_{j, t 1}^{0}-Y_{j, t 0}^{0}\right)\right]
$$

where period $t 1$ lies after and $t 0$ before treatment of individual $i, N_{1}$ is the number of participants $i$ for whom the $t 1-t 0$ difference can be determined, and due to Ashenfelter's Dip t0 must lie before $\tau-a d .^{14}$

CDiD is a valid estimator if the employment process in equation (5) does not exhibit state dependence and if the idiosyncratic error term is conditionally mean independent of treatment status $D$ and covariates $X_{i}$, i.e. $E\left(u_{i, t} \mid D=1, X_{i}\right)=E\left(u_{i, t} \mid D=\right.$ $\left.0, X_{i}\right)=0$ for $t \geq \tau$ and $t<\tau-a d, a^{e}\left(X_{i}, t\right)=a^{n}\left(X_{i}, t\right), c_{i}=c_{i}^{e}=c_{i}^{n}$, and $u_{i, t}=u_{i, t}^{e}=u_{i, t}^{n}$. However, the common individual specific effect $c_{i}$ does not have to be conditionally mean independent $D$ and $X_{i}$.

\subsubsection{Conditional Difference-in-Differences in Hazard Rates (CDiDHR)}

Based on the employment model in equation (5), we develop the following Conditional Difference-in-Differences in Hazard Rates (CDiDHR) estimator as an extension of the CDiD estimator to a state dependent employment process. We simply

\footnotetext{
${ }^{12}$ See also Blundell et al. (2003) for an application of the CDiD, where age and regional variation is used to take account of selection effects.

${ }^{13}$ Although our model is defined in discrete time we use the word 'rate', as it can be aggregated to a probability in discrete time.

${ }^{14}$ We do not take symmetric differences $\left(\tau_{0}-t 0=t 1-\tau_{1}\right.$ with $\tau_{0}$ begin of program and $\tau_{1}$ end of program) as in Heckman/Ichimura/Smith/Todd (1998) or Heckman/Smith (1999). We think their approach assumes an implausible symmetry between those effects driving Ashenfelter's Dip and the recovery process after participation, see also discussion in footnote 10 above.
} 
estimate the treatment effect on the probability to be employed via CDiD conditional on employment status in the previous month by

$$
\frac{1}{N^{l}} \sum_{i \in \mathcal{N}^{l}} g_{i}\left[Y_{i, t 1}^{1}-Y_{i, t 0}^{0}-\sum_{j} w_{i, j}\left(Y_{j, t 1}^{0}-Y_{j, t 0}^{0}\right)\right]
$$

where $l$ denotes the employment status in the previous month $(l=1$ if previously employed and $l=0$ if previously nonemployed), $\mathcal{N}^{l}$ is the set of treated individuals for whom $Y_{i, t 1-1}=Y_{i, t 0-1}=l$, where $t 1$ after and $t 0$ before treatment of individual i. $N^{l}$ is the number of individuals in $\mathcal{N}^{l}$. Also, only nonparticipants $j$ for whom $Y_{j, t 1-1}=Y_{j, t 0-1}=l . g_{i}$ is a set of weights to account for the fact that $\mathcal{N}^{l}$ does not include the entire treatment sample. For $l=0$ and $l=1$, expression (6) estimates the reemployment probabilities when unemployed and the probability to remain employed, respectively.

To properly account for selection bias in the nonparticipation outcome, CDiDHR only requires the idiosyncratic error terms to be conditionally mean independent of treatment status $D$ and covariates $X_{i}$, i.e. $E\left(u_{i, t}^{e} \mid D=1, X_{i}\right)=E\left(u_{i, t}^{e} \mid D=0, X_{i}\right)=$ $E\left(u_{i, t}^{n} \mid D=1, X_{i}\right)=E\left(u_{i, t}^{n} \mid D=0, X_{i}\right)=0$ for $t \geq \tau$ and $t<\tau-a d$. Analogous to $\mathrm{CDiD}$, the individual specific effects $c_{i}^{l}$ do not have to be conditionally mean independent of treatment status $D$ and covariates $X_{i}$. Also for CDiDHR, t0 must lie before $-a d$, i.e. before anticipation and participation rules can take effect, because of the possibility of Ashenfelter's Dip.

A disadvantage at first glance lies in the fact that using weights $g_{i}=1, \mathrm{CDiDHR}$ does not identify the unconditional TT $E\left(\delta_{i, t 1, \tau}^{k} \mid D=1\right)$ but instead the TT $E\left(\delta_{i, t 1, \tau}^{k} \mid D=1, Y_{t 1-1}=l, Y_{t 0-1}=l\right)$ conditional on the employment status $l$ both in the previous month $(l=0$ if $k=n$ and $l=1$ if $k=e)$ and in the month before the baseline period $t 0$. The latter TT is not the same as the unconditional TT with the potential treatment effects $\delta_{i, t, \tau}^{k}$ being defined irrespective of the employment status of individual $i$ in the previous month. To estimate the unconditional TT, it would be necessary both to account for the differences in the distribution of the $X_{i}$ characteristics and of the individual specific effects $c_{i}^{k}$ with $k=e, n$, since the individual specific treatment effects in the employment model (5) as well as the observed employment status in the previous month presumably depend upon both $X_{i}$ and the $c_{i}^{k}$ 's. Differences in $X_{i}$ and the $c_{i}^{k}$ 's result in a sorting of high employment individuals into the group of employed individuals in the previous month and vice versa.

In section 4 , we define the weights $g_{i}$ to integrate out the distribution of $X_{i}$ in the treatment sample by using a regression model where the mean effect is evaluated at the average of the $X_{i}$ in the treatment sample. Effectively, we then identify the TT

$$
E_{X_{i}, D=1}\left\{E\left(\delta_{i, t 1, \tau}^{k} \mid D=1, Y_{t 1-1}=l, Y_{t 0-1}=l, X_{i}\right) \mid D=1, Y_{t 1-1}=l, Y_{t 0-1}=l\right\}
$$

conditional on the employment status $l$ in the previous month and in the month 
before the baseline period $t 0$ where the outer expectation $E_{X_{i}, D=1}$ integrates out with respect to the distribution of $X_{i}$ in the sample $D=1$. Thus, conditioning on $\left(Y_{t 1-1}=l, Y_{t 0-1}=l\right)$ only affects the distribution of the individual specific effects and the latter is partly controlled for through the correlation between $X_{i}$ and the $c_{i}^{k}$ 's. Regarding the information in the $c_{i}^{k}$ 's not controlled for, our treatment effect weights the individual treatment effects by the frequencies that individuals are employed and not employed in the previous period before and after treatment, respectively.

Our approach estimates the unconditional TT under the following two stringent conditions: First, the treatment effects are conditionally mean independent of the individual specific effects when also conditioning on $X_{i}$, i.e. $E\left(\delta_{i, t 1, \tau}^{k} \mid c_{i}^{e}, c_{i}^{n}, X_{i}\right)=$ $E\left(\delta_{i, t 1, \tau}^{k} \mid X_{i}\right)$. Second, we do observe each treated individual in both employment states before anticipation and participation rules take effect so that the beforeafter-difference can be calculated for some $t 0$ in the past. The second assumption is quite innocuous in our application since we consider the preprogram situation up to 18 months in the past. The preprogram level is then the average transition rate conditional on the employment state in the previous month. For almost all treated individuals, these averages are available for both states. The first condition does not hold when the selection into treatment depends upon the treatment effects $\delta_{i, t 1, \tau}^{k}$ conditional upon $X_{i}$ via the individual specific effects. We do not think that the latter condition is likely to hold.

There is no ready procedure to estimate the unconditional TT by also integrating out the individual specific effects without imposing further stringent assumptions. Thus, we only integrate out the $X_{i}$ distribution in the treatment sample. It is quite plausible that, conditional on $X_{i}$, both treatment effects $\delta_{i, t 1, \tau}^{k}$ are positively correlated with the individual specific effects and that the two individual specific effects are positively correlated. Then, our approach will overestimate the TT for the probabilities to remain employed and it will underestimate the TT for the reemployment probabilities. Given this, we will nevertheless be able to draw conclusions on the effectiveness of training programs based on the estimation results.

\subsection{Multiple Treatments and Carousel Effects}

To take into account multiple sequential treatments such that an individual participates in labor market programs more than once, we extend our evaluation approach to the analysis of a first and second treatment. We specify the TT of participation in a second program compared to the situation of not having participated in this specific treatment sequence. The treatment dummy $D$ is defined such that $D=1$ indicates treatment in this specific treatment sequence and $D=0$ indicates all three other alternatives, i.e. (i) no program participation, (ii) a first training program and 
no further treatment or another second program not considered here, or (iii) a first treatment other than training.

The estimation of the combined effect of the sequence of the first and second treatment is a straight forward application of the single binary treatment case. Individuals with at most one training program participation $D=0$ are matched to individuals who participate in a second program $D=1$. For $\operatorname{CDiD}(\mathrm{HR})$, we use the differences between the period after the second treatment and the period before the first treatment.

To evaluate the incremental effect of the second program we suggest the following heuristic two step procedure. Based on the timing of events, the incremental treatment effect is estimated by $\mathrm{CDiD}(\mathrm{HR})$ using the outcome before and after the second treatment in the matched sample. Treating previous program participation as nonemployment, the average incremental effect of the second program is obtained. The matching procedure uses all nonparticipants of the second program, i.e. the estimated effect relates to the composition of this group. To properly account for selection into the second treatment, we assume that the impact of the individual specific effects enters the individual treatment effects $\delta_{i, t, \tau}^{k}$ for the first program as an additive constant. Unfortunately, our approach does not allow for the selection into the second program to depend directly upon the individual treatment effect of the first program.

Evaluating the combined and incremental effects of multiple program participation, it is possible to investigate whether multiple treatments occur for individuals with particularly bad labor market prospects, whether a further treatment improves the outcome, or whether it just occurs because the participants are unlikely to find a job after the first treatment and this is still the case after further program participation ("carousel effect"). In our approach, a pairwise ("data hungry") evaluation (see Lechner (1999) and footnote 4 above for the evaluation of heterogeneous treatments) can be avoided.

\section{Empirical Analysis}

\subsection{Data}

Our analysis uses the Labor Market Monitor Sachsen-Anhalt ${ }^{15}$ (Arbeitsmarktmonitor Sachsen-Anhalt, LMM-SA) for the years 1997, 1998, and 1999. The LMM-SA is a panel survey of the working-age population of the state (Bundesland) of Sachsen-

\footnotetext{
${ }^{15}$ Although the data refer to the state of Sachsen-Anhalt only, the results are likely to be representative for East Germany as a whole (see Schulz, 1998). For further information on the data set, see Ketzmerik (2001).
} 
Anhalt with 7,100 participants in 1997, 5,800 in 1998, and 4,760 in 1999. 1999 is the last year in which the survey was conducted. Only in the three years used, retrospective questionnaires on the monthly employment status between 1990 and up to December 1999 were included. The monthly data provide all possible labor market states, i.e. employment, unemployment, or participated in a program of ALMP, as well as periods in the education system, inactivity, or in military. Individuals who did not participate in the 1998 survey are recorded until at least September 1997, those who dropped out in 1999 at least until October 1998.

\section{Selection of Sample}

Unfortunately, in the three survey years used the categories of the labor market states differ. For compatibility, the data set also includes a combined monthly calendar for the three survey years (compiled by the ZSH institute). This calendar distinguishes the following categories: Education, full-time employed, part-time employed, unemployed, job-creation scheme, training, retirement, pregnancy/maternity leave, not in active workforce.

We only consider individuals with complete information on their labor market history between January 1990 and at least until September 1997 (i.e. individuals who completed the retrospective question in 1997). The individuals are between 25 and 50 years old in January 1990 and employed before the start of the "Economic and Social Union" in June 1990. This way, only individuals are included who had belonged to the active labor force of the former GDR, who therefore were fully hit by the transformation shock, and who are not too close to retirement. ${ }^{16}$ Individuals, who are later on in education or on maternity leave are excluded completely from the analysis. The goal is to construct a consistent data base excluding individuals who have left the labor market completely. In addition, individuals without valid information on those individual characteristics, on which we build the matching, are excluded. We aggregate the remaining labor market states to the four categories $\mathrm{em}$ ployment, which comprises part- and full-time employment, nonemployment, which comprises unemployment and out of labor force, training and job creation.

Our outcome variable employment is defined with nonemployment as alternative resulting in a binary outcome variable. Modeling transitions between unemployment and being out of labor force is here an impossible task. People move occasionally back and forth between the two states in the data and it is not obvious whether the individuals precisely distinguish between unemployment and being out of labor force, since no formal definition of unemployment is given in the questionnaire.

The resulting sample consists of 5,165 individuals and it is likely to be quite representative for the labor force in the former GDR. Table 1 summarizes participation

\footnotetext{
${ }^{16}$ Massive early retirement programs were implemented in the early 1990 s in order to reduce the labor force.
} 
in ALMP based on our data. The two programs considered, Training (TR) and Job Creation Schemes (JC), were implemented at a large scale. In total, $27 \%$ of our sample participated at least once in one of the two programs. While 13\% (689 cases) participated at least once in JC, TR was the most important program with a rate of $20 \%$ (1,021 cases). ${ }^{17}$ Our data do not distinguish between further training and retraining. Therefore, the estimated treatment effects are an average of the two programs.

After a first training program, a second treatment in training or JC occurred in 326 cases, i.e. more than $36 \%$ of the 889 cases in a first treatment in TR participated in another program at least a second time. Because of the importance of the timing of events, we differentiate between the effects of a first and a second treatment. This paper focuses on the effects of TR, thus restricting ourselves to TR being the first treatment. Using the evaluation approach described in section 3, we estimate first the effects of FTR (participation in training as the first program) (889 cases) and then the effect of the second treatment for the two sequences TR-TR (150 cases) and TR-JC (176 cases). No further treatment afterwards is analyzed, since the number of cases is very small.

\section{Recall Errors}

Retrospective data, which in our case covers at least 8 years, entails the danger of recall errors. In the following, we will argue that recall errors are less problematic in our analysis than it is typically the case with retrospective data.

First of all, note that the individuals were asked about their employment history starting with the year 1990. This year constitutes a turning point in the biography of East Germans, as the political and economic system changed dramatically. The connection of biographic events with historic events, as done here, typically improves the validity of recall data (Loftus/Marburger, 1983, Robinson, 1986). Additionally, starting with the salient year 1990 the individuals had to answer in chronological order, which is now commonly viewed as the best technique in collecting life history data in a single survey (Sudman/Bradburn, 1987). Second, our broad definition of employment states circumvents some of the recall errors which are present when analyzing more than two labor market states. It helps especially to merge the states unemployment and out of the labor force. For instance, after some time in unemployment, women tend to label this as having been out of the labor force (Dex/McCulloch, 1998). Third, our evaluation design (CDiDHR estimator) allows for recall errors occurring in the same fashion among treatment and matched control group. In particular, if both groups forget to mention transitions in a similar way then the errors simply cancel out.

\footnotetext{
${ }^{17}$ The question in the LMM-SA on training does also include privately financed training. However, calculations based on the German Socioeconomic Panel for East Germany show that a very high share of training is in fact public sector sponsored training (in 1993 more than 88\%).
} 
Thus, recall errors in our analysis might only increase the standard errors of our estimates. However, if we were estimating individual labor market flows, recall errors would be more worrying (Paull, 2002) and it might be useful to change the methodological approach (e.g. following Magnac/Visser, 1999).

\subsection{Implementation of Evaluation Approach}

We estimate the following five treatment effects: (1) FTR: participation in training as the first program, (2) TR-TR: incremental effect, (3) TR-TR: combined effect, (4) TR-JC: incremental effect, and (5) TR-JC: combined effect. For FTR, TR-TR, and $\mathrm{TR}-\mathrm{JC},{ }^{18}$ the treatment probability (propensity score) is estimated by separate parametric probit models. Since the data do not provide time-varying information (except for the labor market status), the regressors are the static observable characteristics education, occupational degree, gender, age, residence (at the time of the survey) and interactions of gender and education or occupational degree (results can be found in table 2). The probit model does not model when the participation in the program actually takes place. We do not think that the data is sufficiently rich to model the timing. Using a bootstrap estimator for the covariance matrix of the estimated treatment effects, we capture the estimation error in the propensity score.

For matching based on the propensity score, the group of "nonparticipants" $\{D=0\}$ represents the entire sample of individuals who are not participating in the treatment sequence under consideration but who might be a participant in another program. We do not match on the employment history shortly before the program (see Lechner, 1998, for such an approach) due to the possibility of Ashenfelter's Dip. Our $\mathrm{CDiD}(\mathrm{HR})$ estimators control for remaining long-run preprogram differences after matching upon the propensity score.

The results of the probit estimates for the propensity score are reported in table 2 . Figures $3-6$ show the high degree of overlap in the distributions of the estimated propensity score ${ }^{19}$ between participants (Treated) and nonparticipants (Nontreated) for the treatments FTR and TR-TR (the graphs are similar in nature for TR-JC). The graphs are stratified conditional upon nonemployment and employment in the previous month, respectively. Since the employment status changes over time and since after 1997 no complete data is available for all individuals, the overlap can change over time. Here, the graphs show the overlap of the distributions for the two months 5/1993 and 5/1997, being representative for other periods. Only in rare cases, such as FTR in 5/1993 and being previously nonemployed, we find a slightly less than perfect overlap. Based on this evidence, there is no serious problem of lack

\footnotetext{
${ }^{18}$ Recall from the previous subsection that the evaluation of combined and incremental treatments only differ regarding the choice of the preprogram period for the CDiD(HR) estimators.

${ }^{19}$ The graphs depict the fitted values of the latent index for the probit model. The estimated treatment probability is the cdf of the standard normal applied to this index.
} 
of common support for matching and we match the entire treatment sample.

So far, we have not been explicit about the post program evaluation period. We use two different starting points in time, which are widely used in the literature: The evaluation of treatment effects starts either after the end of the program or with the beginning of the program. The former approach excludes the treatment period from the employment history when evaluating the success of the respective treatment because treatment is viewed as time spent outside of the labor market. This exclusion is somewhat unsatisfactory since labor market history continues, especially so for the nonparticipants. In contrast, the second approach views the treatment just as a different nonemployment state while searching for a job.

The start of the evaluation period depends also upon the outcome variables considered. For employment rates and reemployment probabilities, the evaluation period starts one month after the last or the first month of the treatment depending on whether evaluation starts after or at the beginning of the treatment. For probabilities to remain employed, the evaluation period starts one month later than for the other two outcome variables, since we first have to observe employed former participants. We choose the length of the evaluation period to be 36 months (as far as being observed in the data set - otherwise set to missing). As preprogram period, we take 18 months before the beginning of the treatment. For the incremental effect of TR-TR and TR-JC, the preprogram period is taken before the beginning of the second treatment and for the combined effect before the beginning of the first treatment.

Based on the estimated propensity scores, we construct matched samples of participants and comparable "nonparticipants" (matched nonparticipants) both during the preprogram and the evaluation period. Alignment occurs in the same calendar month. The characteristics and outcomes of matched nonparticipants are the fitted values obtained by the local linear kernel regression of characteristics and outcomes, respectively, on the estimated propensity score in the sample of nonparticipants as a whole. Table 3 and 4 give evidence on the balancing properties in the matched samples for the two cases FTR and TR-TR (combined effect). The first column shows the average characteristics in the whole sample. The remaining columns show the average characteristics conditional upon employment state in the previous month. For example, when calculating the average characteristics for the previously nonemployed, the individual contribution to the mean characteristics is weighted by the number of months the individual's state was nonemployment during the time period under consideration. For the matched nonparticipants, the average reported uses all available observations.

Table 3 and 4 show that participants are younger than the nonparticipants and that women participate at a higher rate in training than men. There is no clear cut difference in the skill distribution. It is evident, that the matching process balances well 
the characteristics of the participants and the matched nonparticipants conditional upon employment status in the previous month. For example, $27 \%$ of the previously nonemployed nonparticipants were aged between 25 and 34 in 1990, whereas $40 \%$ of the participants belonged to this age group. In the matched sample, $36 \%$ of the matched nonparticipants belong to this age group. The balancing works especially well for the previously employed in all cases and for the previously nonemployed in most cases. However, the labor market region does not seem perfectly balanced for the latter group.

Furthermore, table 3 and 4 shed some light on the differences in characteristics across employment states in the previous month. Previously employed participants are younger than previously nonemployed. Male participants were more often previously employed compared to females. In the case of FTR, previously employed participants more often have a university education.

\subsection{Specification of Outcome Equation}

In the matched samples, the $\mathrm{CDiD}(\mathrm{HR})$ estimators are based on a flexible semiparametric linear probability model for the employment dummy as outcome variable. The state of nonemployment includes the participation in ALMP programs such that previous and subsequent participation in a program are both accounted for as nonemployment. We estimate an average employment effect of a program relative to all possible nonemployment states for the treated individuals thus estimating TT (with CDiDHR conditioned on the employment status in the previous month). For CDiDHR, we also control for observed, time-invariant characteristics $X_{i}$ in the outcome equation. The $X_{i}$ variables enter the equation as deviations from their averages in the treatment sample.

We assume treatment of individual $i$ begins in period $\tau$ and we consider the employment outcome $Y$ before the begin of treatment $t 0=-18, \ldots,-a d-1$, as well as during the time of Ashenfelter's Dip and the evaluation period of 36 months $t 1=-a d, \ldots,-1,1, \ldots, 36$. Now, $t 0$ is defined relative to the start of the treatment, whereas the definition of $t 1$ depends on the evaluation perspective and the success criterion. When then evaluation starts at the begin of the program then $t 1$ is measured relative to $\tau$ in case the unconditional employment probability or the reemployment probability are the outcome variables, whereas $t 1$ is measured relative to $\tau+1$ in case of the probability to remain employed. However, when the evaluation starts after the end of the program $\tau$ is replaced by the last month of the program.

We estimate the following three steps both for CDiD (sample of all participants) and CDiDHR (separately depending on the employment status in the previous month): 
1. We calculate the average long-run preprogram difference between participant $i$ (treatment starts in $\tau$ ) and comparable nonparticipants as

$$
\hat{a}_{i, \tau}=\frac{1}{18-a d(\tau)} \sum_{t 0=-18}^{-a d(\tau)-1}\left(Y_{i, t 0}^{0}-\sum_{j} w_{i, j} Y_{j, t 0}^{0}\right) .
$$

2. Then, $\hat{a}_{i, \tau}$ is subtracted from the difference during Ashenfelter's Dip and during the evaluation period resulting in the following model to estimate the treatment effects $\left(I(\right.$.$) denotes the indicator function, \nu_{i, t 1}$ the error term)

$$
\begin{gathered}
Y_{i, t 1}^{1}-\sum_{j} w_{i, j} Y_{j, t 1}^{0}-\hat{a}_{i, \tau}=\sum_{s=-a d(\tau)}^{36} \delta_{s} I(t 1=s) \\
+\left(\gamma_{1}^{a d} \tau+\gamma_{2}^{a d} \tau^{2}\right) I(-a d(\tau) \leq t 1<0)+\left(\gamma_{1}^{p o} \tau+\gamma_{2}^{p o} \tau^{2}\right) I(t 1>0)+\nu_{i, t 1} .
\end{gathered}
$$

For CDiDHR, we include deviations of the $X_{i}$ characteristics from their average in the treatment sample as additional regressors in equation (7).

3. The average long-run preprogram differences $\hat{a}_{i, \tau}$ are regressed on a second order polynomial in the starting month of the treatment. We will report the predictions from this regression

$$
\hat{\alpha}(\tau)=\alpha_{0}+\alpha_{1} \tau+\alpha_{2} \tau^{2}
$$

to illustrate how the average long-run preprogram differences (三 residual se-

\begin{tabular}{|c|c|}
\hline$\alpha_{0}, \alpha_{1}, \alpha_{2}$ & $\begin{array}{l}\text { coefficients measuring the long-run preprogram differences } \\
\text { depending upon the month when the program starts } \tau \text {, }\end{array}$ \\
\hline $\operatorname{ad}(\tau)$ & $\begin{array}{l}\text { month before the begin of the program when Ashenfelter's } \\
\text { Dip starts depending upon } \tau \text {, }\end{array}$ \\
\hline$\delta_{s}, \gamma_{1}^{a d}, \gamma_{2}^{a d}, \gamma_{1}^{p o}, \gamma_{2}^{p o}$ & $\begin{array}{l}\text { coefficients modeling the DiD effect relative to the long-run } \\
\text { preprogram differences } \hat{a}_{i, \tau} \text {, and }\end{array}$ \\
\hline$w_{i, j}$ & $\begin{array}{l}\text { weights implementing local linear kernel regression on the } \\
\text { estimated propensity score. }\end{array}$ \\
\hline
\end{tabular}
lection effect due to permanent individual specific effects) between participants and nonparticipants after matching depend upon the timing of the program.

The following definitions complement the description:

Estimating equation (7) as a linear regression, the $\mathrm{CDiD}(\mathrm{HR})$ estimators are implemented in a semiparametric way by including the employment situation before treatment in the dummy regression of outcomes and by allowing the effect of the program to depend both upon the time since treatment $(t 1>0)$ and upon the begin of the program $\tau$. The long-run preprogram employment differences $\hat{a}_{i, \tau}$ prove critical for the alignment of the $\operatorname{CDiD}(\mathrm{HR})$ estimators. Dummy variables for the effect of Ashenfelter's Dip are included to capture the decline in the employment 
probability shortly before the program. The specification allows the employment differences before and after the program to depend in a flexible way upon $\tau$. Also the length of Ashenfelter's Dip is allowed to depend upon the time when the program starts. During the period shortly after unification, it is likely that the dip is fairly short since program participation could not have been anticipated long before and participation rules were applied in a very lax way. The situation changes with the occurrence of high unemployment when people realized that labor market problems were quite severe and that ALMP at a large scale was likely to be a permanent feature of the labor market.

To capture Ashenfelter's Dip, the following heuristic approach is chosen. For the first program, a visual inspection of the average employment differences between treated and matched controls before and after the program as a function of the time when the program starts indicates that the dip occurs during one to two months in 90/91 and increases over time to something of at most six months for TR and to at most nine months for JC. In order to obtain a lower bound for the employment effect of a program (the employment of the future participants decreases during the dip), we are conservative in defining $a d(\tau)$. Before November 90, we set $\operatorname{ad}(\tau)=-1$. Between November 1990 and July 1994, ad $(\tau)$ increases linearly in absolute value from 2 months to 6 months for TR and 9 months for JC, respectively, where $\operatorname{ad}(\tau)$ is rounded to the nearest integer. After July 1994, $\operatorname{ad}(\tau)$ remains constant. Our approach is conservative in the sense that taking a shorter period for Ashenfelter's Dip would effectively result a higher difference-in-differences estimate of the treatment effect.

For a program, which started in $\tau$, the following expression captures both the estimate for the disproportionately decline in employment during Ashenfelter's Dip and the estimated TT after the program

$$
\operatorname{DiD}(t 1, \tau)=\left\{\begin{array}{lc}
\delta_{t 1}+\gamma_{1}^{a d} \tau+\gamma_{2}^{a d} \tau^{2} \\
\delta_{t 1}+\gamma_{1}^{p o} \tau+\gamma_{2}^{p o} \tau^{2}
\end{array} \quad \text { for } \quad-a d(\tau) \leq t 1 \leq-1\right.
$$

If we assume for CDiDHR that the linear specification of the outcome equation in the $X_{i}$ characteristics holds exactly, then $D i D(t 1, \tau)$ estimates the TT conditional on previous employment status while integrating out the distribution of the $X_{i}$ in the treatment sample, see also section 3.3.

For the multiple, sequential treatments, $D i D(t 1, \tau)$ estimates the incremental employment effect of the second treatment when the begin of the second program is taken as the begin of the treatment. The combined effect of the program sequence is obtained taking the begin of the first program. For the incremental effect, the effect of a first treatment is possibly included in the permanent preprogram effect for the participants. Since all TT's are estimated for the specific selection of individuals participating in a certain treatment, it is clear that the TT for FTR and the incremental TT do not have to add up to the combined effect of the treatment sequence. 


\subsection{Estimated Treatment Effects}

Before turning to the $\mathrm{CDiD}(\mathrm{HR})$ estimates for the treatments considered, we discuss the outcomes in the matched sample for the treatment FTR. Figure 7 reports the average differences in employment rates for the matched sample with individuals starting treatment in the two-year periods $1990 / 91,1991 / 92$, etc. If the CIA $E\left(Y^{0} \mid D=1, X\right)=E\left(Y^{0} \mid D=0, X\right)$ did actually hold with respect to the time invariant characteristics $X_{i}$, then the average differences in employment rates for the matched samples would be a proper estimate of TT. Right after treatment, the employment rates of the participants are between 40 and 60 percentage points (ppoints) lower that for comparable nonparticipants. There is a noticeable recovery for the participants afterwards - basically the time path reflects the changes for participants since employment rates for nonparticipants are almost constant - but the difference comes nowhere close to zero except at the end for 1997/98 (the latter can be dismissed since it is based on a very small number of cases). Even three years after treatment, employment rates are still between 20 (90/91) and 40 (mid to late 90s) ppoints lower than for comparable nonparticipants. Thus, under the CIA as stated above one had to conclude that FTR results in a considerable reduction of employment rates, which is a common result found in the literature when matching is based on observable characteristics (see the survey in Hagen/Steiner, 2000).

Considering the preprogram effects in figure 7 raises a number of issues, which are addressed by our CDiD(HR) estimators, and could lead to a different conclusion. While in 1990/91 there is no preprogram difference 13 to 18 months before the treatment, long-run preprogram differences in the order of 10 to 20 ppoints exist for later years. We take this as an indication for the importance of remaining unobservable differences in the matched sample. Thus, our CDiD(HR) estimators take account of possible individual specific effects. It is also apparent here that a simple CDiD estimate based on the difference between long-run postprogram and long-run preprogram outcomes will result in a negative estimate for TT (as we will see in the following). There is also a strong decline in employment rates shortly before the program starts and the decline starts earlier in the later years. In 1990/91, the decline starts within the last six months before the treatment and the average differences immediately before the start of the program amount to 33 ppoints, whereas in 1997/98 the employment rate of the treated declines already 16 months before the treatment. We take this as an indication for Ashenfelter's Dip which a credible difference-in-differences estimator has to take account of. Basing CDiD on the difference between postprogram outcomes and preprogram outcomes shortly before the begin of the program would erroneously result in a positive estimate for TT. Finally, analyzing employment rates entails the danger that one misses the state dependence in employment. The continuous decline before the program and the recovery process after the program suggest that employment rates do not adjust instantaneously. Thus, one should check for state dependence as well. 
In the following we discuss the results obtained by CDiD and CDiDHR for the treatments considered. We mainly rely on graphical illustrations of the DiD estimates in equation (9) and the average preprogram levels $\hat{a}_{i, \tau}$. To avoid estimates which are based on the extrapolation of the parametric model in equation (7), our graphical illustrations only report point estimates representing at least 10 observations. Tables 5-11 report all the estimated coefficients.

\subsubsection{CDiD Results}

Figure 8 depicts the estimated CDiD employment effects $D i D(t 1, \tau)$ in equation (9) for $\mathrm{FTR}^{20}$ during the evaluation period $t 1=1, \ldots, 36$ and for the period of Ashenfelter's Dip $t 1=-a d(\tau), \ldots,-1$. We only report the results for the evaluation period starting after the end of the program. The effects for the evaluation period starting at the begin of the program are also similar in nature. To illustrate the changes over time, the estimates are shown in four separate graphs for the starting dates $\tau$ being the month of December in the years 1990, 1992, 1994, and 1996. The thick, changing line in the graphs represents the estimated $D i D(t 1, \tau)$ for $t 1=$ $-a d(\tau), \ldots, 36$. The dotted lines around represent the $95 \%$-confidence interval. The constant line with dotted lines around represents the estimated long-run preprogram differences $\hat{\alpha}(\tau)$ ("alpha") with associated 95\%-confidence interval. The confidence intervals are based on the bootstrap covariance estimates. ${ }^{21}$

For all cases, the CDiD employment effects of FTR prove significantly negative during the postprogram period, as to be expected from figure 7. However, the negative employment effect becomes weaker over time. For the treatment starting in 1990, we estimate an effect -14 ppoints 36 months after the treatment, the corresponding estimate for the year 1996 is -10 ppoints. Our estimates also clearly show that the employment rates become considerably lower shortly before the program starts (Ashenfelter's Dip) and this effect becomes more pronounced over time. There are also important changes in the long-run preprogram differences over time. For participants starting treatment in 1990, $\hat{\alpha}(\tau)$ is not significantly different from zero. For 1992, we find already significantly reduced long-run preprogram differences (-16 ppoints) and this feature becomes more important over time (1996: -22 ppoints). This finding corresponds to training programs becoming more focussed on groups with severe problems of finding regular employment during the course of the 1990s, see section 2 .

\footnotetext{
${ }^{20}$ Since we consider the CDiDHR estimates more credible, we do not report here the CDiD results for the treatments $\mathrm{TR}-\mathrm{TR}$ and $\mathrm{TR}-\mathrm{JC}$ to save space. Also for the same reason, we only report the FTR results for the evaluation period starting after the end of the program.

${ }^{21}$ When comparing the bootstrap standard errors to conventional heteroscedasticity consistent standard errors, we find that bootstrap standard errors of both $D i D(t 1, \tau)$ and $\hat{\alpha}(\tau)$ are higher, the increase being stronger for the latter. This is also the case for the CDiDHR estimates.
} 


\subsubsection{CDiDHR Results}

The CDiDHR esimates take the state dependence in the employment process explicitly into account. The outcome variable used is either the reemployment probability of the previously nonemployed or the probability to remain employed for the previously employed. Figures 9 to 20 display the estimated CDiDHR employment effects $\operatorname{DiD}(t 1, \tau)$ in equation (9). All graphs for CDiDHR are organized in the same way as described above for $\mathrm{CDiD}$ referring to figure 8 .

Beginning with the treatment FTR, figure 9 summarizes the estimated TT on the reemployment probability. Evaluation starts after the first month of the program. The first graph of figure 9 shows the employment effects of a FTR treatment which began in December 1990. We find positive employment effects during the evaluation period, which are, however, rarely significant. For example, one year after the program started the participants have a 4 ppoints higher reemployment probability than in the nonparticipation case. These positive effects of a FTR vanish for programs starting later. For December 1994 and later, the effect takes sometimes negative values, which are significant shortly after the program started. This is not too surprising since one would expect a reduced search effort when the program has just started. During Ashenfelter's Dip, we find a slight decline in the reemployment probability for the group of participants. This decline is not significant in most cases and it is much less pronounced than for the CDiD employment effects. The longrun preprogram difference is significantly negative shortly after the reunification (-6 ppoints), it becomes less negative over time, and it is effectively zero for December 1996. This is in contrast to the CDiD results where the long-run preprogram difference does increase over time.

Letting the evaluation period start after the end of the program, figure 10 naturally shows more positive effects on the reemployment chances of former participants. Also for all cases there is a significantly positive spike in the first month after treatment. This spike can not be interpreted as pure employment effect. This is because it could reflect the endogenous, premature termination of the program due to a job offer and then the clock starts to run. However, we also observe smaller but significantly positive program effects after the first month. For example, 12 months after the program the reemployment probability increased by approximately 8 ppoints. For later starting dates, the positive effects are reduced and more often insignificant.

FTR can have different effects on the probability to remain employed. Figure 11 provides results when the evaluation period starts two months after the begin of the program. The estimated effect is close to zero for programs which start in December 1990. However, for later starting dates, the effect becomes significantly positive. For example, one year after the program started in December 1996 the probability to remain employed increases by approximately 6 ppoints. Ashenfelter's 
Dip is very pronounced here with strong significantly negative effects. Anticipation but also participation rules might play a role here. Shortly after the unification, the long-run preprogram difference is slightly negative and significant. It becomes more negative in later periods ( -5 ppoints for programs which started in December 1996). In contrast to the results for the reemployment probability, the preprogram effects for the probability to remain employed are very similar in nature to the CDiD results above. Changing the evaluation period to start two months after the begin of the program, the results for the probability to remain employed do not change qualitatively (see figure 12).

Naturally the question arises, why the results differ for the two outcome variables, reemployment probability and probability to remain employed. We think that the results are driven mainly by changes in the content of the training programs over time. Shortly after unification a large part of training consisted in short courses mainly aiming at increasing the placement potential, see section 2.3. This could be an explanation for the small positive effect on the reemployment probability. However, later on, the composition of training courses changed towards longer courses intended to provide substantive skills. These additional skills could improve the quality of the match between participants and employers thus increasing the employment stability, once a participant finds a job. However, these additional skills do not seem to help finding a job at a faster rate.

Also, changes in the search behavior of East Germans due to a better understanding of the labor market and the benefit system in unified Germany might play a role for the differences. Shortly after unification, unemployed East Germans, not being used to a labor market in a market economy, probably tended to accept quickly a new job without focussing on wages and a high expected job duration. As a result, a positive effect of training programs might show up in an increase of their reemployment probability rather than in an increase of the probability to remain employed. Later on, individuals searching for a job became perhaps more aware of the importance of finding a 'good' job, which is not only important for their job stability, but also for the level of potential future unemployment benefits being defined by the earnings in the last job. In addition, the entitlement for transfer payments is prolonged by taking part in a training program for some time after the program, lowering the opportunity costs of job search for participants compared to other unemployed individuals. Thus, participants tended to search longer to find a 'better' job match resulting in a positive effect on the probability to remain employed.

However, an important caveat regarding the interpretation of the CDiDHR results is in order here. Since our estimated TT conditions on previous employment, it is likely that the estimates for the probability to remain employed overestimate and the estimates for the reemployment probability underestimate the true TT for the FTR treatment sample as a whole, see section 3.3. For this group, it might well be 
the case that reemployment chances increase on average and the positive effect on employment stability is smaller.

Another feature of the results which should be explained are the changes in the long-run preprogram differences. The CDiDHR estimator matches participants and nonparticipants month by month conditional upon the same employment status in the previous month. Shortly after the unification the labor market was quite turbulent. Everybody faced a high risk of becoming unemployed, resulting in a relatively small difference in the long-run preprogram difference in the probability to remain employed. However, some individuals found quickly another job and did not participate in a training program, leading to a large long-run preprogram difference in the reemployment probability at the begin of the 90's. Later on, unemployment became persistent. The difference in transitions out of nonemployment between participants and nonparticipants was then less pronounced. ${ }^{22}$ The change in the long-run preprogramm differences in the probability to remain employed most likely reflects the stricter targeting of labor market policy on unemployed individuals.

Let us now turn to the results for the multiple, sequential treatments TR-TR and TR-JC. For the combined effect, the evaluation period starts at the begin of the respective program sequence, whereas for the incremental effect it starts at the begin of the second treatment. Figures 13, 15, 17, and 19 show the estimates for the combined effects. The combined effects on the transition probabilities are mostly close to zero and always insignificant. This implies that ex ante it was not a successful strategy on average to assign the group of participants to the program sequences TR-TR or TR-JC. Also the incremental effects on the reemployment probability are not significantly different from zero (figures 14 and 18). However, we do find significantly positive incremental effects for the probability to remain employed (figures 16 and 20), especially for TR-JC. Note that the number of preprogram observations conditioning on being employed in the previous month is particularly small in these cases. Taken literally, the results obtained imply that the participation in a second program after a first training program improved employment stability for the group of participants. Put differently, even though the two treatments combined do not appear successful ex ante, ex post after the first training program, the second program seems partly successful.

\section{Conclusions}

This paper investigates the average employment effects for participants in Public Sponsored Training in East Germany during the time period 1990 to 1999. Modeling employment as a state-dependent outcome variable, we develop a new semi-

\footnotetext{
${ }^{22}$ Note that this explanation of the changes in the long-run preprogram difference does not violate the assumption of permanent fixed effects since participants change over time.
} 
parametric conditional difference-in-differences estimator for the treatment effect. For the implementation of this estimator, we use the transition rates between employment and nonemployment as our outcome variables and we compare the results with the effects on the employment rate per se. We account for the likely occurrence of Ashenfelter's Dip caused by anticipation effects and institutional program participation rules. In addition, we develop a heuristic approach to estimate the effects of multiple sequential program participation. Thus, we estimate the effect of treatment-on-the-treated for individuals who participated in training as their first treatment. We also consider the cases where participation in a second training program or in a job creation scheme occurs afterwards. We take account of the sampling error in matching by bootstrapping.

We find negative effects of training on the employment probability. However, taking account of the state dependency of the employment process, the bleak picture concerning the effects of training brightens. This is especially the case for the reemployment probabilities. Concerning training programs which took place shortly after reunification, we find some positive program effects on the reemployment probability - although we have been twice conservative in modeling the effects. First, our alignment of the difference-in-differences estimation on a long-run preprogram difference is conservative (which is of course also true for the other estimates). Secondly, due to the potential positive correlation between the individual specific and the program effect when being nonemployed in the previous month, for which we do not control, we estimate a lower bound for the reemployment probability. Thus, our results indicate that modeling transition rates is more appropriate and more informative than using unconditional employment rates. Using only employment rates as success criterion might result in misleading conclusions concerning the effectiveness of ALMP programs.

Further results include that the program effects depend heavily on the time the programs took place corresponding to the institutional changes during the 1990s. Combined sequences of two programs with a first training program (e.g. a combination "training first and then job experience through a Job Creation program") are not successful from an ex ante point of view. In contrast, the incremental effects of the second treatment appear to have slightly positive effects on the probability to remain employed. Again, there is no positive effect on the reemployment probability when being nonemployed.

Overall, our results are not as negative as previous results in the literature and it is unlikely that training on average reduces considerably the future employment chances of participants. We also find noticeable differences among different treatment types. At the same time, it remains questionable whether on average training programs are justified in light of the large costs incurred. Our study makes some methodological progress, particularly regarding modeling the dynamic employment process in the context of program evaluation. In future research, we intend to re- 
fine the estimation of the unconditional effect of treatment-on-the-treated. Finally, our results are also of interest for other transformation countries considering the introduction of training programs as part of ALMP.

\section{References}

Abbring, J., and G.J. van den Berg (2003). "The Nonparametric Identification of Treatment Effects in Duration Models." Econometrica 71:1491-1517.

Ashenfelter, O. (1978). "Estimating the Effect of Training Program on Earnings." Review of Economics and Statistics 60:47-57.

Bergemann, A., B. Fitzenberger, B. Schultz and S. Speckesser (2000). "Multiple Active Labor Market Policy Participation in East Germany: An Assessment of Outcomes." Konjunkturpolitik 51(Suppl.):195-244.

Blundell, R., M. Costa-Dias, C. Meghir, and J. Van Reenen (2003). "Evaluating the Employment Effects of a Mandatory Job Search Program." Discussion Paper 03-05 Department of Economics of the University College London.

Bundesanstalt für Arbeit (1993). Berufliche Weiterbildung. Nürnberg: Bundesanstalt für Arbeit.

Bundesanstalt für Arbeit (1997). Berufliche Weiterbildung. Nürnberg: Bundesanstalt für Arbeit.

Bundesanstalt für Arbeit. (2001). Berufliche Weiterbildung. Nürnberg: Bundesanstalt für Arbeit.

Bundesanstalt fuer Arbeit (2003), Geschäftsbericht 2002, Nürnberg: Bundesanstalt für Arbeit. Einundfünfzigster Geschäftsbericht der Bundesanstalt für Arbeit,

Dex, S. and A. McCulloch (1998). "The Reliability of Retrospective Unemployment History Data." Work, Employment and Society 12:497-509.

Fitzenberger, B. and H. Prey (2000). "Evaluating Public Sector Sponsored Training in East Germany." Oxford Economic Papers 52:497-520.

Fitzenberger, B. and S. Speckesser (2002). "Weiterbildungsmaßnahmen in Ostdeutschland. Ein Misserfolg der Arbeitsmarktpolitik?" In: Schmähl, W. (Hg.), Wechselwirkungen zwischen Arbeitsmarkt und sozialer Sicherung, Schriftenreihe des Vereins für Socialpolitik, Duncker und Humblodt.

Frölich, M. (2001). "Nonparametric Covariate Adjustment: Pair-matching versus Local Polynomial Matching." Discussion Paper, University of St. Gallen.

Hagen, T. and V. Steiner (2000). Von der Finanzierung der Arbeitslosigkeit zur Förderung der Arbeit. ZEW Wirtschaftsanalysen, 51. Baden-Baden: Nomos Verlagsgesellschaft. 
Heckman, J., H. Ichimura, and P. Todd (1998). "Matching as an Econometric Evaluation Estimator." Review of Economic Studies 65:261-294.

Heckman, J., H. Ichimura, J. A. Smith and P. Todd (1998). "Characterizing Selection Bias using Experimental Data." Econometrica 65:1017-1098.

Heckman, J., R. J. LaLonde, and J. A. Smith (1999). "The Economics and Econometrics of Active Labor Market Programs." In: O. Ashenfelter and D. Card (eds.), Handbook of Labor Economics, Vol. 3 A, Amsterdam: Elsevier Science, 1865-2097.

Heckman, J. and R. Robb (1985). "Alternative Methods for Evaluating the Impact of Interventions." in: Heckman, J. and B. Singer (eds.), Longitudinal Analysis of Labor Market Data, New York: Wiley, 156-245.

Heckman, J. and J. A. Smith (1999). "The preprogram Earnings Dip and the Determinants of Participation in a Social Program: Implications for Simple Program Evaluation Strategies." Economic Journal 108:313-348.

Ichimura, H. and O. Linton (2001). "Asymptotic Expansions for some Semiparametric Program Evaluation Estimators." Discussion paper, London School of Economics and University College London.

Imbens, G. (2000): The Role of the Propensity Score in Estimating Dose-Response Functions" Biometrica 87:706-710.

Ketzmerik, T. (2001). "Ostdeutsche Frauen mit instabilen Erwerbsverläufen am Beispiel Sachsen-Anhalts." Forschungsbericht aus dem zsh 01-1.

Lechner, M. (1998). Training the East German Labor Force, Microeconometric Evaluations of Continuous Vocational Training after Unification. Heidelberg: Physica-Verlag.

Larsson, L. (2003). "Evaluation of Swedish Youth Labour Market Programmes" The Journal of Human Ressources 38:891-927.

Lechner, M. (1999). "Identification and Estimation of Causal Effects of Multiple Treatments under the Conditional Independence Assumption." In: M. Lechner and F. Pfeifer (eds.) (2000), Econometric Evaluation of Active Labor Market Politics in Europe, Heidelberg: Physica-Verlag.

Lechner, M. and R. Miquel (2001). "A Potential Outcome Approach to Dynamic Programme Evaluation - Part I: Identification." Discussion Paper 2001-07, SIAW. St. Gallen:University of St. Gallen.

Loftus, E.F. and W. Marburger (1983). "Since the Eruption of Mt. St. Helens, Has Anyone Beaten You up? Improving the Accuracy of Retrospective Reports with Landmark Events." Memory and Cognition 54:330-345.

Magnac, T. and M. Visser (1999). "Transition Models with Measurement Errors." Review of Economics and Statistics 81:466-474. 
Pagan A. and A. Ullah (1999). Nonparametric Econometrics. Cambridge: Cambridge University Press.

Paull, G. (2002). "Biases in the Reporting of Labor Market Dynamics." The Institute for Fiscal Studies Working Paper 02/10. London: The Institute for Fiscal Studies.

Robinson, J.A. (1986). "Temporal Reference Systems and Autobiographical Memory." In: D.C. Rubin (ed.), Autobiographical Memory, Cambridge: University Press, $159-188$.

Rosenbaum, P. R. and D.B. Rubin (1983). "The Central Role of the Propensity Score in Observational Studies for Causal Effects." Biometrika 70:41-55.

Roy, A.D. (1951). "Some Thoughts on the Distribution of Earnings." Oxford Economic Papers 3:135-146.

Rubin, D. B. (1974). "Estimating Causal Effects of Treatments in Randomized and Nonrandomized Studies." Journal of Educational Psychology 66:688-701.

Schultz, B. (1998). "Hohe Verfestigung der Arbeitslosigkeit in Ostdeutschland." Wirtschaft im Wandel 16:3-8.

Seifert, B. and T. Gasser (1996). "Finite-Sample Variance of Local Polynomials: Analysis and Solutions." Journal of the American Statistical Association 91:267-275.

Sudman, S. and N.M. Bradburn (1987). "Effects of Time and Memory Factors on Response in Surveys." Journal of the American Statistical Association 64:805-815. 


\section{Appendix}

Figure 1: Entries into Training in East Germany, Annual Totals

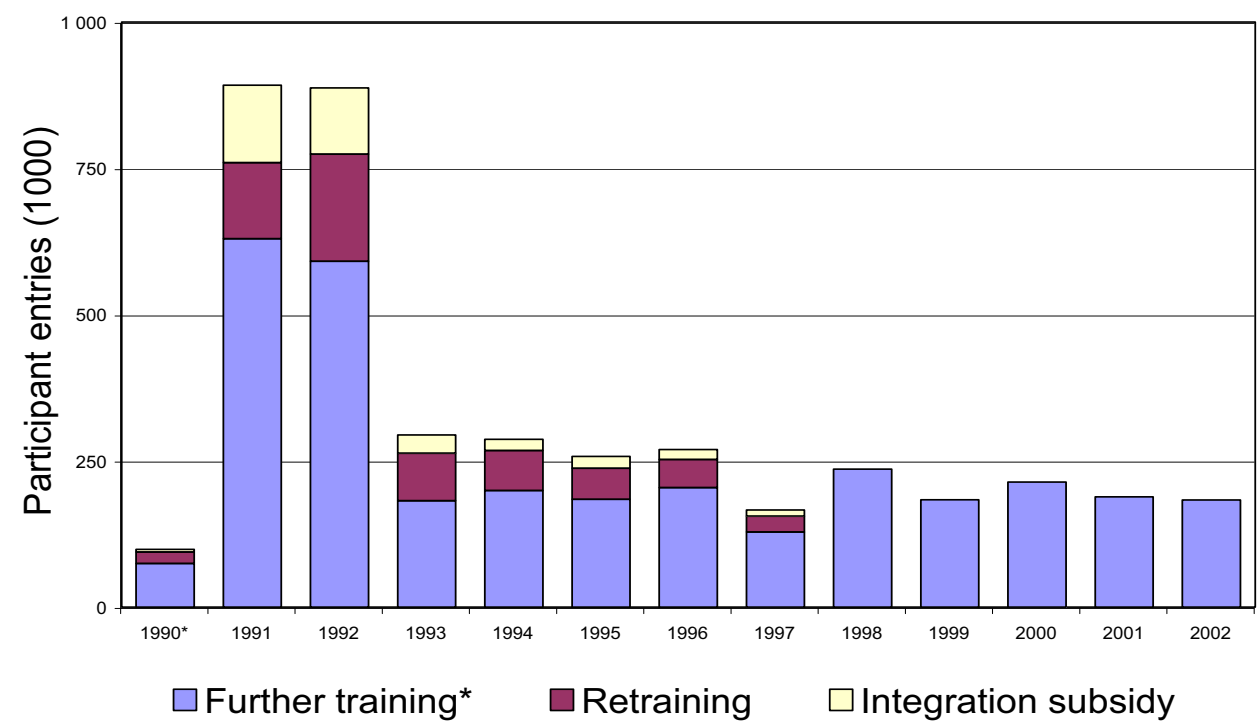

* In 1990, only in October, November and December training programs took place. Following the 1998 reform, further training can no longer be subdivided into three categories. Source: Bundesanstalt für Arbeit (1993, 1997, 2001, 2003), own calculations

Figure 2: Participation Stocks in Training and Expenditure per Participant / Year, Annual Average

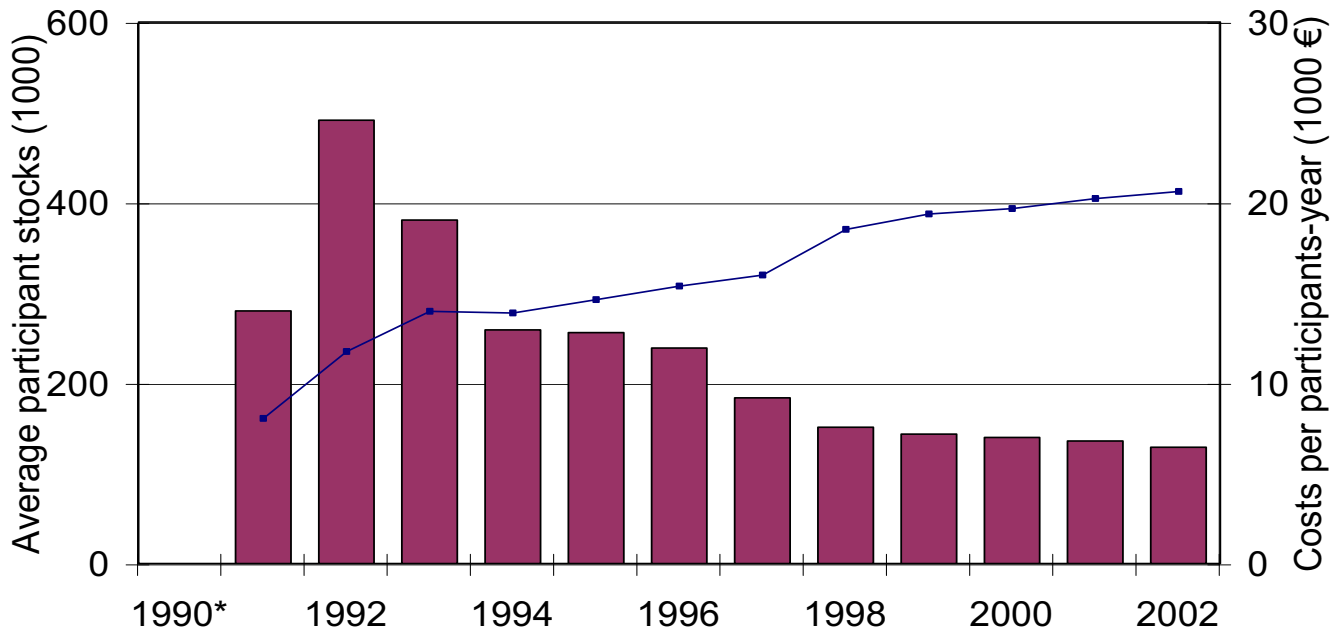

$\square$ Participant stocks --Expenditure (€ per participants-year)

${ }^{*}$ For 1990 no yearly stock can be calculated. Source: Bundesanstalt für Arbeit (1993, 1997, 2001, 2003), own calculations 
Figure 3: Overlap of Distributions of Propensity Score Index for FTR - Nonemployment in Previous Month
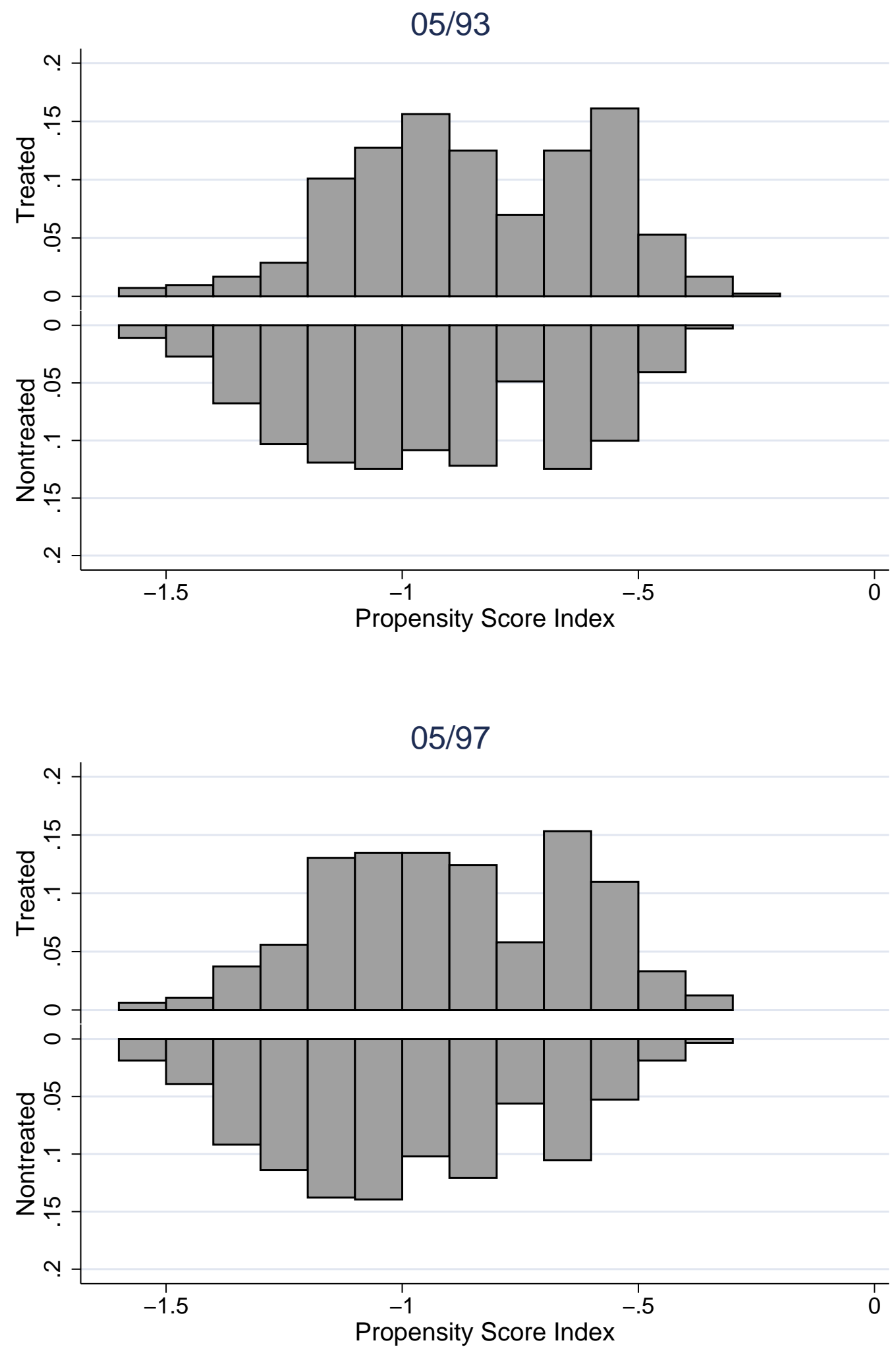
Figure 4: Overlap of Distributions of Propensity Score Index for FTR - Employment in Previous Month
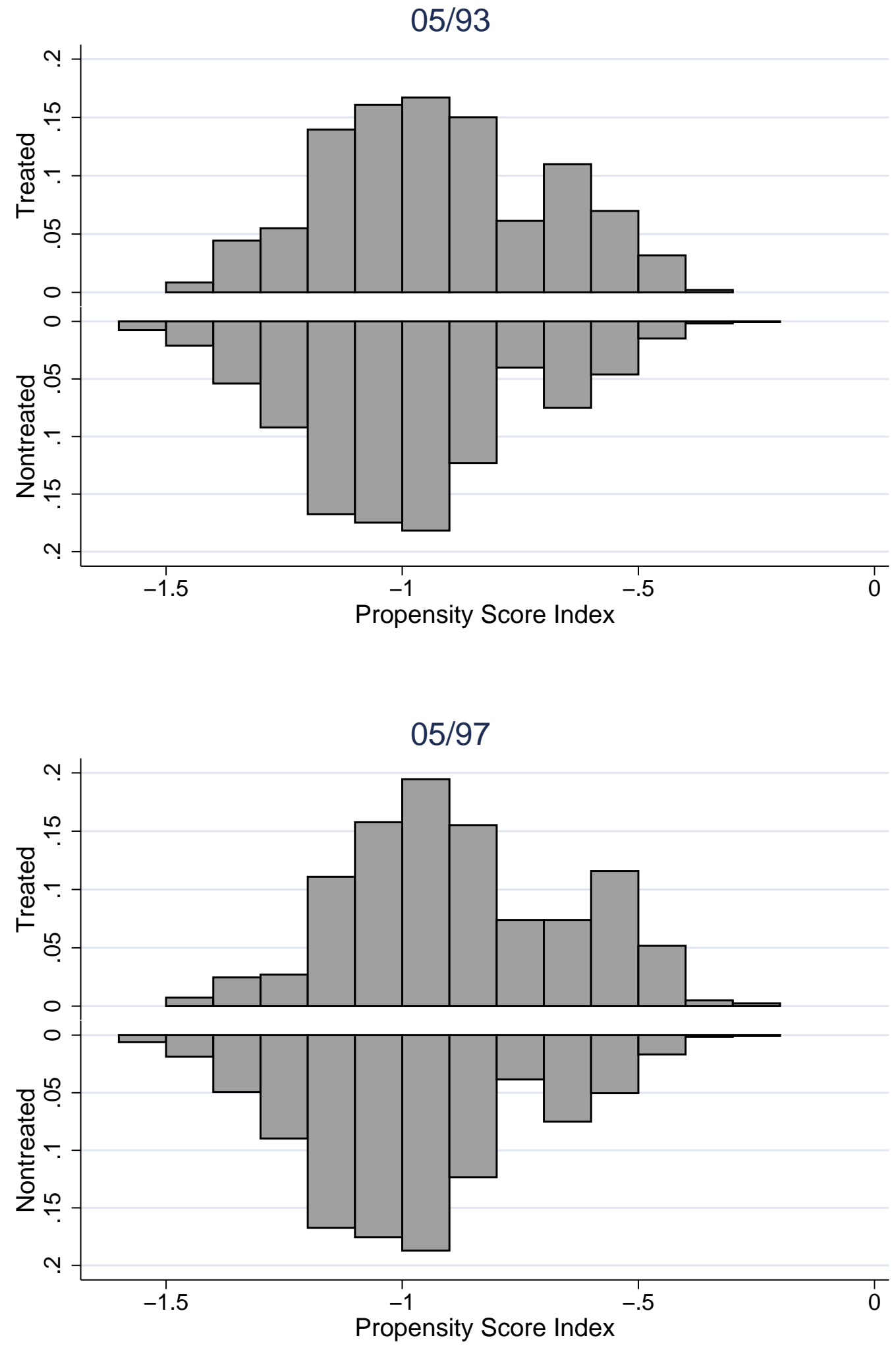
Figure 5: Overlap of Distributions of Propensity Score Index for TR-TR - Nonemployment in Previous Month
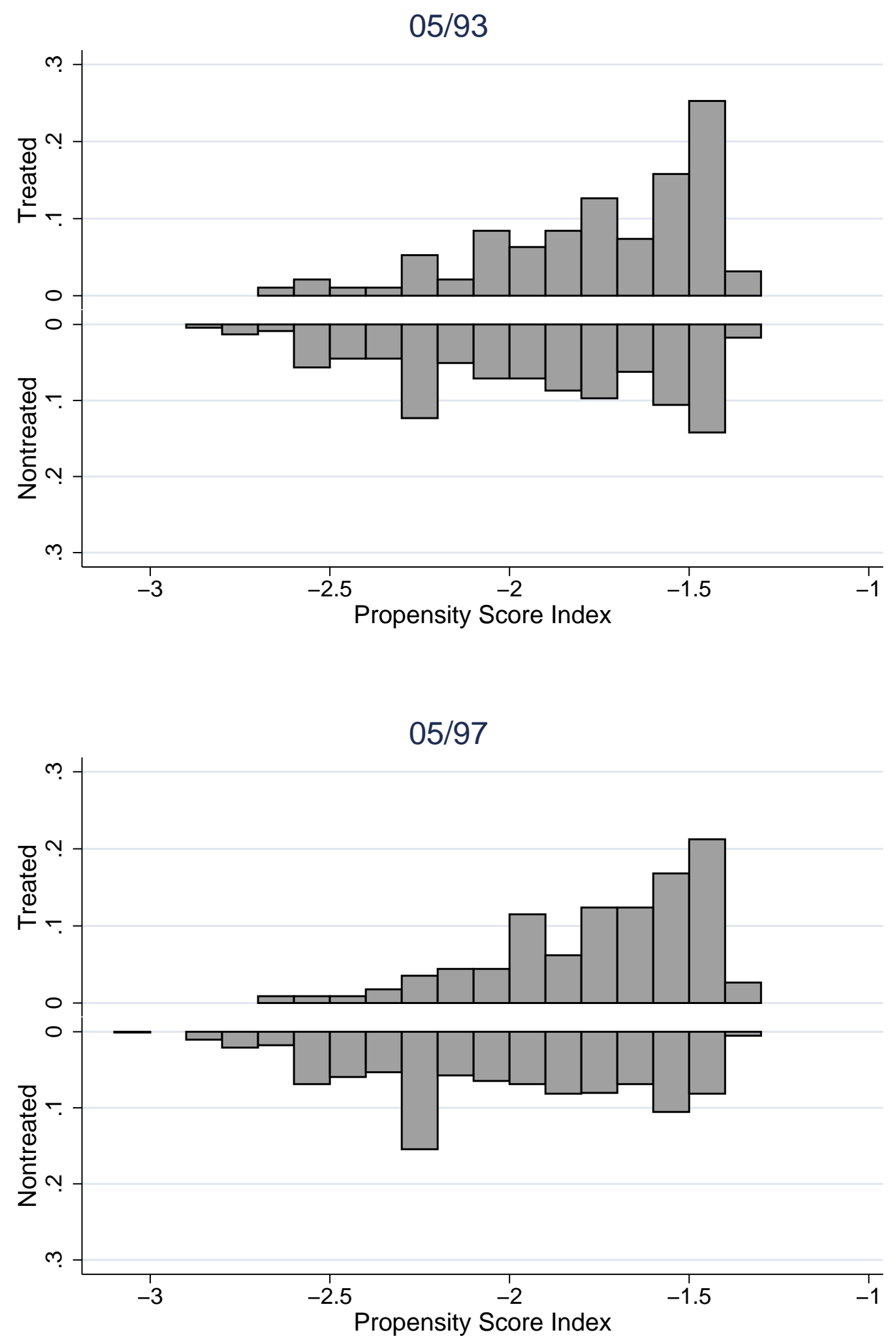
Figure 6: Overlap of Distributions of the Propensity Score Index for TR-TR Employment in Previous Month
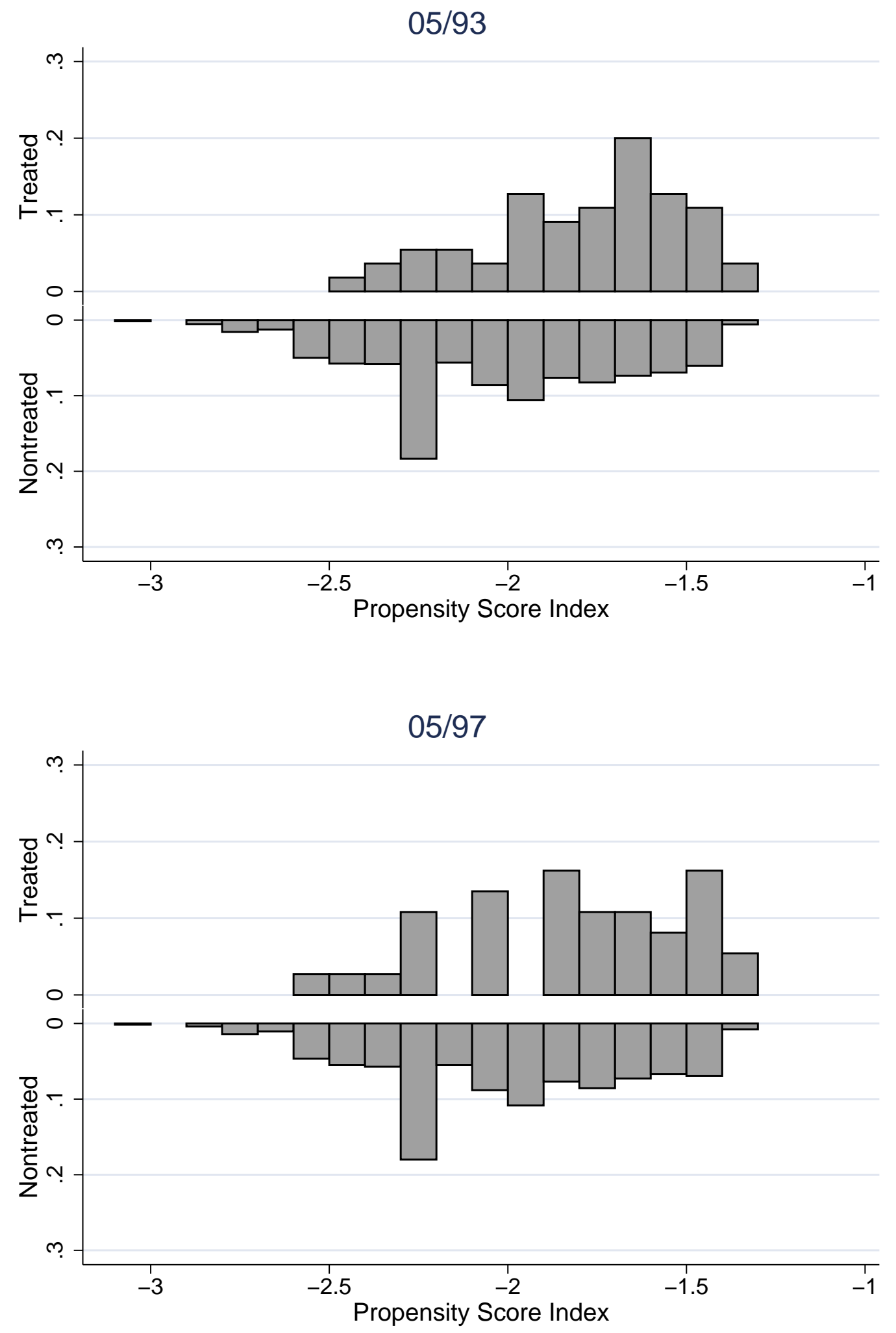
Figure 7: Differences in Outcome Variable (Matched Sample): First TR Beginning in Two-Year-Interval 90/91, . , 97/98

First Program is TR - Differences in Outcome Variable after Matching

Estimated Difference 1990/91

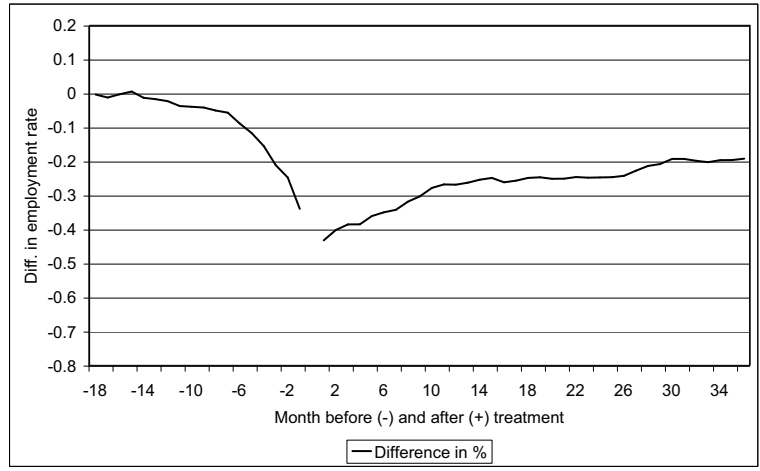

Estimated Difference 1992/93

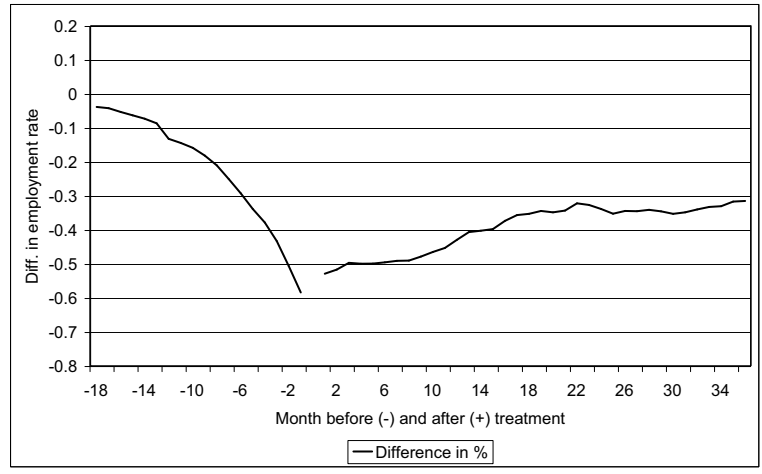

Estimated Difference 1994/95

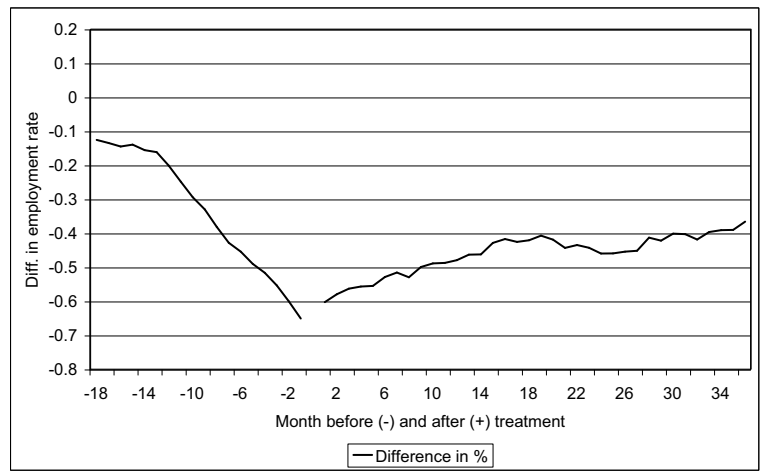

Estimated Difference 1996/97

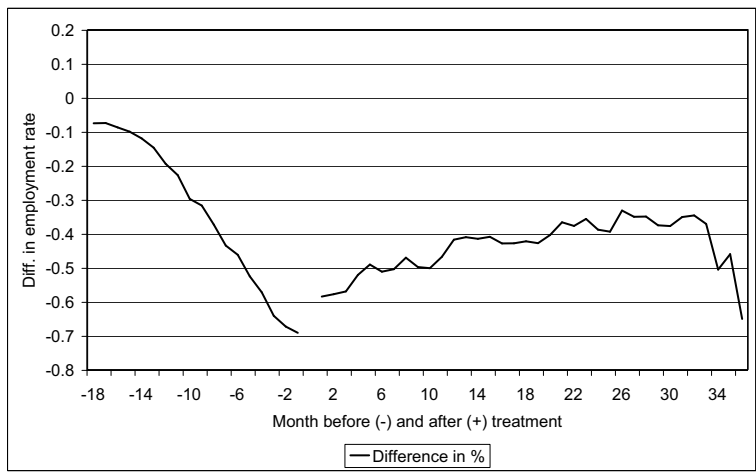

Estimated Difference 1991/92

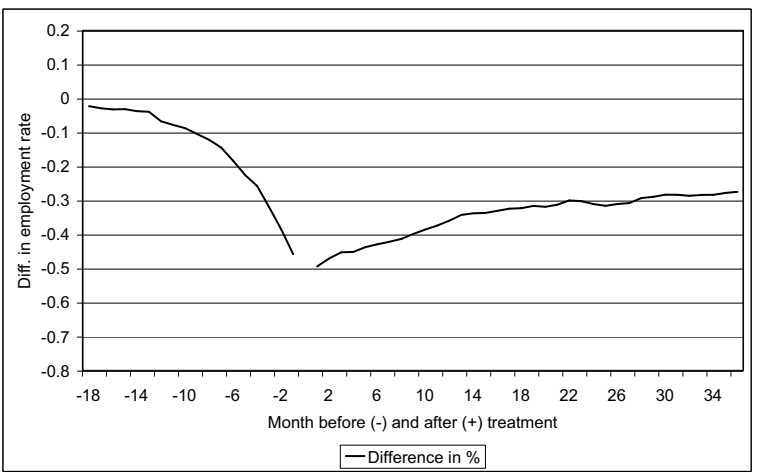

Estimated Difference 1993/94

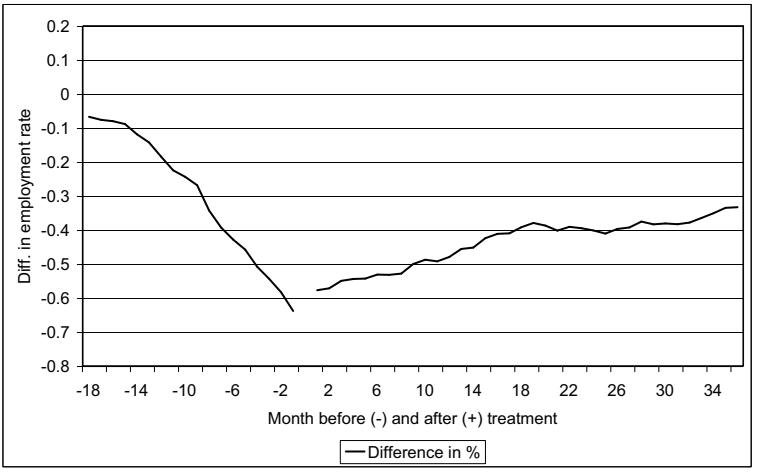

Estimated Difference 1995/96

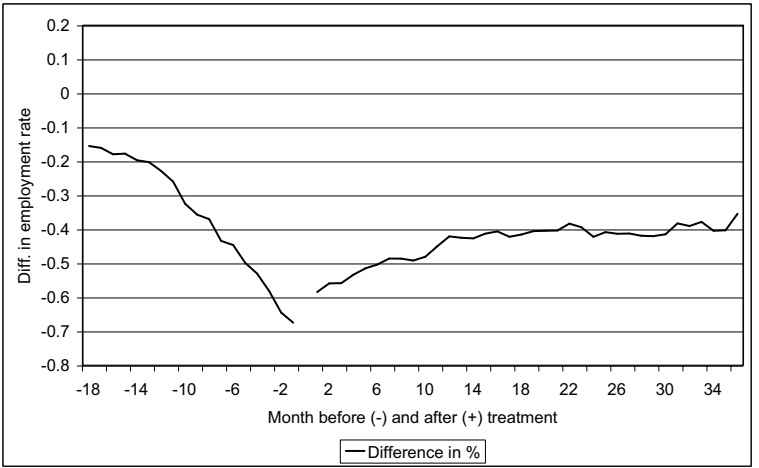

Estimated Difference 1997/98

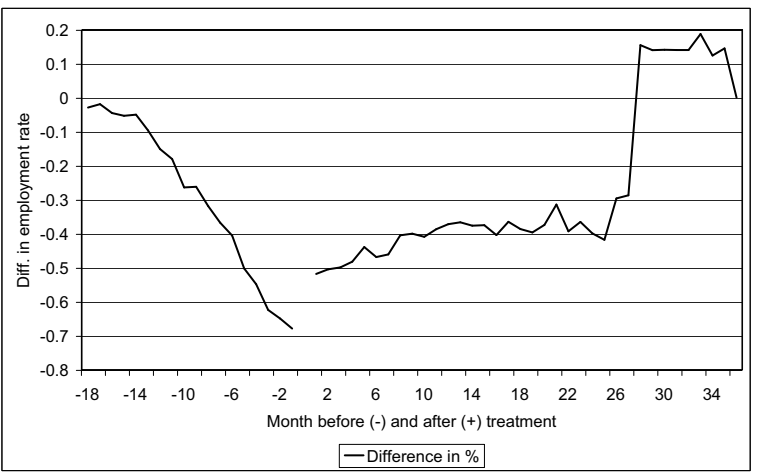


Figure 8: Employment Effects of FTR - CDiD - Evaluation Starts after End of Treatment
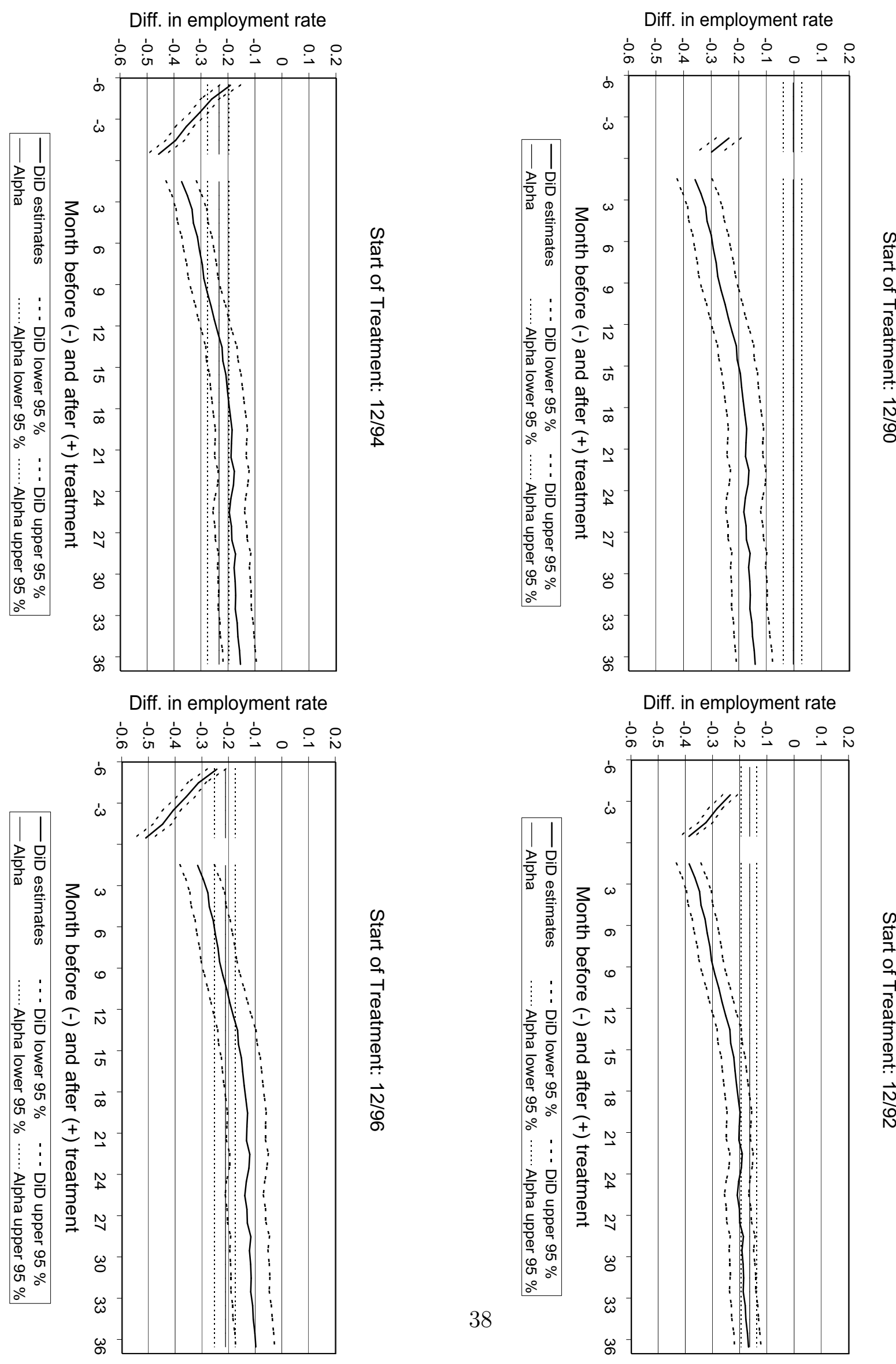

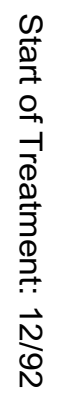


Figure 9: Employment Effects of FTR - CDiDHR - Nonemployment in the Previous Month - Evaluation Starts after Begin of Treatment
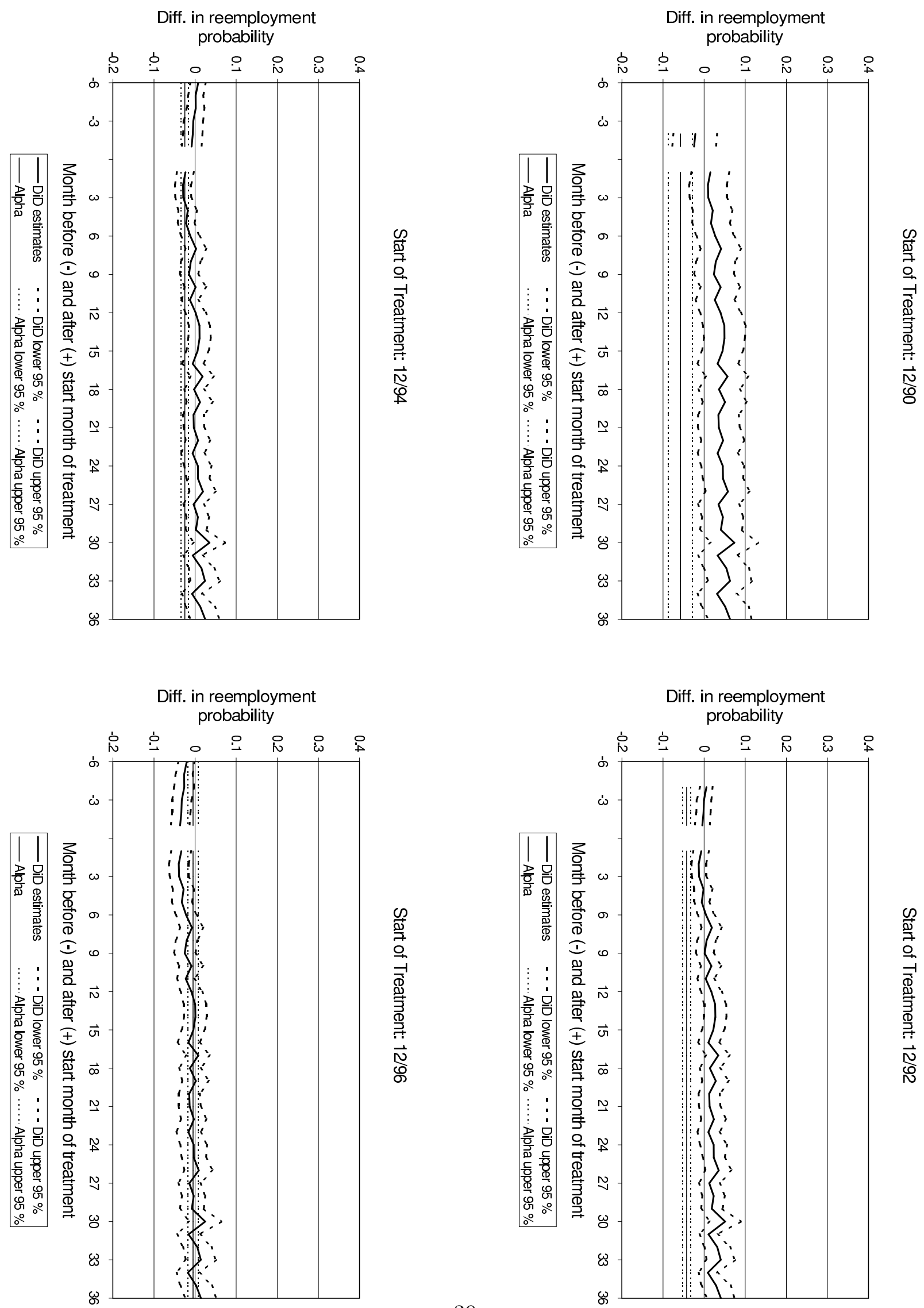
Figure 10: Employment Effects of FTR - CDiDHR - Nonemployment in the Previous Month - Evaluation Starts after End of Treatment
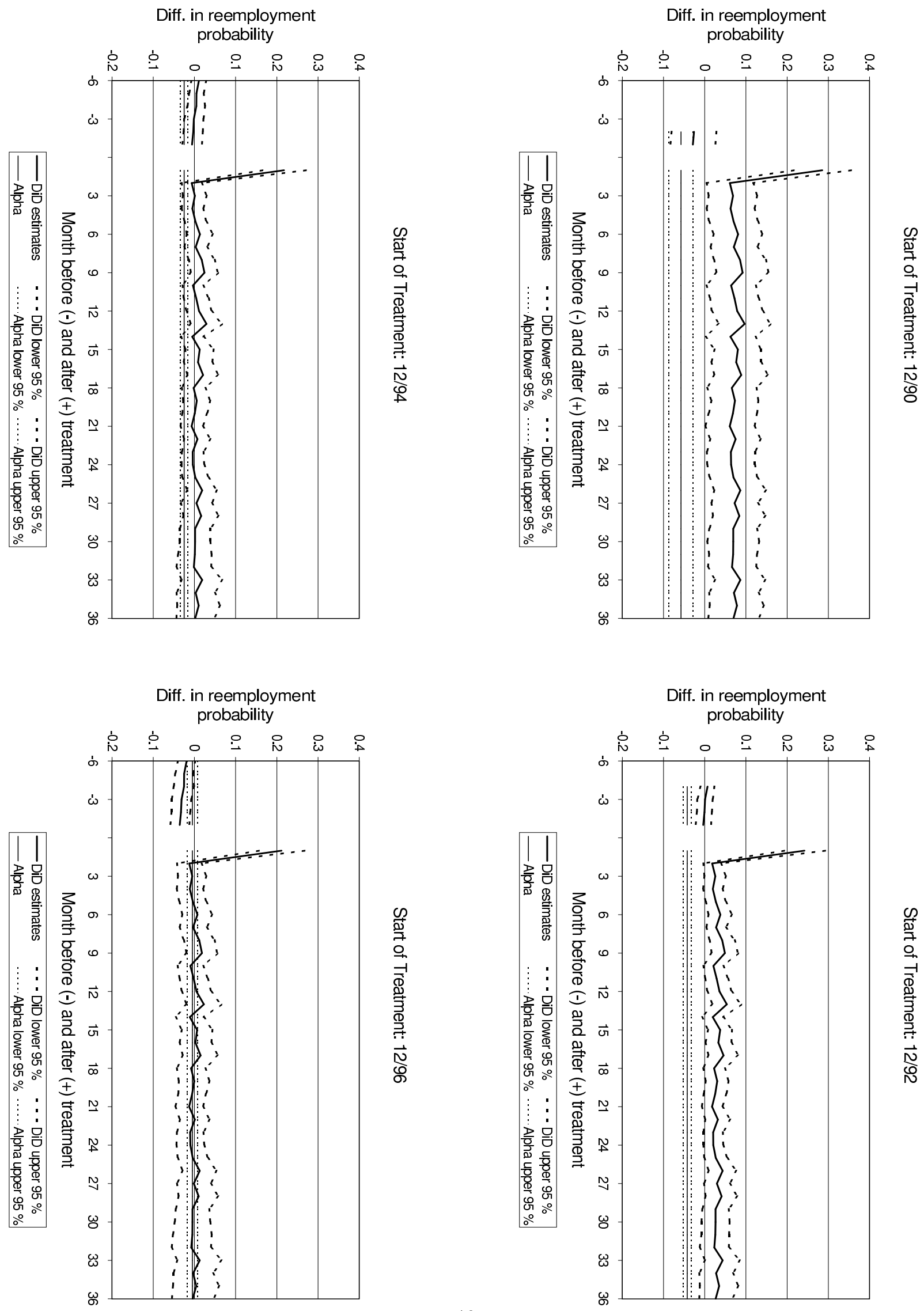
Figure 11: Employment Effects of FTR - CDiDHR - Employment in the Previous Month - Evaluation Starts after Begin of Treatment
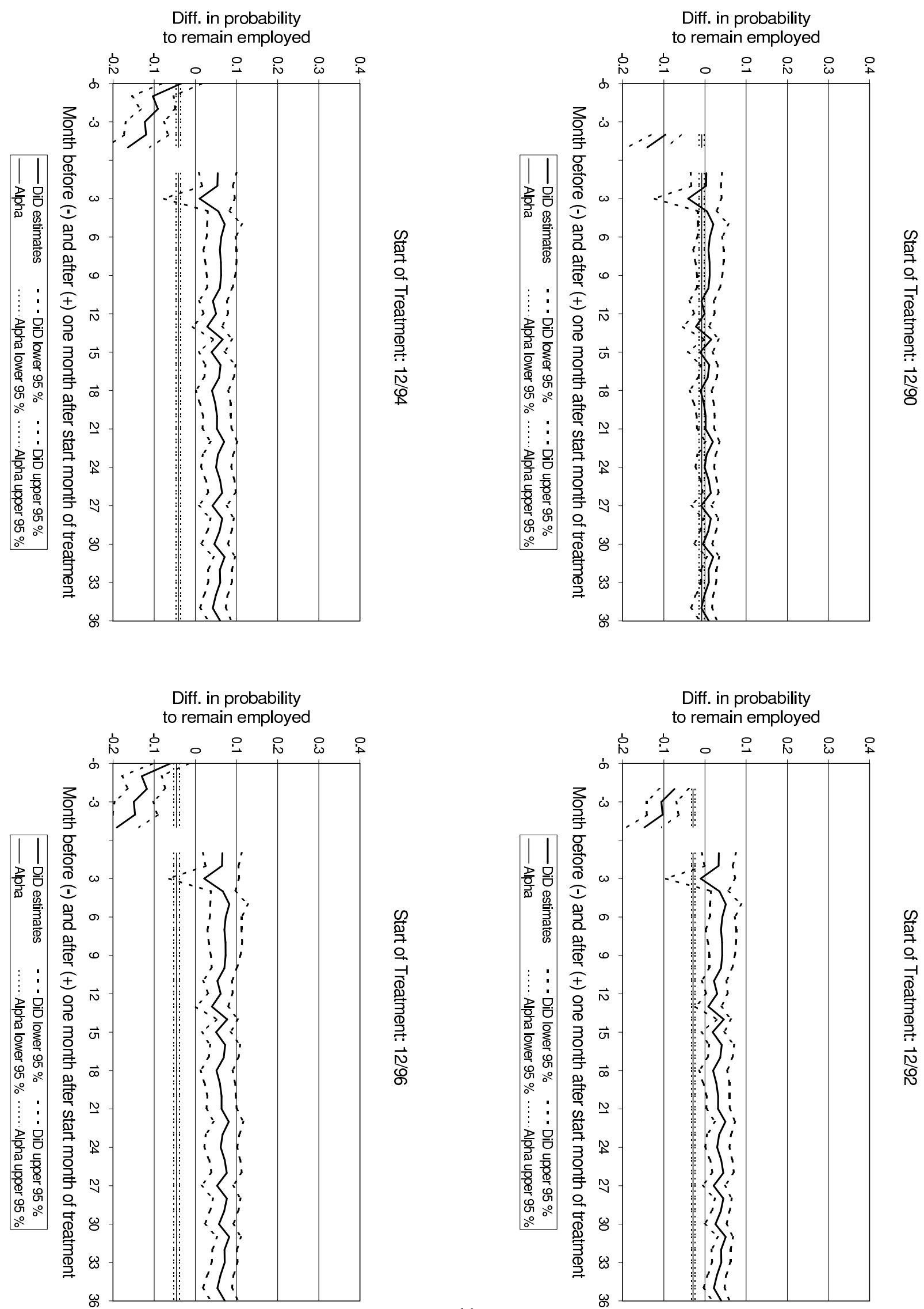
Figure 12: Employment Effects of FTR - CDiDHR - Employment in the Previous Month - Evaluation Starts after End of Treatment
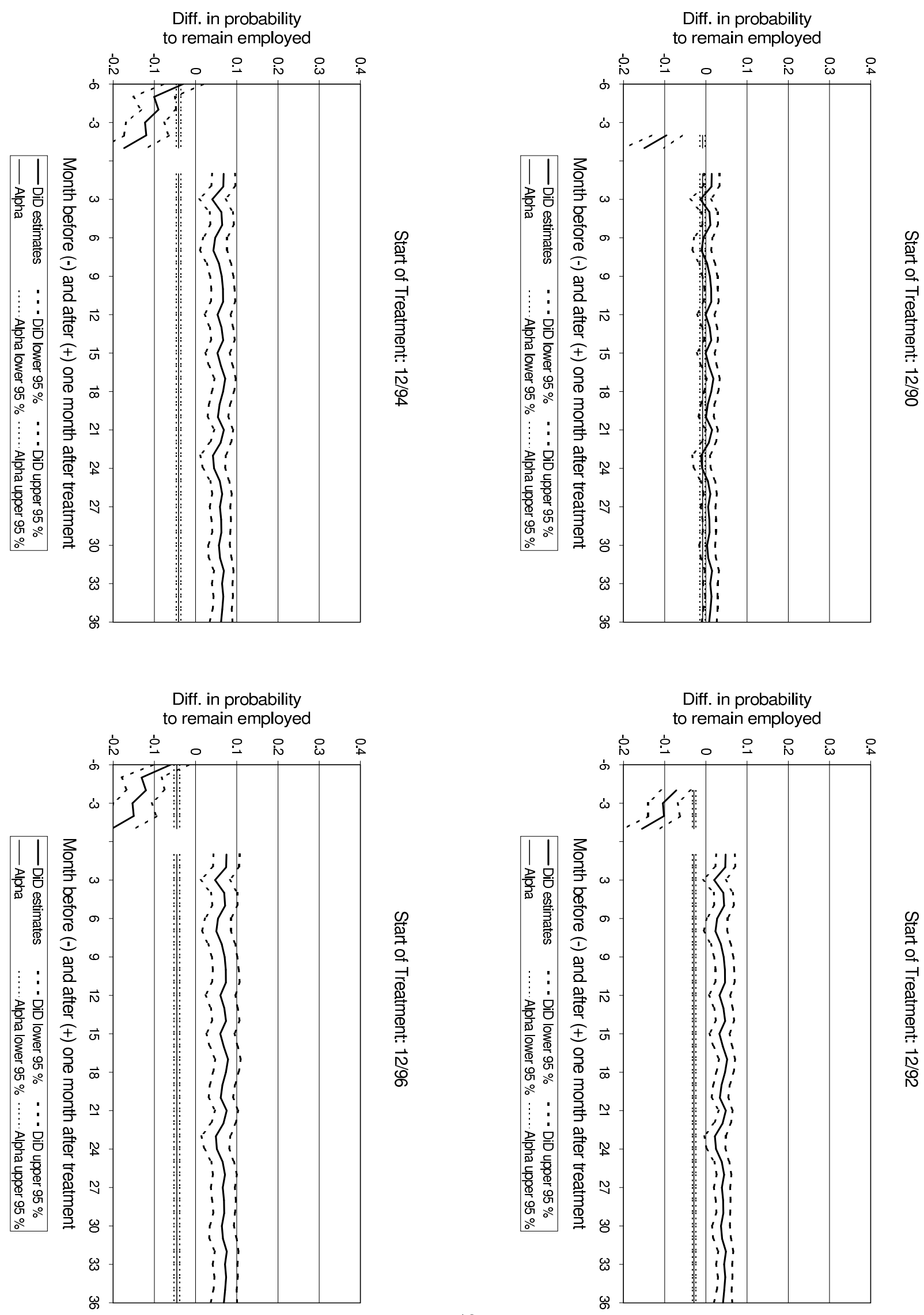
Figure 13: Combined Employment Effects of TR-TR - CDiDHR - Nonemployment in Previous Month - Evaluation Starts after Begin of Treatment

Start of Treatment: 12/90

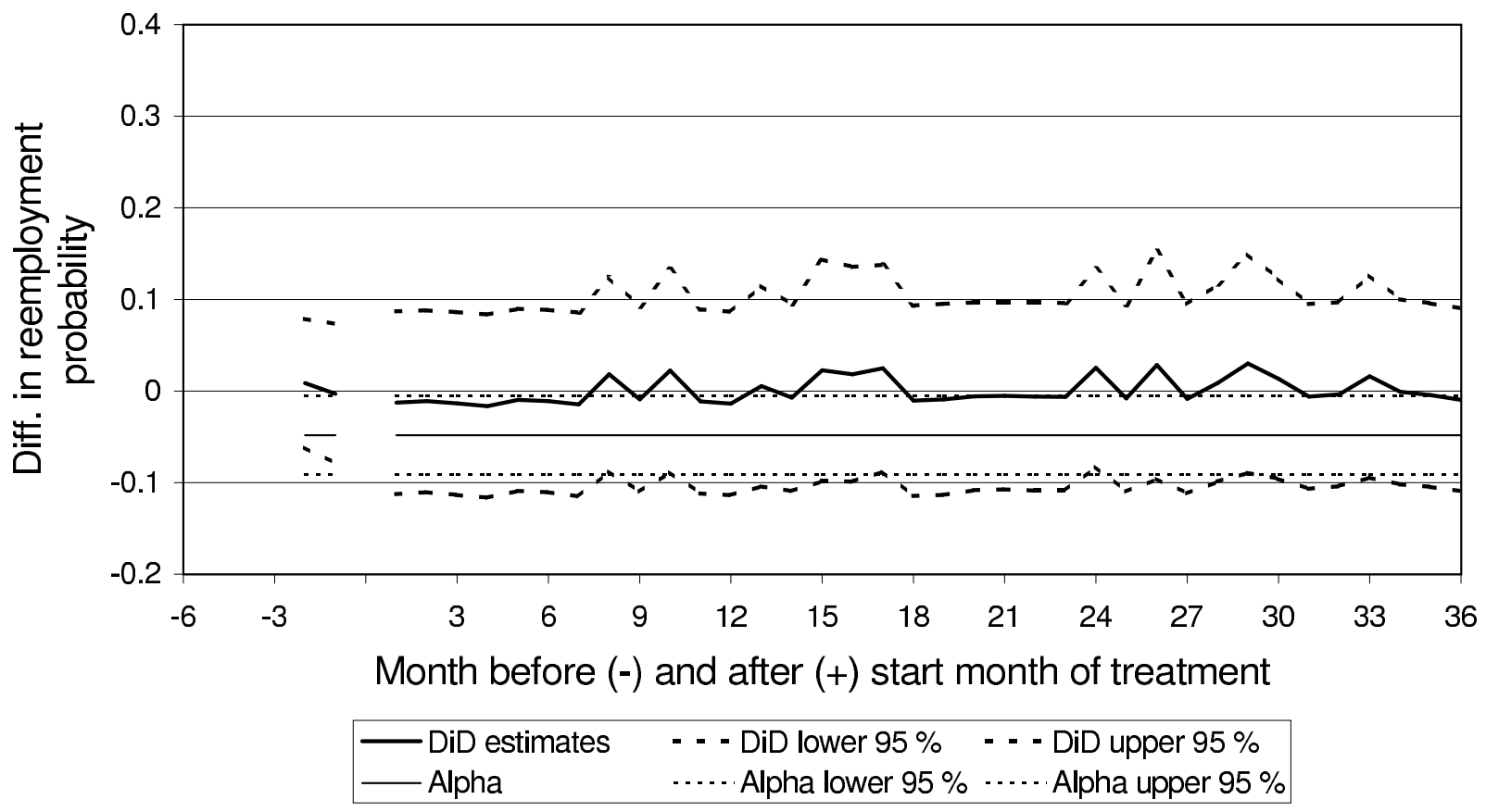

Start of Treatment: 12/92

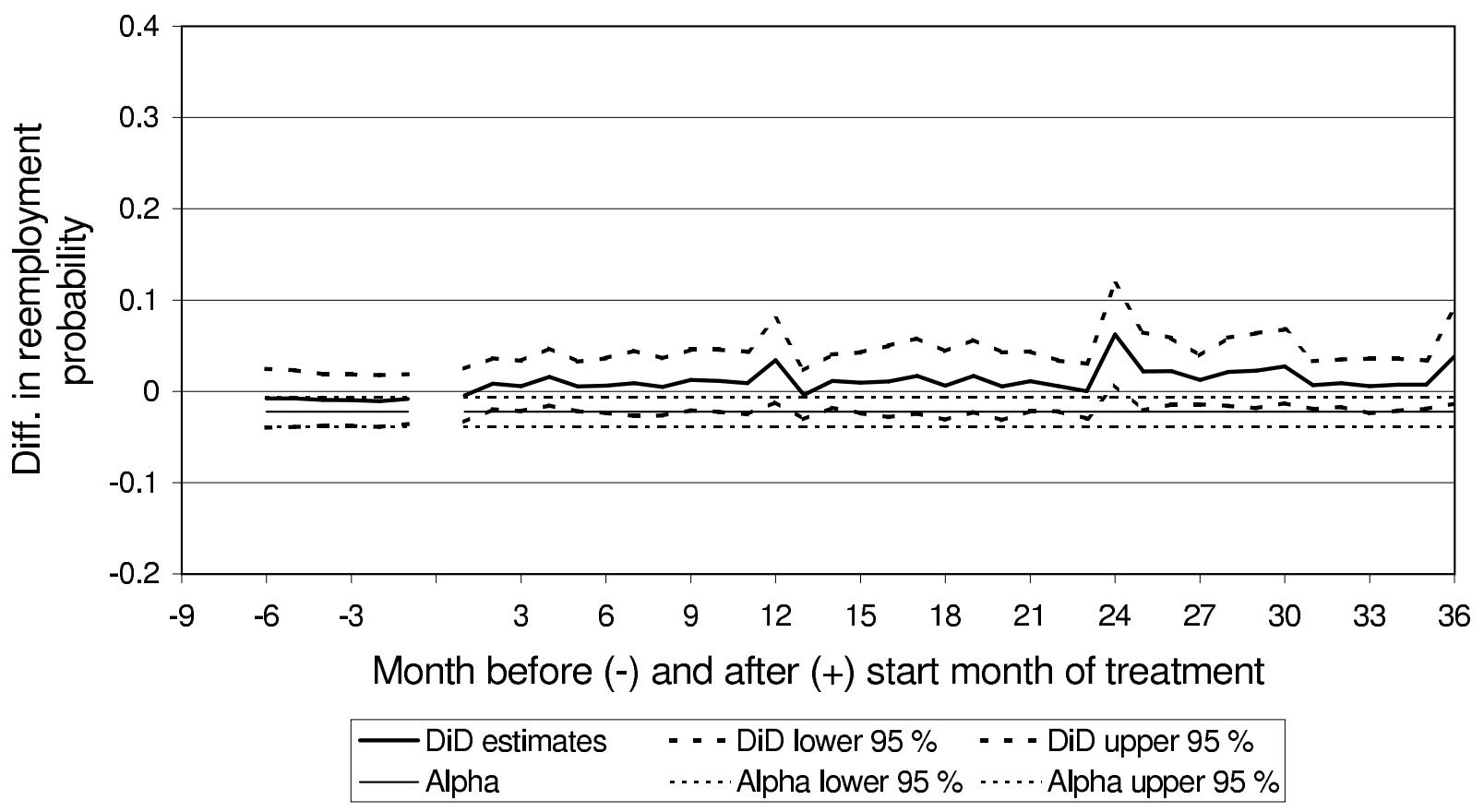


Figure 14: Incremental Employment Effects of TR-TR - CDiDHR - Nonemployment in Previous Month - Evaluation Starts after Begin of Treatment

Start of Treatment: 12/94

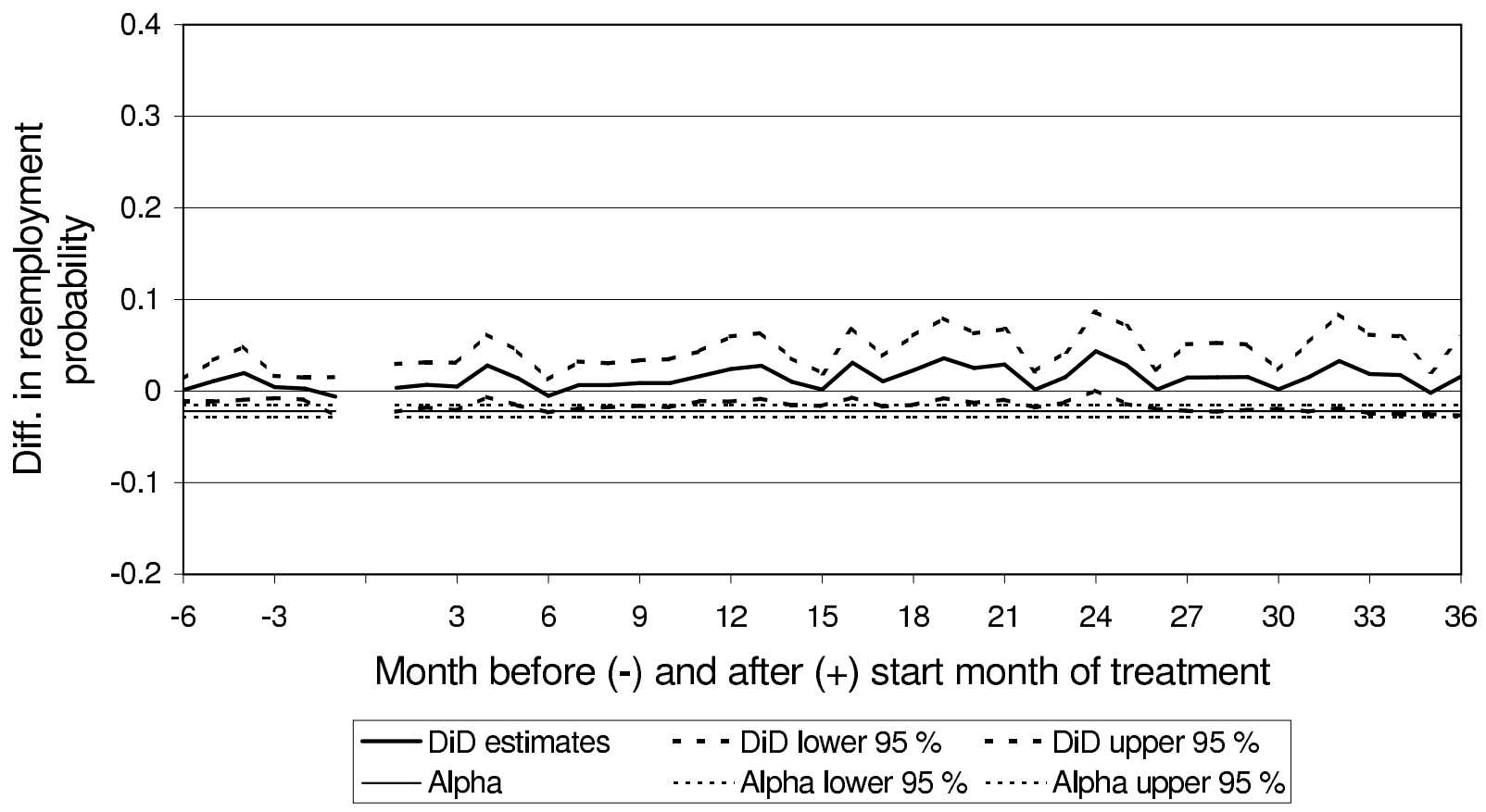

Start of Treatment: 12/96

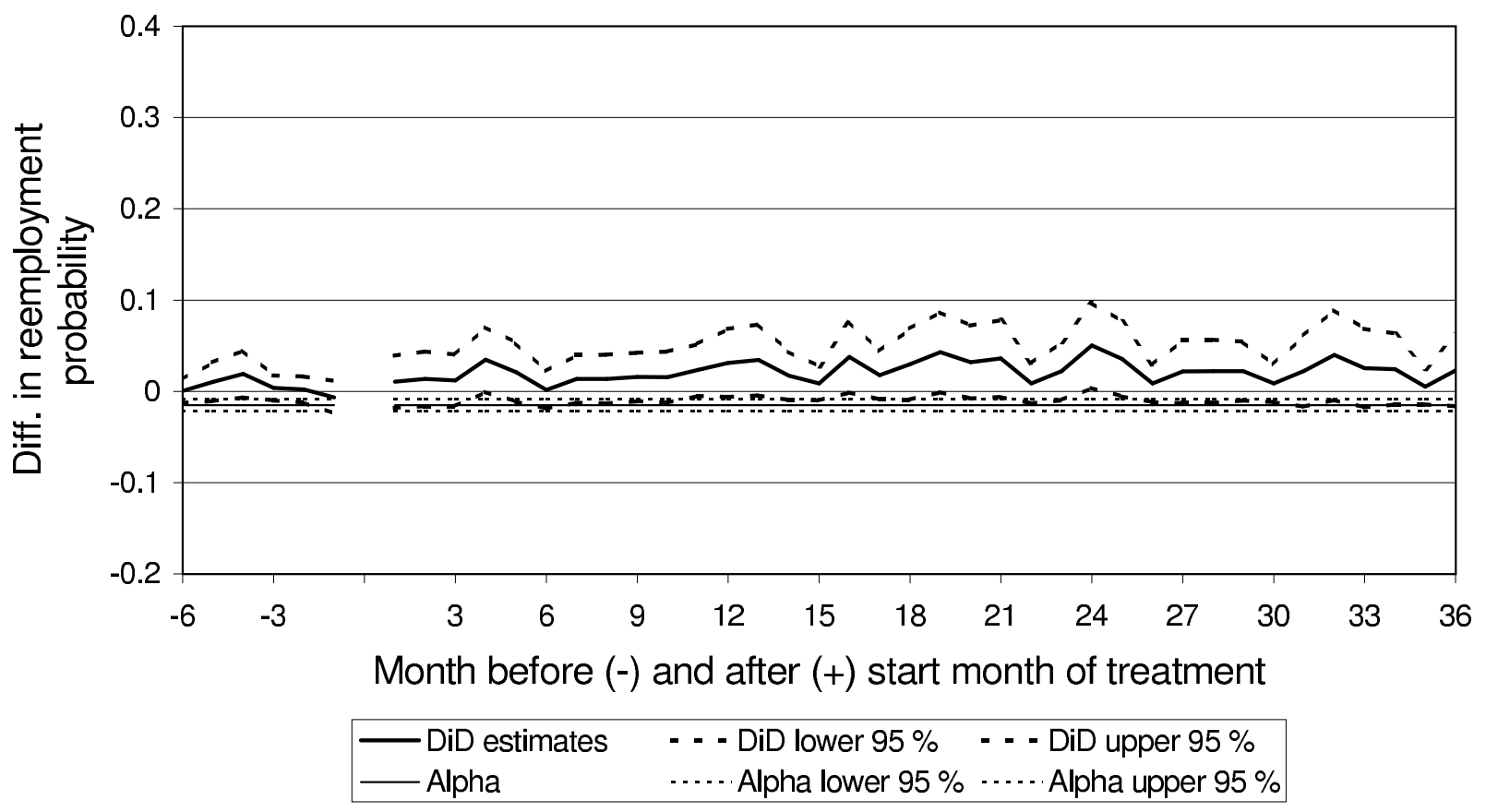


Figure 15: Combined Employment Effects of TR-TR - CDiDHR - Employment in Previous Month - Evaluation Starts after Begin of Treatment

Start of Treatment: $12 / 90$

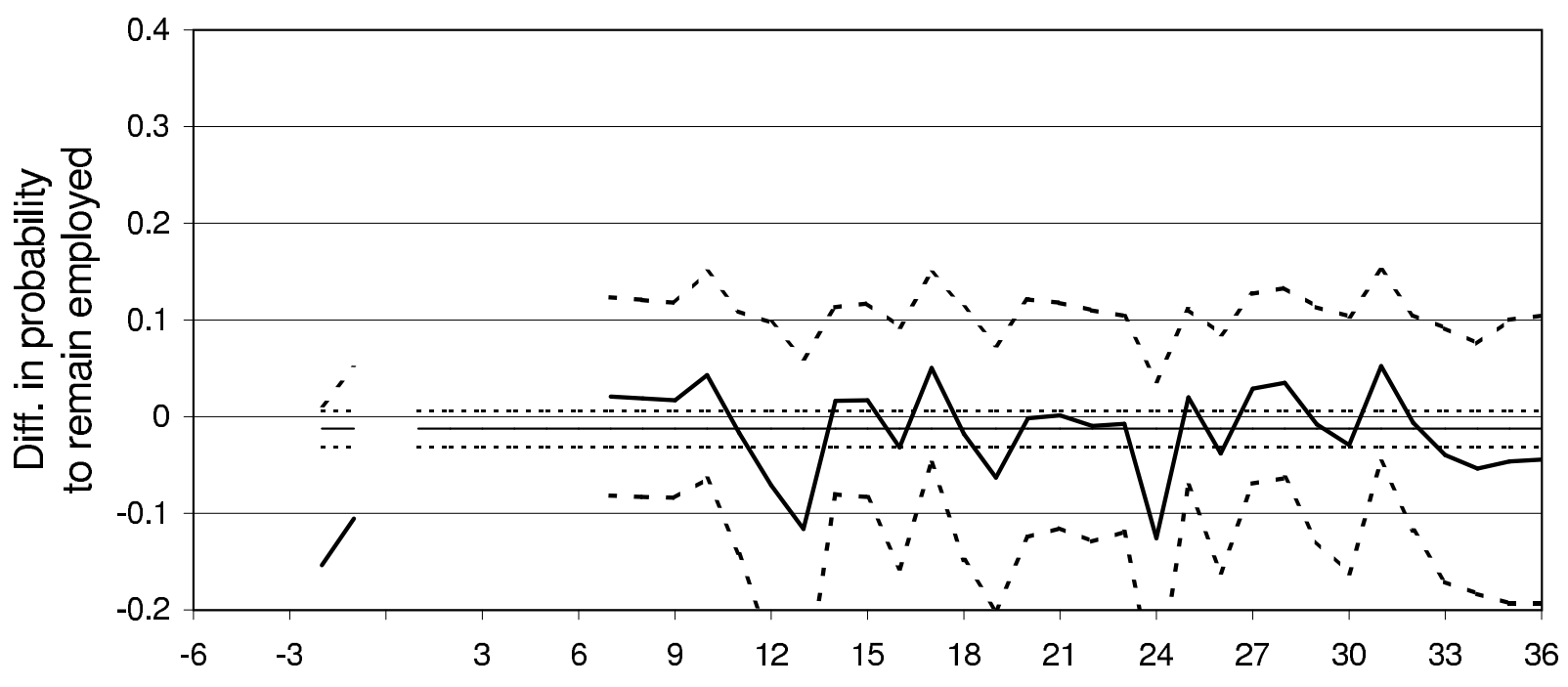

Month before (-) and after (+) one month after start month of treatment

\begin{tabular}{|c|c|}
\hline $\begin{array}{l}\text { - DiD estimates } \\
\text { Alpha }\end{array}$ & $\begin{array}{l}-\ldots \text { - DiD lower } 95 \% \\
\ldots \text { - Alpha lower } 95 \%\end{array}$ \\
\hline
\end{tabular}

Start of Treatment: 12/92

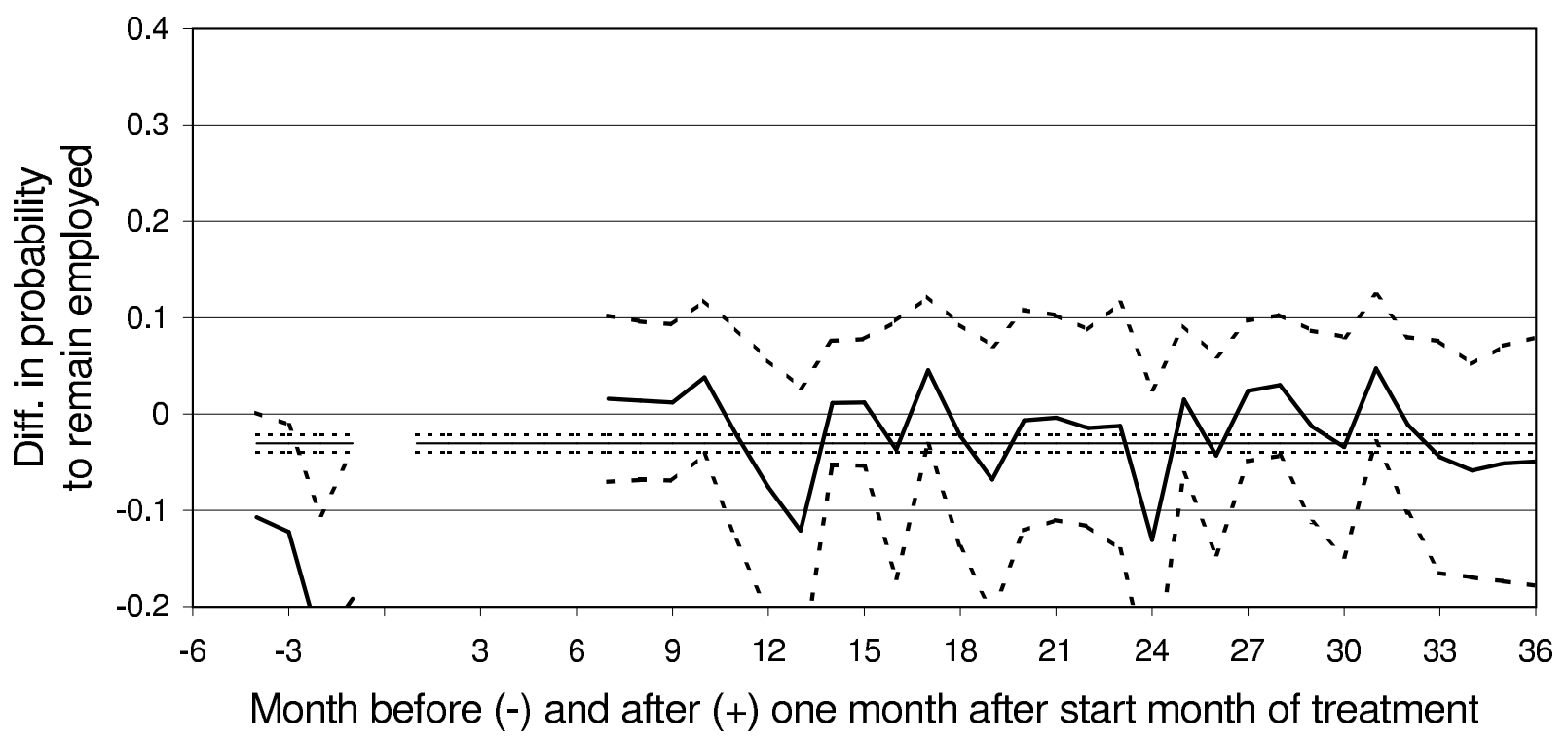

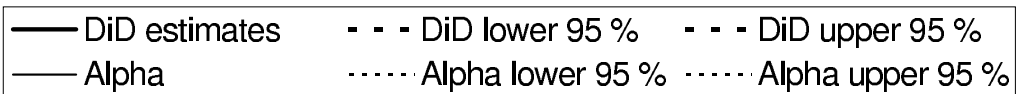


Figure 16: Incremental Employment Effects of TR-TR - CDiDHR - Employment in Previous Month - Evaluation Starts after Begin of Treatment

\section{Start of Treatment: $12 / 94$}

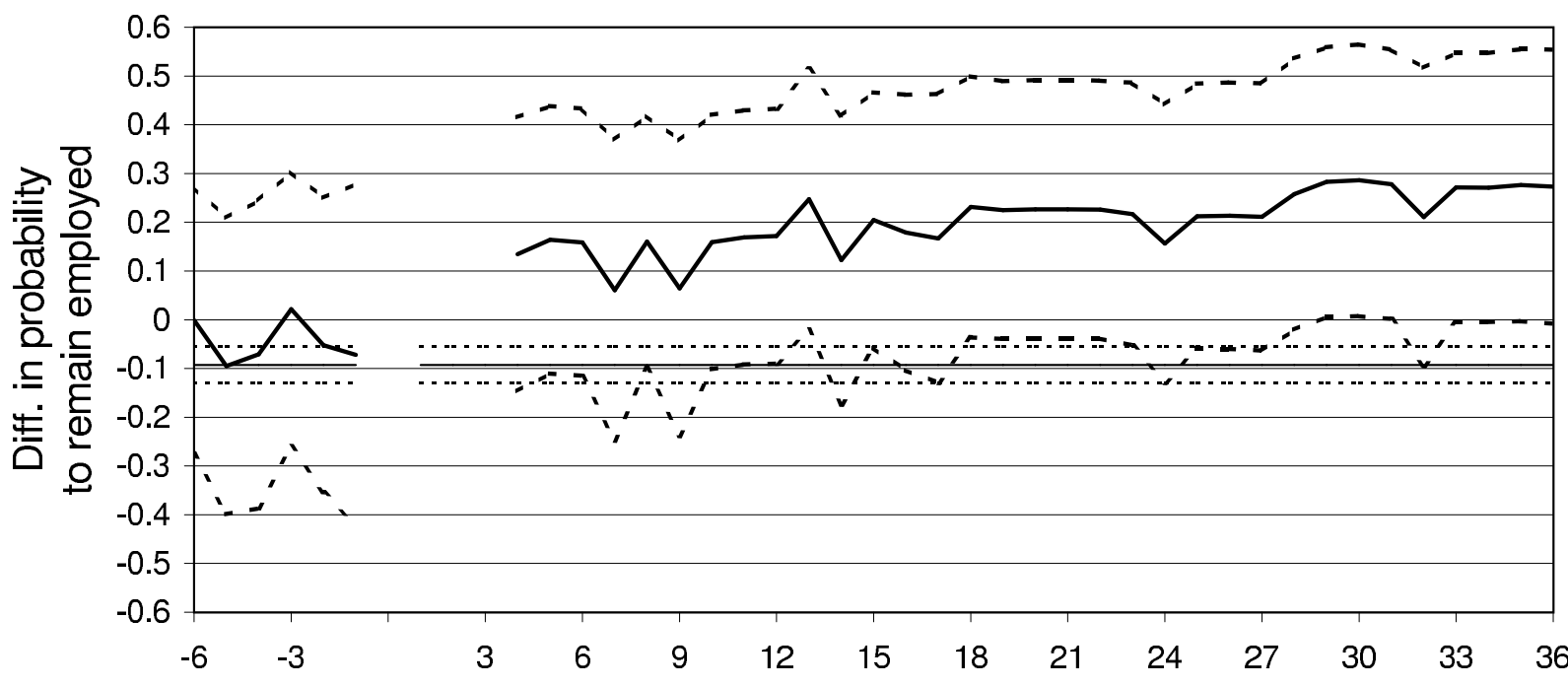

Month before (-) and after $(+)$ one month after start month of treatment

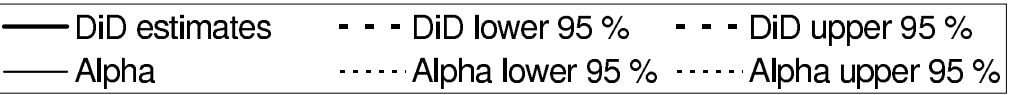

Start of Treatment: 12/96

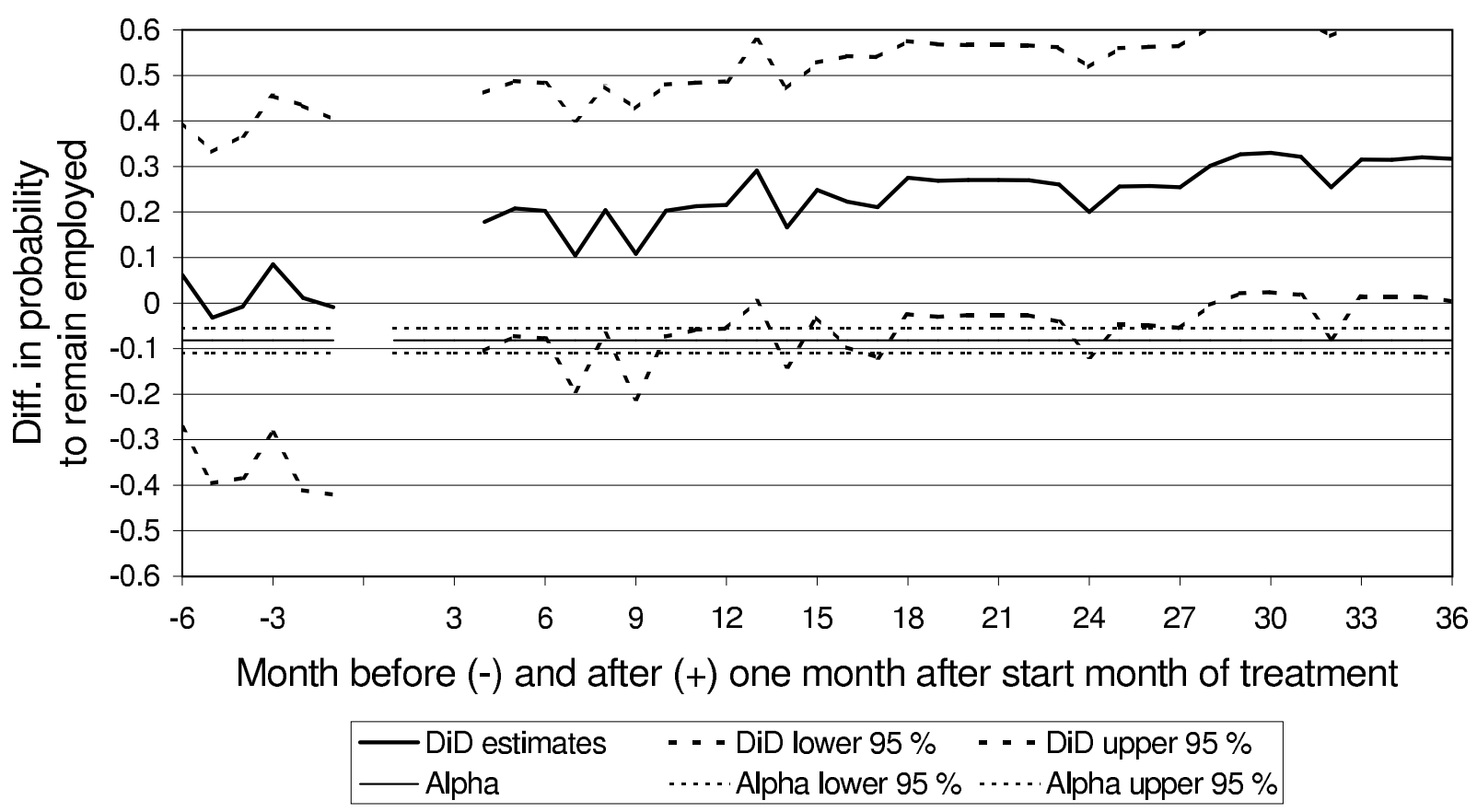


Figure 17: Combined Employment Effects of TR-JC - CDiDHR - Nonemployment in Previous Month - Evaluation Starts after Begin of Treatment

Start of Treatment: 12/90

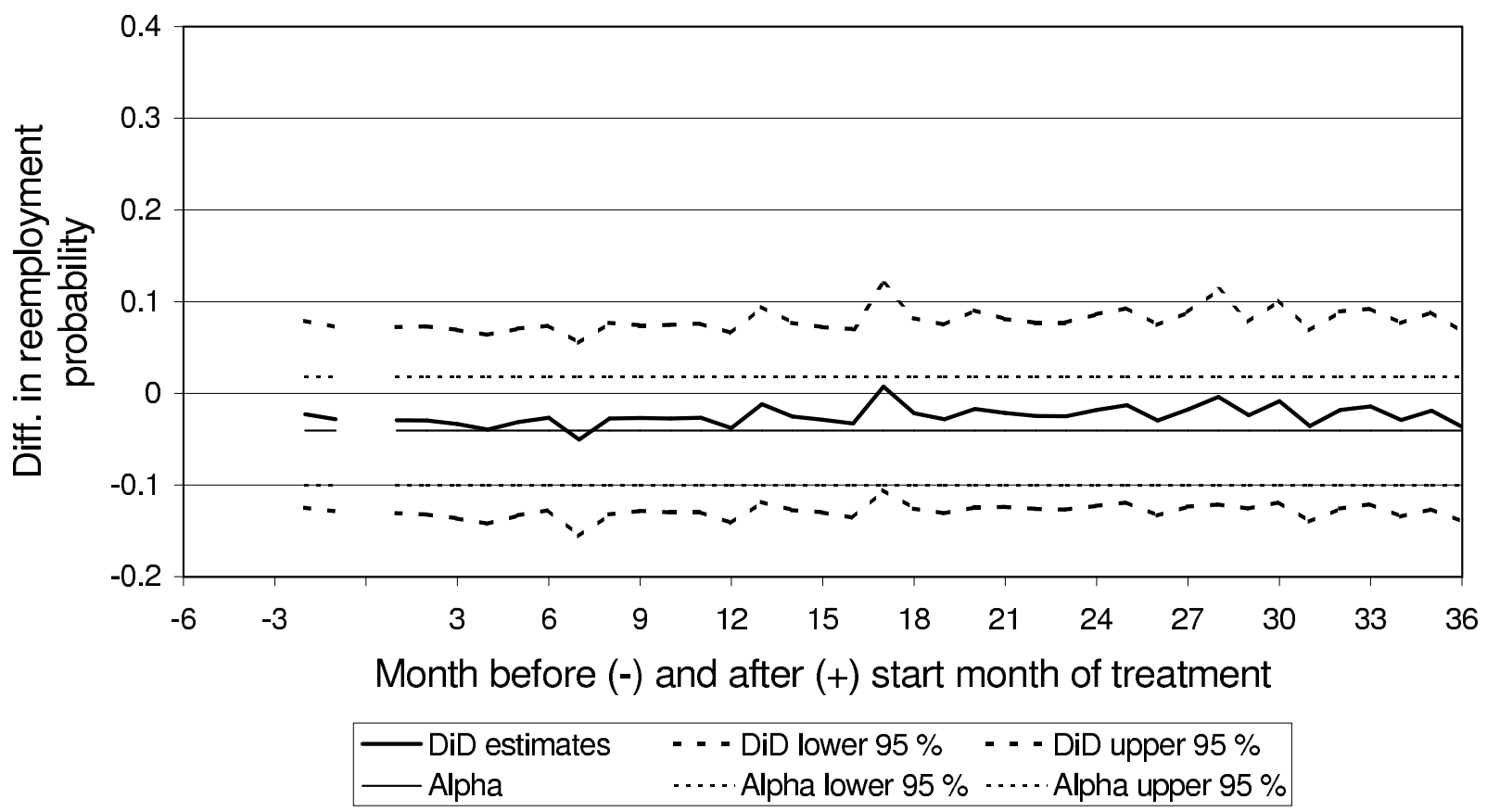

Start of Treatment: 12/92

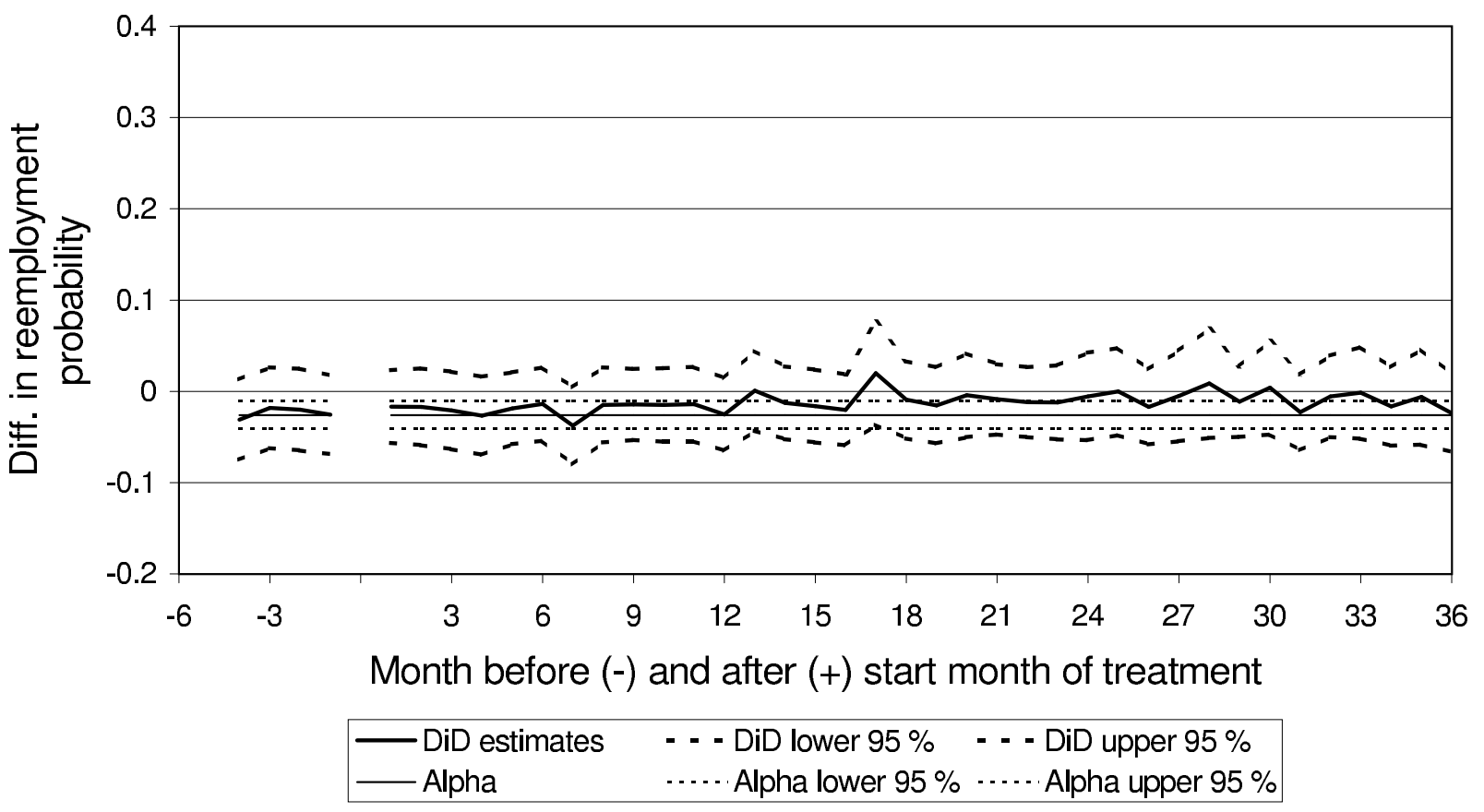


Figure 18: Incremental Employment Effects of TR-JC - CDiDHR - Nonemployment in Previous Month - Evaluation Starts after Begin of Treatment

Start of Treatment: 12/94

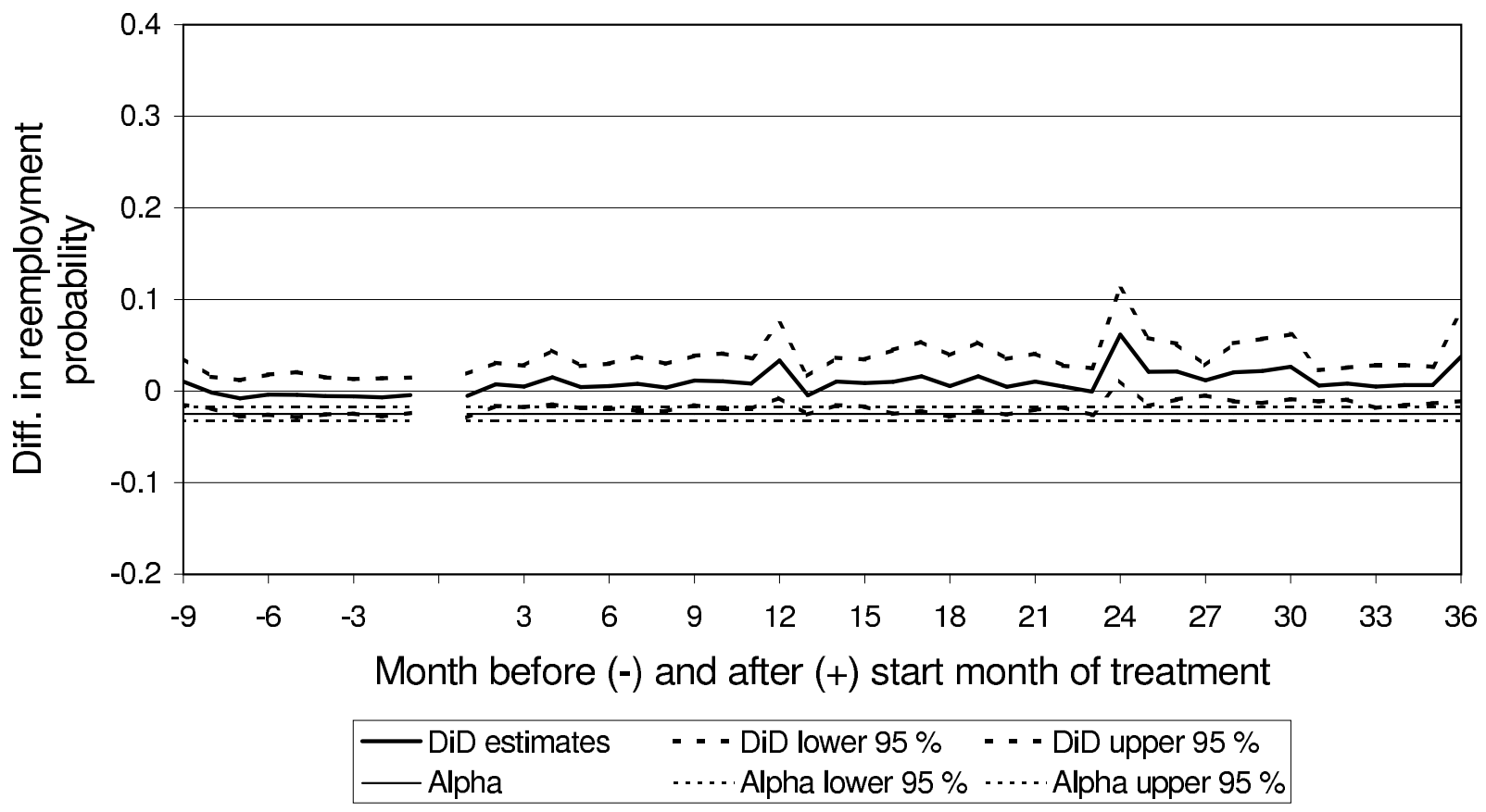

Start of Treatment: 12/96

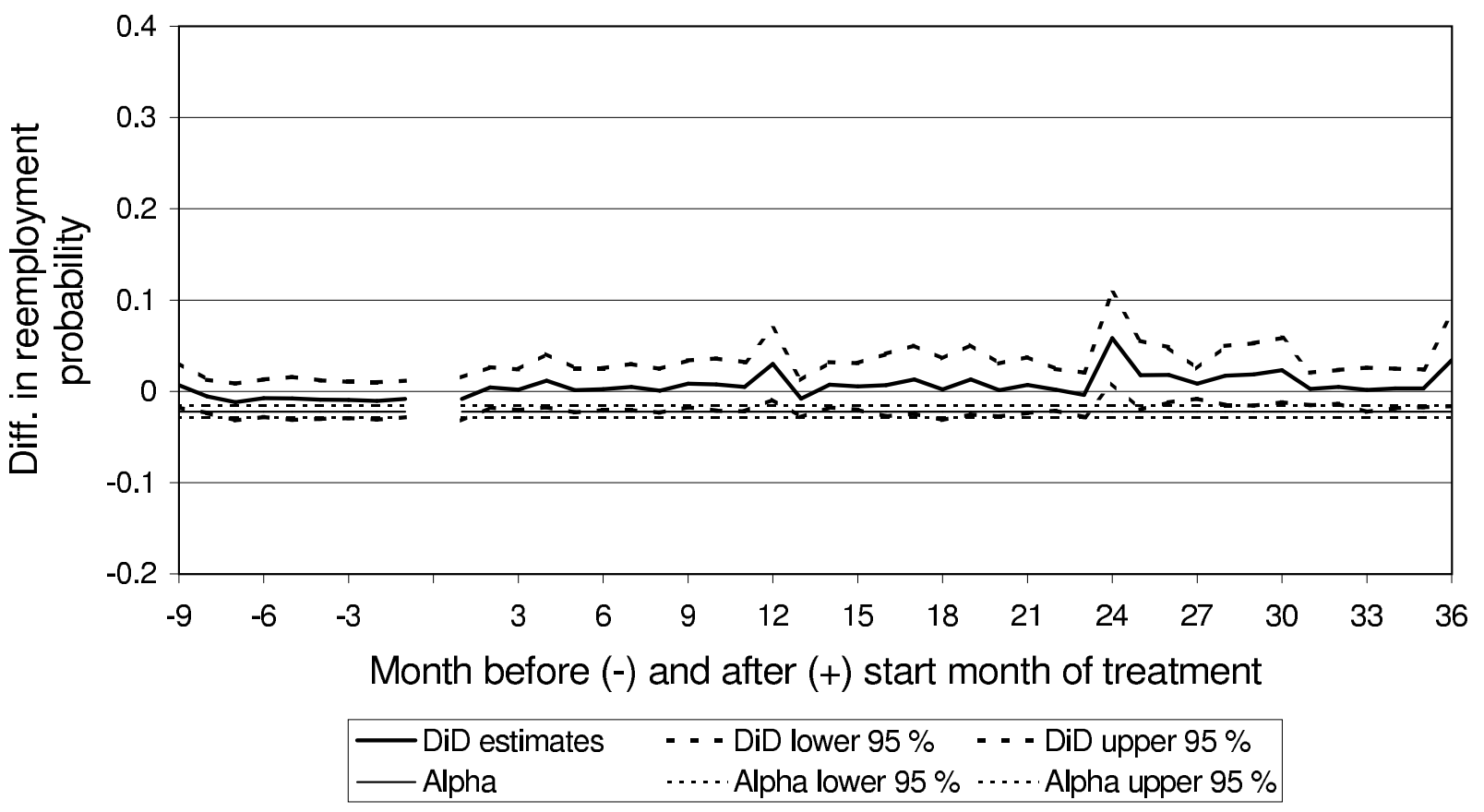


Figure 19: Combined Employment Effects of TR-JC - CDiDHR - Employment in Previous Month - Evaluation Starts after Begin of Treatment

Start of Treatment: 12/90

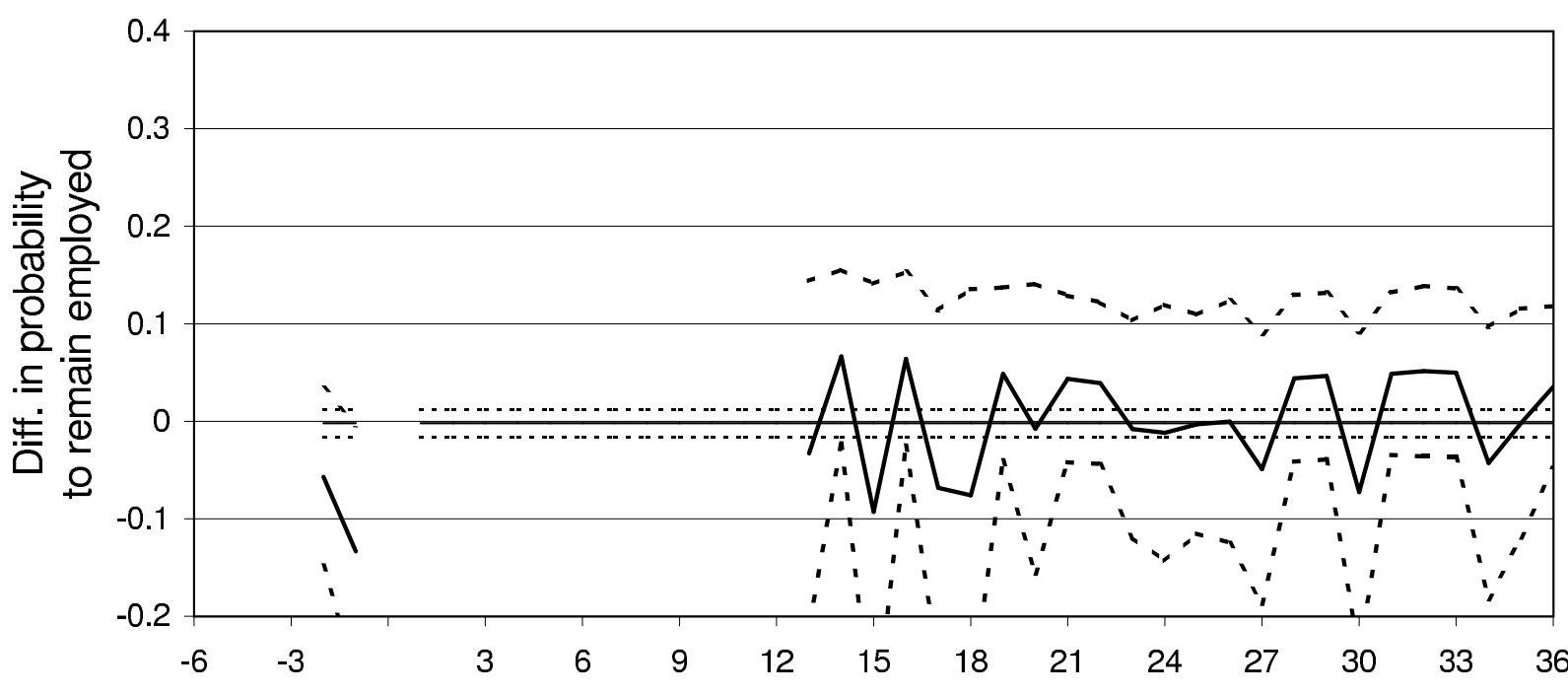

Month before (-) and after (+) one month after start month of treatment

\begin{tabular}{|c|c|}
\hline $\begin{array}{l}\text { - DiD estimates } \\
\text { Alpha }\end{array}$ & $\begin{array}{l}-\ldots \text { - DiD lower } 95 \% \\
\ldots \text { - Alpha lower } 95 \%\end{array}$ \\
\hline
\end{tabular}

Start of Treatment: 12/92

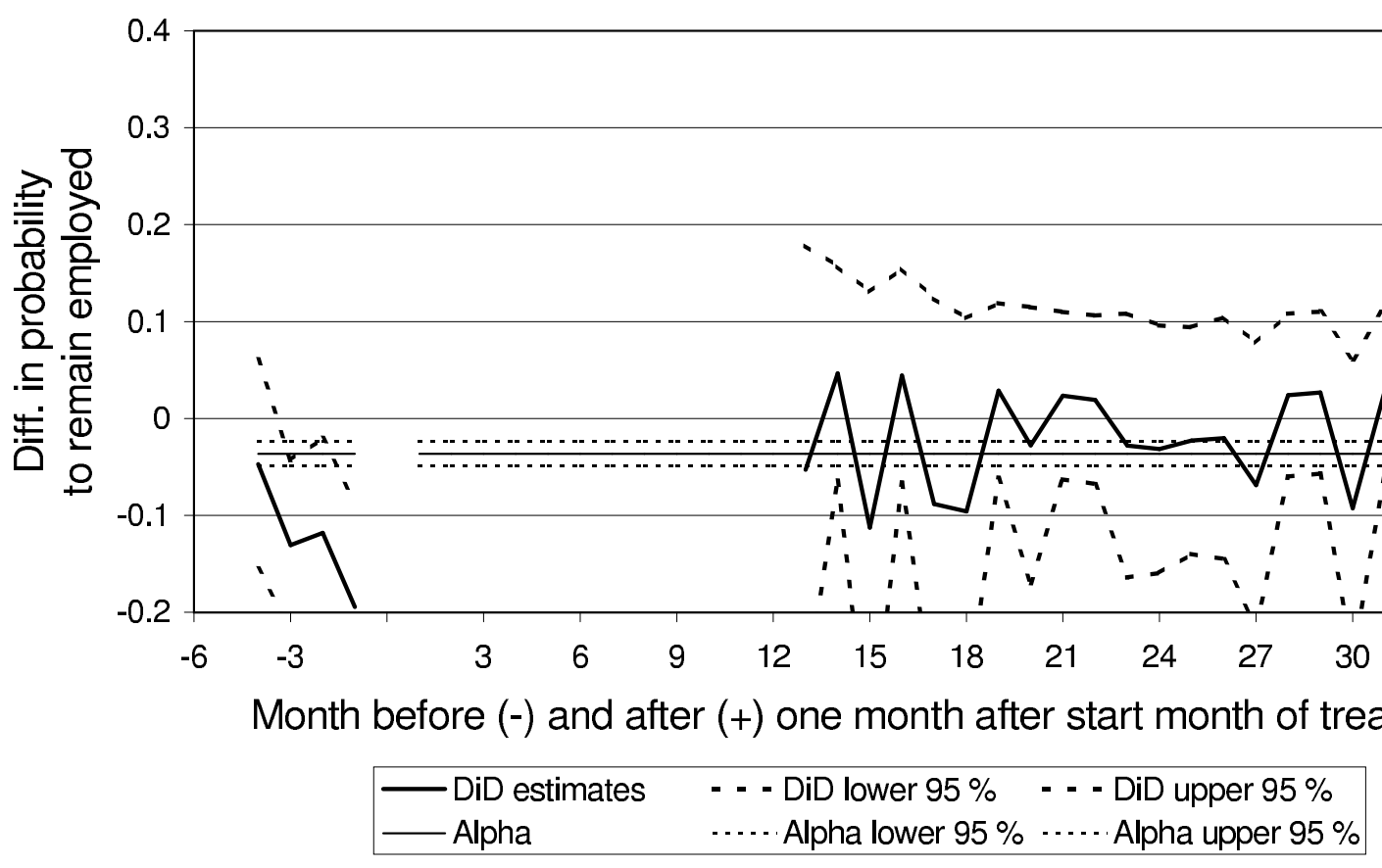


Figure 20: Incremental Employment Effects of TR-JC - CDiDHR - Employment in Previous Month - Evaluation Starts after Begin of Treatment

\section{Start of Treatment: 12/94}

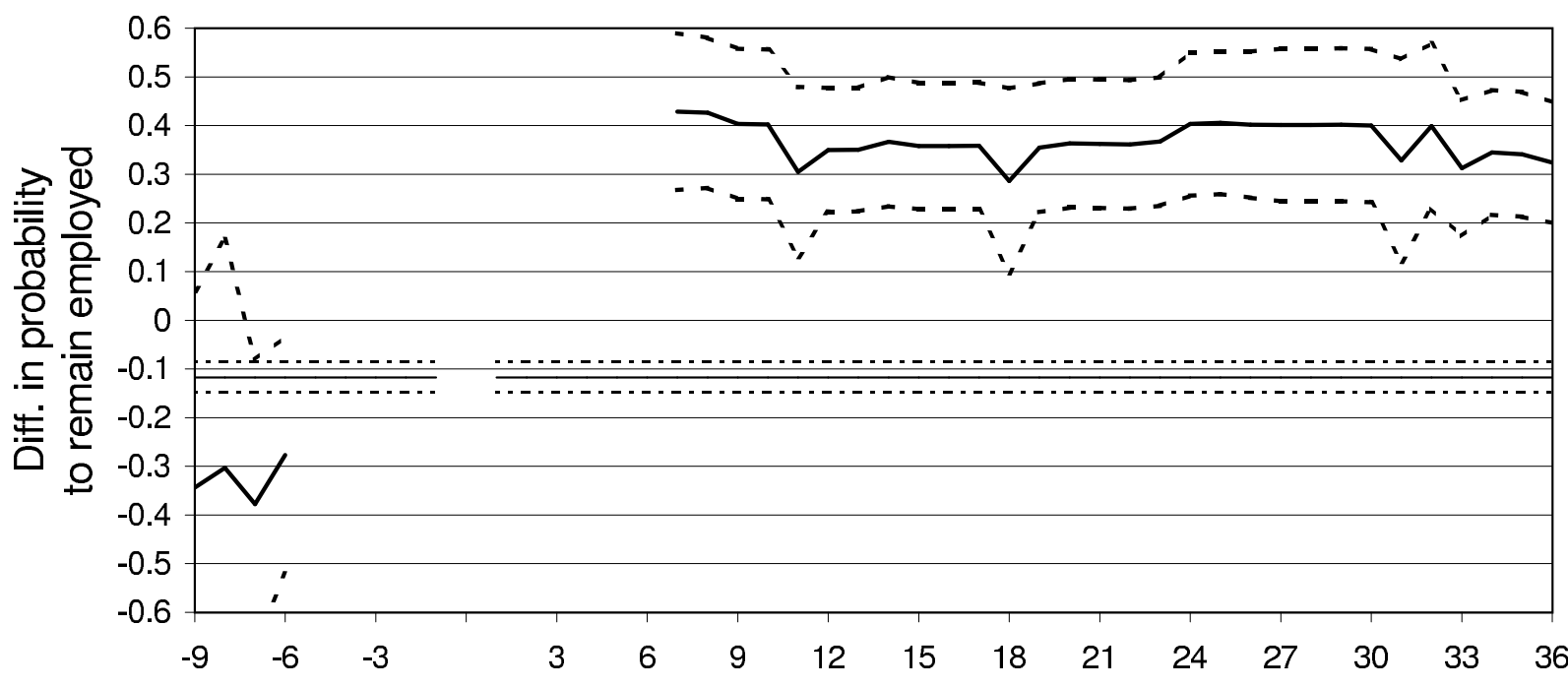

Month before (-) and after (+) one month after start month of treatment

\begin{tabular}{|c|c|}
\hline $\begin{array}{l}\text { - DiD estimates } \\
\text { Alpha }\end{array}$ & $\begin{array}{l}-\ldots \text { - DiD lower } 95 \% \\
\ldots \text { - Alpha lower } 95 \%\end{array}$ \\
\hline
\end{tabular}

Start of Treatment: $12 / 96$

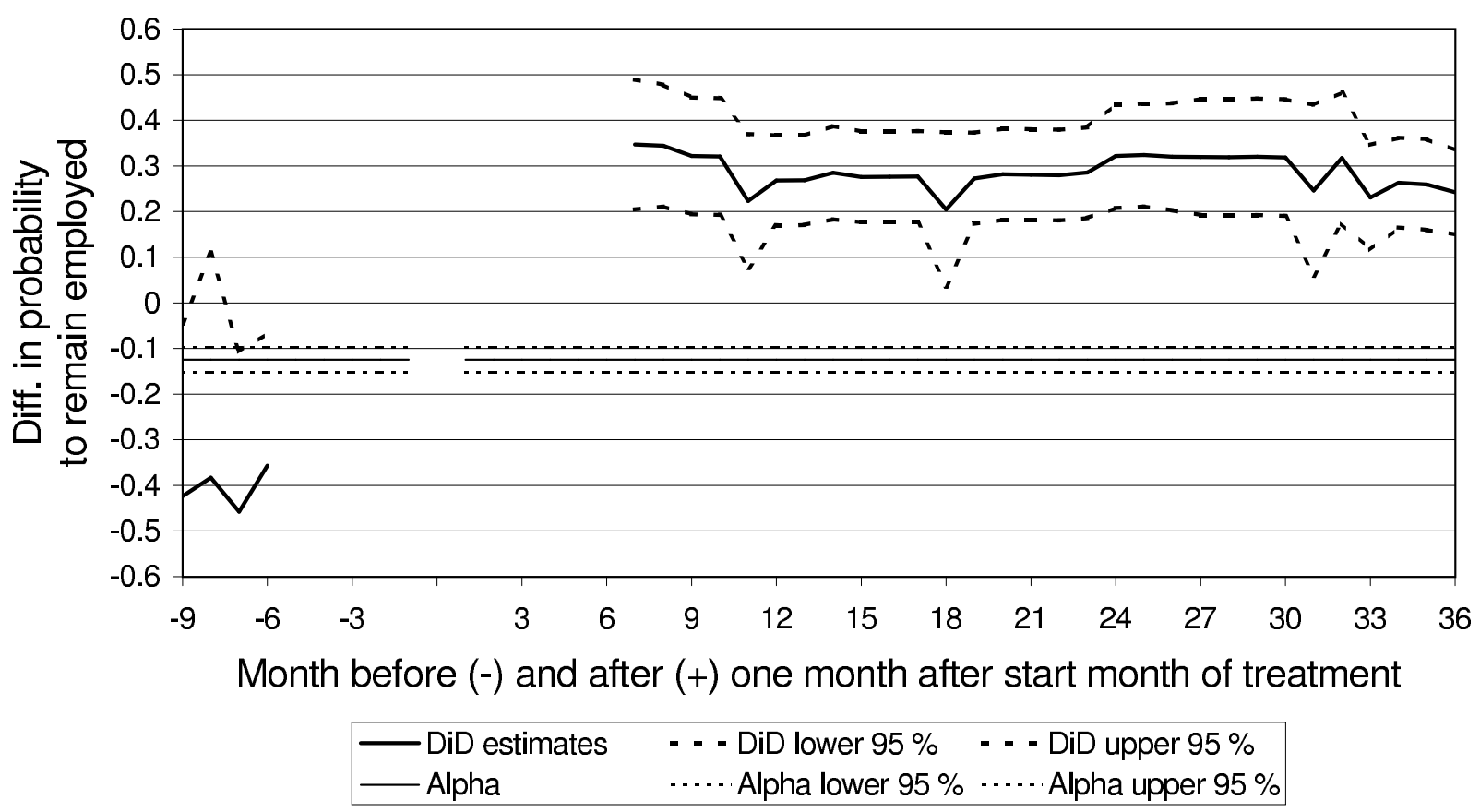


Table 1: Program Participation (number of individuals) in the LMM-SA during 1990 and 1999

\begin{tabular}{l|c|c}
\hline One Program & $\mathrm{JC}^{a}$ & $\mathrm{TR}^{b}$ \\
\hline At least once & 689 & 1021 \\
As first program & 484 & 889 \\
\hline
\end{tabular}

\begin{tabular}{l|c|c|c}
\hline Program Sequences $^{c}$ & JC-JC & JC-TR & JC alone \\
\hline First and Second & 105 & 113 & 266 \\
\hline Program Sequences & TR-JC & TR-TR & training alone \\
First and Second & 176 & 150 & 563 \\
\hline
\end{tabular}

a: Training b: Job Creation Scheme

c: For instance, TR-JC indicates that a first participation in training and a second treatment in JC occurred

Table 2: Propensity Score Estimations

\begin{tabular}{|c|c|c|c|}
\hline \multirow[b]{2}{*}{ Variable } & FTR & TR-TR & TR-JC \\
\hline & Coef. (s.e.) & Coef. (s.e.) & Coef. (s.e.) \\
\hline Constant & $-1.036(0.161)$ & $-2.084 \quad(0.140)$ & $-1.625(0.211)$ \\
\hline \multicolumn{4}{|c|}{ Age in 1990: Age $25-34$ is omitted category } \\
\hline Age $35-44$ & $-0.094(0.047)$ & $-0.078(0.081)$ & $0.140 \quad(0.084)$ \\
\hline Age $45-50$ & $-0.311(0.058)$ & $-0.342(0.109)$ & $0.224(0.094)$ \\
\hline \multicolumn{4}{|c|}{ Labor Market Region: Dessau is missing category } \\
\hline Halberstadt & $-0.109(0.090)$ & $-0.253(0.164)$ & $-0.026(0.144)$ \\
\hline Halle & $-0.163(0.077)$ & $-0.126(0.128)$ & $-0.423(0.137)$ \\
\hline Magdeburg & $-0.126(0.073)$ & $-0.121(0.121)$ & $-0.140(0.117)$ \\
\hline Merseburg & $-0.110(0.082)$ & $-0.156(0.140)$ & $-0.176(0.136)$ \\
\hline Sangerhausen & $0.009(0.087)$ & $-0.093(0.149)$ & $0.154(0.132)$ \\
\hline Stendal & $-0.214(0.097)$ & $-0.414(0.190)$ & $-0.181(0.159)$ \\
\hline Wittenberg & $-0.146(0.111)$ & $-0.183(0.193)$ & $0.036 \quad(0.166)$ \\
\hline
\end{tabular}

Professional education (all): Unskilled, semi-skilled or other skills are missing category

\begin{tabular}{l|cc|cc|cc}
\hline Skilled Worker & 0.097 & $(0.156)$ & - & $(-)$ & -0.645 & $(0.211)$ \\
Craftsman & -0.020 & $(0.176)$ & -0.182 & $(0.269)$ & -0.915 & $(0.312)$ \\
Technical college & 0.271 & $(0.173)$ & 0.129 & $(0.221)$ & -0.391 & $(0.244)$ \\
University education & 0.204 & $(0.159)$ & 0.288 & $(0.144)$ & -0.295 & $(0.204)$ \\
\hline Professional education (women) & \multicolumn{5}{|l}{ (women } \\
\hline Skilled worker & $0.500(0.063)$ & 0.762 & $(0.119)$ & 0.747 & $(0.122)$ \\
Craftsman & 0.819 & $(0.182)$ & 0.630 & $(0.397)$ & 1.295 & $(0.322)$ \\
Technical college & 0.035 & $(0.104)$ & 0.456 & $(0.214)$ & 0.074 & $(0.190)$ \\
University education & 0.137 & $(0.082)$ & 0.191 & $(0.143)$ & 0.296 & $(0.127)$ \\
\hline
\end{tabular}


Table 3: Balancing Properties of Matching for Participation in FTR, Evaluation Starts at the Beginning of the Program

\begin{tabular}{|c|c|c|c|c|c|c|c|}
\hline \multirow[b]{2}{*}{ Variable } & \multicolumn{7}{|c|}{ Means of Variable in Subgroups } \\
\hline & All & $\begin{array}{r}\text { Nonpar- } \\
\text { ticipants } \\
\text { avera } \\
\text { iously }\end{array}$ & $\begin{array}{l}\text { Parti- } \\
\text { cipants } \\
\text { ped ove } \\
\text { nonem }\end{array}$ & $\begin{array}{l}\text { Matched } \\
\text { Nonpart. } \\
\text { prev- } \\
\text { loyed }\end{array}$ & $\begin{array}{r}\text { Nonpar- } \\
\text { ticipants } \\
\text { avera } \\
\text { ious }\end{array}$ & $\begin{array}{l}\text { Parti- } \\
\text { cipants } \\
\text { ced over } \\
\text { ly emplc }\end{array}$ & $\begin{array}{l}\text { Matched } \\
\text { Nonpart. } \\
\text { prev- } \\
\text { yyed }\end{array}$ \\
\hline Age $25-34$ & 0.37 & 0.27 & 0.40 & 0.36 & 0.37 & 0.45 & 0.43 \\
\hline Age $35-44$ & 0.40 & 0.36 & 0.41 & 0.39 & 0.40 & 0.41 & 0.41 \\
\hline Age 45-50 & 0.23 & 0.37 & 0.19 & 0.26 & 0.23 & 0.14 & 0.16 \\
\hline Dessau & 0.12 & 0.12 & 0.14 & 0.15 & 0.11 & 0.14 & 0.14 \\
\hline Halberstadt & 0.09 & 0.07 & 0.10 & 0.06 & 0.10 & 0.08 & 0.09 \\
\hline Halle & 0.19 & 0.17 & 0.17 & 0.15 & 0.19 & 0.16 & 0.18 \\
\hline Magdeburg & 0.24 & 0.23 & 0.23 & 0.21 & 0.24 & 0.25 & 0.24 \\
\hline Merseburg & 0.13 & 0.16 & 0.13 & 0.17 & 0.13 & 0.14 & 0.13 \\
\hline Sangerhausen & 0.10 & 0.11 & 0.12 & 0.15 & 0.09 & 0.12 & 0.11 \\
\hline Stendal & 0.08 & 0.09 & 0.07 & 0.08 & 0.08 & 0.07 & 0.07 \\
\hline Wittenberg & 0.05 & 0.06 & 0.05 & 0.05 & 0.05 & 0.05 & 0.05 \\
\hline Unskilled, semi- or other skilled & 0.02 & 0.09 & 0.02 & 0.05 & 0.02 & 0.01 & 0.01 \\
\hline Skilled worker & 0.43 & 0.50 & 0.50 & 0.57 & 0.41 & 0.46 & 0.46 \\
\hline Craftsman & 0.08 & 0.08 & 0.06 & 0.06 & 0.08 & 0.06 & 0.06 \\
\hline Technical college & 0.19 & 0.16 & 0.19 & 0.16 & 0.20 & 0.20 & 0.20 \\
\hline University education & 0.27 & 0.18 & 0.24 & 0.16 & 0.29 & 0.27 & 0.27 \\
\hline Female & 0.48 & 0.54 & 0.64 & 0.65 & 0.45 & 0.55 & 0.58 \\
\hline Female unskilled worker & 0.01 & 0.05 & 0.01 & 0.03 & 0.01 & 0.00 & 0.01 \\
\hline Female skilled worker & 0.21 & 0.30 & 0.34 & 0.42 & 0.17 & 0.27 & 0.29 \\
\hline Craftswoman & 0.01 & 0.01 & 0.03 & 0.03 & 0.01 & 0.02 & 0.02 \\
\hline Female and technical college & 0.13 & 0.10 & 0.14 & 0.10 & 0.14 & 0.14 & 0.14 \\
\hline Female and university education & 0.11 & 0.08 & 0.12 & 0.08 & 0.12 & 0.12 & 0.13 \\
\hline
\end{tabular}


Table 4: Balancing Properties of Matching for Participation in TR-TR (Combined Effect), Evaluation Starts at the Beginning of the Program

\begin{tabular}{|c|c|c|c|c|c|c|c|}
\hline \multirow[b]{2}{*}{ Variable } & \multicolumn{7}{|c|}{ Means of Variable in Subgroups } \\
\hline & All & $\begin{array}{c}\text { Nonpar- } \\
\text { ticipants } \\
\text { averag } \\
\text { iously }\end{array}$ & $\begin{array}{l}\text { Parti-- } \\
\text { cipants } \\
\text { ed over } \\
\text { nonem }\end{array}$ & $\begin{array}{l}\text { Matched } \\
\text { Nonpart. } \\
\text { prev- } \\
\text { loyed }\end{array}$ & $\mid \begin{array}{r}\text { Nonpar- } \\
\text { ticipants }\end{array}$ & $\begin{array}{l}\text { Parti- } \\
\text { cipants } \\
\text { ced over } \\
\text { ly empl }\end{array}$ & $\begin{array}{l}\text { Matched } \\
\text { Nonpart. } \\
\text { prev- } \\
\text { yed }\end{array}$ \\
\hline Age 25-34 & 0.37 & 0.32 & 0.43 & 0.41 & 0.38 & 0.45 & 0.44 \\
\hline Age $35-44$ & 0.40 & 0.38 & 0.43 & 0.41 & 0.40 & 0.43 & 0.42 \\
\hline Age $45-50$ & 0.23 & 0.30 & 0.14 & 0.18 & 0.23 & 0.12 & 0.15 \\
\hline Dessau & 0.12 & 0.13 & 0.17 & 0.16 & 0.11 & 0.14 & 0.15 \\
\hline Halberstadt & 0.09 & 0.08 & 0.08 & 0.06 & 0.10 & 0.06 & 0.07 \\
\hline Halle & 0.19 & 0.16 & 0.19 & 0.16 & 0.19 & 0.17 & 0.20 \\
\hline Magdeburg & 0.24 & 0.23 & 0.25 & 0.22 & 0.24 & 0.28 & 0.25 \\
\hline Merseburg & 0.13 & 0.15 & 0.11 & 0.17 & 0.13 & 0.15 & 0.13 \\
\hline Sangerhausen & 0.10 & 0.11 & 0.10 & 0.13 & 0.09 & 0.13 & 0.10 \\
\hline Stendal & 0.08 & 0.08 & 0.05 & 0.05 & 0.08 & 0.03 & 0.05 \\
\hline Wittenberg & 0.05 & 0.06 & 0.05 & 0.05 & 0.05 & 0.04 & 0.05 \\
\hline Unskilled, semi- or other skilled & 0.02 & 0.06 & 0.00 & 0.03 & 0.02 & 0.00 & 0.01 \\
\hline Skilled worker & 0.43 & 0.50 & 0.53 & 0.62 & 0.41 & 0.52 & 0.53 \\
\hline Craftsman & 0.08 & 0.07 & 0.02 & 0.04 & 0.08 & 0.04 & 0.04 \\
\hline Technical college & 0.19 & 0.17 & 0.21 & 0.16 & 0.20 & 0.22 & 0.21 \\
\hline University education & 0.27 & 0.20 & 0.24 & 0.16 & 0.29 & 0.22 & 0.22 \\
\hline Female & 0.48 & 0.57 & 0.79 & 0.79 & 0.46 & 0.68 & 0.67 \\
\hline Female unskilled worker & 0.01 & 0.04 & 0.00 & 0.02 & 0.01 & 0.00 & 0.01 \\
\hline Female skilled worker & 0.21 & 0.31 & 0.46 & 0.56 & 0.18 & 0.36 & 0.40 \\
\hline Craftswomen & 0.01 & 0.02 & 0.01 & 0.02 & 0.01 & 0.02 & 0.01 \\
\hline Female and technical college & 0.13 & 0.11 & 0.19 & 0.13 & 0.14 & 0.17 & 0.17 \\
\hline Female and university education & 0.11 & 0.09 & 0.12 & 0.10 & 0.12 & 0.13 & 0.11 \\
\hline
\end{tabular}


Table 5: Coefficient estimates for CDiD

\begin{tabular}{|c|c|c|}
\hline Parameter & Coef. & $\begin{array}{l}\text { FTR } \\
\text { bootstrap - s.e. }\end{array}$ \\
\hline \multicolumn{3}{|c|}{ Long-run preprogram difference } \\
\hline Const & 0.109538 & $(0.031724)$ \\
\hline$\tau$ & -0.010506 & ( $1.62 \mathrm{E}-03)$ \\
\hline$\tau^{2}$ & $7.93 \mathrm{E}-05$ & $(1.43 \mathrm{E}-05)$ \\
\hline \multicolumn{3}{|c|}{ Outcome-equation } \\
\hline$I(t 1=-6)$ & 0.015666 & $(0.051966)$ \\
\hline$I(t 1=-5)$ & -0.053436 & $(0.051006)$ \\
\hline$I(t 1=-4)$ & -0.098527 & $(0.049093)$ \\
\hline$I(t 1=-3)$ & -0.147712 & $(0.047869)$ \\
\hline$I(t 1=-2)$ & -0.18752 & $(0.046773)$ \\
\hline$I(t 1=-1)$ & -0.250343 & $(0.047172)$ \\
\hline$I(t 1=1)$ & -0.331277 & $(0.072718)$ \\
\hline$I(t 1=2)$ & -0.310247 & $(0.073391)$ \\
\hline$I(t 1=3)$ & -0.293056 & $(0.072545)$ \\
\hline$I(t 1=4)$ & -0.287756 & $(0.07347)$ \\
\hline$I(t 1=5)$ & -0.27302 & $(0.073619)$ \\
\hline$I(t 1=6)$ & -0.265125 & $(0.073884)$ \\
\hline$I(t 1=7)$ & -0.254978 & $(0.074463)$ \\
\hline$I(t 1=8)$ & -0.24921 & $(0.074907)$ \\
\hline$I(t 1=9)$ & -0.236731 & $(0.074903)$ \\
\hline$I(t 1=10)$ & -0.222417 & $(0.074433)$ \\
\hline$I(t 1=11)$ & -0.210578 & $(0.074053)$ \\
\hline$I(t 1=12)$ & -0.196867 & $(0.074775)$ \\
\hline$I(t 1=13)$ & -0.181907 & $(0.074531)$ \\
\hline$I(t 1=14)$ & -0.178723 & $(0.07364)$ \\
\hline$I(t 1=15)$ & -0.167247 & $(0.074247)$ \\
\hline$I(t 1=16)$ & -0.162639 & $(0.073198)$ \\
\hline$I(t 1=17)$ & -0.157038 & $(0.073196)$ \\
\hline$I(t 1=18)$ & -0.150819 & $(0.072676)$ \\
\hline$I(t 1=19)$ & -0.144263 & $(0.073454)$ \\
\hline$I(t 1=20)$ & -0.146938 & $(0.073612)$ \\
\hline$I(t 1=21)$ & -0.148433 & $(0.074218)$ \\
\hline$I(t 1=22)$ & -0.136203 & $(0.073933)$ \\
\hline$I(t 1=23)$ & -0.139326 & $(0.074613)$ \\
\hline$I(t 1=24)$ & -0.149236 & $(0.074444)$ \\
\hline$I(t 1=25)$ & -0.154556 & $(0.072969)$ \\
\hline$I(t 1=26)$ & -0.146676 & $(0.073267)$ \\
\hline$I(t 1=27)$ & -0.145388 & $(0.073807)$ \\
\hline$I(t 1=28)$ & -0.132021 & $(0.0731)$ \\
\hline$I(t 1=29)$ & -0.137155 & $(0.073106)$ \\
\hline$I(t 1=30)$ & -0.133065 & $(0.073812)$ \\
\hline$I(t 1=31)$ & -0.131043 & $(0.073167)$ \\
\hline$I(t 1=32)$ & -0.132572 & $(0.072657)$ \\
\hline$I(t 1=33)$ & -0.125412 & $(0.072885)$ \\
\hline$I(t 1=34)$ & -0.122935 & $(0.073045)$ \\
\hline
\end{tabular}


Table 5: Coefficient estimates $<$ continued $>$

\begin{tabular}{l|cc}
\hline Parameter & Coef. & $\begin{array}{l}\text { FTR } \\
\text { bootstrap }- \text { s.e. }\end{array}$ \\
\hline$I(t 1=35)$ & -0.117068 & $(0.074169)$ \\
$I(t 1=36)$ & -0.113323 & $(0.073629)$ \\
$A D: \tau$ & $-4.41 \mathrm{E}-03$ & $(2.01 \mathrm{E}-03)$ \\
$A D: \tau^{2}$ & $1.53 \mathrm{E}-05$ & $(1.72 \mathrm{E}-05)$ \\
$P O: \tau$ & $-2.89 \mathrm{E}-03$ & $(3.63 \mathrm{E}-03)$ \\
$P O: \tau^{2}$ & $3.63 \mathrm{E}-05$ & $(3.49 \mathrm{E}-05)$ \\
\hline AD: Ashenfelter's Dip $\equiv I(a d(\tau) \leq \tau<0)$ \\
PO: After end of program $\equiv I(\tau>0)$ \\
comb.: combined effect of first and second program \\
incr.: incremental effect of second program
\end{tabular}


Table 6: Coefficient estimates for CDiDHR - FTR - Nonemployment in Previous Month

\begin{tabular}{|c|c|c|c|c|}
\hline \multirow{2}{*}{$\begin{array}{l}\text { Start of Evaluation: } \\
\text { Variable }\end{array}$} & \multicolumn{2}{|c|}{$\begin{array}{l}\text { One Month after } \\
\text { Start Month }\end{array}$} & \multicolumn{2}{|c|}{$\begin{array}{l}\text { One Month after } \\
\text { End }\end{array}$} \\
\hline & Coef. & (s.e.) & Coef. & (s.e.) \\
\hline \multicolumn{5}{|c|}{ Long-run preprogram difference } \\
\hline Const & -0.065 & $(0.023)$ & -0.065 & $(0.023)$ \\
\hline$t$ & $5.45 \mathrm{E}-04$ & ( 8.11E-04 ) & $5.45 \mathrm{E}-04$ & ( 8.11E-04) \\
\hline$t^{2}$ & $1.93 \mathrm{E}-06$ & ( $6.61 \mathrm{E}-06)$ & $1.93 \mathrm{E}-06$ & $(6.61 \mathrm{E}-06)$ \\
\hline \multicolumn{5}{|l|}{ Outcome-Equation } \\
\hline $\bar{I}(t 1=-6)$ & -0.027 & $(0.049)$ & -0.035 & $(0.050)$ \\
\hline$I(t 1=-5)$ & -0.034 & $(0.050)$ & -0.041 & $(0.050)$ \\
\hline$I(t 1=-4)$ & -0.033 & $(0.049)$ & -0.042 & $(0.049)$ \\
\hline$I(t 1=-3)$ & -0.039 & $(0.048)$ & -0.048 & $(0.049)$ \\
\hline$I(t 1=-2)$ & -0.040 & $(0.048)$ & -0.049 & $(0.048)$ \\
\hline$I(t 1=-1)$ & -0.043 & $(0.048)$ & -0.052 & $(0.048)$ \\
\hline$I(t 1=1)$ & 0.029 & $(0.037)$ & 0.314 & $(0.050)$ \\
\hline$I(t 1=2)$ & 0.023 & $(0.037)$ & 0.090 & $(0.046)$ \\
\hline$I(t 1=3)$ & 0.023 & $(0.036)$ & 0.097 & $(0.047)$ \\
\hline$I(t 1=4)$ & 0.034 & $(0.038)$ & 0.091 & $(0.046)$ \\
\hline$I(t 1=5)$ & 0.030 & $(0.037)$ & 0.099 & ( 0.047$)$ \\
\hline$I(t 1=6)$ & 0.041 & $(0.036)$ & 0.110 & $(0.046)$ \\
\hline$I(t 1=7)$ & 0.055 & $(0.038)$ & 0.099 & $(0.046)$ \\
\hline$I(t 1=8)$ & 0.042 & $(0.037)$ & 0.114 & $(0.049)$ \\
\hline$I(t 1=9)$ & 0.037 & $(0.038)$ & 0.120 & $(0.048)$ \\
\hline$I(t 1=10)$ & 0.054 & $(0.037)$ & 0.092 & $(0.047)$ \\
\hline$I(t 1=11)$ & 0.040 & $(0.037)$ & 0.101 & $(0.047)$ \\
\hline$I(t 1=12)$ & 0.053 & $(0.038)$ & 0.107 & $(0.048)$ \\
\hline$I(t 1=13)$ & 0.063 & $(0.039)$ & 0.125 & $(0.048)$ \\
\hline$I(t 1=14)$ & 0.063 & $(0.038)$ & 0.091 & $(0.048)$ \\
\hline$I(t 1=15)$ & 0.058 & $(0.038)$ & 0.109 & $(0.045)$ \\
\hline$I(t 1=16)$ & 0.046 & $(0.038)$ & 0.105 & $(0.047)$ \\
\hline$I(t 1=17)$ & 0.070 & $(0.039)$ & 0.117 & $(0.049)$ \\
\hline$I(t 1=18)$ & 0.050 & $(0.038)$ & 0.094 & $(0.047)$ \\
\hline$I(t 1=19)$ & 0.064 & $(0.039)$ & 0.102 & $(0.045)$ \\
\hline$I(t 1=20)$ & 0.048 & $(0.038)$ & 0.097 & $(0.046)$ \\
\hline$I(t 1=21)$ & 0.049 & $(0.039)$ & 0.089 & $(0.047)$ \\
\hline$I(t 1=22)$ & 0.060 & $(0.039)$ & 0.103 & $(0.047)$ \\
\hline$I(t 1=23)$ & 0.046 & $(0.037)$ & 0.092 & $(0.047)$ \\
\hline$I(t 1=24)$ & 0.059 & $(0.038)$ & 0.092 & $(0.046)$ \\
\hline$I(t 1=25)$ & 0.059 & $(0.037)$ & 0.098 & $(0.046)$ \\
\hline$I(t 1=26)$ & 0.071 & $(0.039)$ & 0.115 & $(0.048)$ \\
\hline$I(t 1=27)$ & 0.048 & $(0.038)$ & 0.101 & $(0.045)$ \\
\hline$I(t 1=28)$ & 0.059 & $(0.038)$ & 0.113 & $(0.048)$ \\
\hline$I(t 1=29)$ & 0.054 & $(0.039)$ & 0.098 & $(0.045)$ \\
\hline$I(t 1=30)$ & 0.087 & $(0.040)$ & 0.098 & $(0.048)$ \\
\hline
\end{tabular}


Table 6: Coefficient estimates $<$ continued $>$

\begin{tabular}{|c|c|c|c|c|}
\hline \multirow{2}{*}{$\begin{array}{l}\text { Start of Evaluation: } \\
\text { Variable }\end{array}$} & \multicolumn{2}{|c|}{$\begin{array}{l}\text { One Month after } \\
\text { Start Month }\end{array}$} & \multicolumn{2}{|c|}{$\begin{array}{l}\text { One Month after } \\
\text { End }\end{array}$} \\
\hline & Coef. & (s.e.) & Coef. & (s.e.) \\
\hline$I(t 1=31)$ & 0.046 & $(0.037)$ & 0.097 & $(0.045)$ \\
\hline$I(t 1=32)$ & 0.068 & $(0.040)$ & 0.095 & $(0.045)$ \\
\hline$I(t 1=33)$ & 0.076 & $(0.038)$ & 0.115 & $(0.046)$ \\
\hline$I(t 1=34)$ & 0.045 & $(0.037)$ & 0.099 & $(0.045)$ \\
\hline$I(t 1=35)$ & 0.065 & $(0.041)$ & 0.107 & $(0.048)$ \\
\hline$I(t 1=36)$ & 0.077 & $(0.039)$ & 0.098 & $(0.046)$ \\
\hline $\mathrm{AD}: \tau$ & $1.83 \mathrm{E}-03$ & ( $1.98 \mathrm{E}-03)$ & $2.21 \mathrm{E}-03$ & $(1.98 \mathrm{E}-03)$ \\
\hline $\mathrm{AD}: \tau^{2}$ & $-2.08 \mathrm{E}-05$ & ( $1.76 \mathrm{E}-05)$ & $-2.40 \mathrm{E}-05$ & $(1.76 \mathrm{E}-05)$ \\
\hline $\mathrm{PO}: \tau$ & $-1.19 \mathrm{E}-03$ & ( $1.31 \mathrm{E}-03)$ & $-2.57 \mathrm{E}-03$ & $(1.65 \mathrm{E}-03)$ \\
\hline $\mathrm{PO}: \tau^{2}$ & $5.28 \mathrm{E}-06$ & $(1.05 \mathrm{E}-05)$ & $1.61 \mathrm{E}-05$ & $(1.35 \mathrm{E}-05)$ \\
\hline \multicolumn{5}{|c|}{ Variables as deviation from their mean value over all treated: } \\
\hline Age $35-44$ & $6.54 \mathrm{E}-03$ & $(1.65 \mathrm{E}-02)$ & $-7.19 \mathrm{E}-03$ & $(1.69 \mathrm{E}-02)$ \\
\hline Age $45-50$ & $-1.40 \mathrm{E}-02$ & $(1.62 \mathrm{E}-02)$ & $-2.81 \mathrm{E}-02$ & $(1.81 \mathrm{E}-02)$ \\
\hline Halberstadt & $5.19 \mathrm{E}-04$ & $(1.74 \mathrm{E}-02)$ & $-1.90 \mathrm{E}-02$ & $(1.90 \mathrm{E}-02)$ \\
\hline Halle & $-2.33 \mathrm{E}-02$ & $(2.48 \mathrm{E}-02)$ & $-3.49 \mathrm{E}-02$ & $(3.17 \mathrm{E}-02)$ \\
\hline Magdeburg & $5.95 \mathrm{E}-03$ & $(1.53 \mathrm{E}-02)$ & $-4.47 \mathrm{E}-03$ & $(1.70 \mathrm{E}-02)$ \\
\hline Merseburg & $-5.56 \mathrm{E}-03$ & ( $1.82 \mathrm{E}-02)$ & $-2.23 \mathrm{E}-03$ & $(1.98 \mathrm{E}-02)$ \\
\hline Sangerhausen & $1.42 \mathrm{E}-02$ & ( $1.72 \mathrm{E}-02)$ & 2.92E-03 & $(1.96 \mathrm{E}-02)$ \\
\hline Stendal & $-2.51 \mathrm{E}-02$ & $(2.95 \mathrm{E}-02)$ & $-4.48 \mathrm{E}-03$ & $(1.98 \mathrm{E}-02)$ \\
\hline Wittenberg & $-8.81 \mathrm{E}-02$ & $(7.32 \mathrm{E}-02)$ & $-1.15 \mathrm{E}-01$ & $(8.92 \mathrm{E}-02)$ \\
\hline Skilled Worker & $-2.78 \mathrm{E}-02$ & ( $3.32 \mathrm{E}-02)$ & $2.46 \mathrm{E}-02$ & $(2.79 \mathrm{E}-02)$ \\
\hline Craftsman & $5.39 \mathrm{E}-05$ & $(2.38 \mathrm{E}-02)$ & $3.03 \mathrm{E}-02$ & $(3.50 \mathrm{E}-02)$ \\
\hline Technical college & $-2.69 \mathrm{E}-02$ & ( $3.04 \mathrm{E}-02)$ & $1.11 \mathrm{E}-02$ & $(4.19 \mathrm{E}-02)$ \\
\hline University education & $-3.35 \mathrm{E}-02$ & ( $3.40 \mathrm{E}-02)$ & $-1.89 \mathrm{E}-02$ & $(4.15 \mathrm{E}-02)$ \\
\hline Female skilled worker & $1.86 \mathrm{E}-02$ & $(2.60 \mathrm{E}-02)$ & $-2.01 \mathrm{E}-02$ & $(2.09 \mathrm{E}-02)$ \\
\hline Craftswoman & $2.37 \mathrm{E}-02$ & ( $4.28 \mathrm{E}-02)$ & $1.74 \mathrm{E}-02$ & $(4.94 \mathrm{E}-02)$ \\
\hline Female and technical college & $2.12 \mathrm{E}-02$ & $(2.88 \mathrm{E}-02)$ & $-5.28 \mathrm{E}-03$ & $(3.83 \mathrm{E}-02)$ \\
\hline Female and university education & $2.70 \mathrm{E}-02$ & ( $3.25 \mathrm{E}-02)$ & $3.04 \mathrm{E}-02$ & $(4.04 \mathrm{E}-02)$ \\
\hline
\end{tabular}


Table 7: Coefficient estimates for CDiDHR - FTR - Employment in Previous Month

\begin{tabular}{|c|c|c|c|c|}
\hline \multirow{2}{*}{$\begin{array}{l}\text { Start of Evaluation: } \\
\text { Variable }\end{array}$} & \multicolumn{2}{|c|}{$\begin{array}{l}\text { Two Month after } \\
\text { Start Month }\end{array}$} & \multicolumn{2}{|c|}{$\begin{array}{l}\text { Two Month after } \\
\text { End }\end{array}$} \\
\hline & Coef. & (s.e.) & Coef. & (s.e.) \\
\hline \multicolumn{5}{|c|}{ Long-run preprogram difference } \\
\hline Const & 0.005 & $(0.006)$ & 0.005 & $(0.006)$ \\
\hline$t$ & $-1.22 \mathrm{E}-03$ & ( $2.69 \mathrm{E}-04)$ & $-1.22 \mathrm{E}-03$ & ( $2.69 \mathrm{E}-04)$ \\
\hline$t^{2}$ & 7.33E-06 & $(2.48 \mathrm{E}-06)$ & 7.33E-06 & $(2.48 \mathrm{E}-06)$ \\
\hline \multicolumn{5}{|l|}{ Outcome-Equation } \\
\hline$I(t 1=-6)$ & -0.011 & $(0.050)$ & -0.008 & $(0.051)$ \\
\hline$I(t 1=-5)$ & -0.080 & $(0.048)$ & -0.078 & $(0.048)$ \\
\hline$I(t 1=-4)$ & -0.068 & $(0.043)$ & -0.068 & $(0.044)$ \\
\hline$I(t 1=-3)$ & -0.099 & $(0.039)$ & -0.100 & $(0.040)$ \\
\hline$I(t 1=-2)$ & -0.096 & $(0.033)$ & -0.097 & $(0.033)$ \\
\hline$I(t 1=-1)$ & -0.141 & $(0.038)$ & -0.151 & $(0.038)$ \\
\hline$I(t 1=1)$ & -0.016 & $(0.024)$ & -0.007 & $(0.016)$ \\
\hline$I(t 1=2)$ & -0.016 & $(0.025)$ & -0.008 & $(0.016)$ \\
\hline$I(t 1=3)$ & -0.060 & $(0.043)$ & -0.035 & $(0.018)$ \\
\hline$I(t 1=4)$ & -0.014 & $(0.020)$ & -0.013 & $(0.016)$ \\
\hline$I(t 1=5)$ & 0.001 & $(0.025)$ & -0.011 & $(0.015)$ \\
\hline$I(t 1=6)$ & -0.007 & $(0.022)$ & -0.028 & $(0.017)$ \\
\hline$I(t 1=7)$ & -0.010 & $(0.025)$ & -0.032 & $(0.016)$ \\
\hline$I(t 1=8)$ & -0.008 & $(0.024)$ & -0.019 & $(0.016)$ \\
\hline$I(t 1=9)$ & -0.007 & $(0.022)$ & -0.012 & $(0.015)$ \\
\hline$I(t 1=10)$ & -0.010 & $(0.021)$ & -0.009 & $(0.014)$ \\
\hline$I(t 1=11)$ & -0.027 & $(0.022)$ & -0.009 & $(0.015)$ \\
\hline$I(t 1=12)$ & -0.020 & $(0.020)$ & -0.022 & $(0.016)$ \\
\hline$I(t 1=13)$ & -0.041 & $(0.023)$ & -0.013 & $(0.016)$ \\
\hline$I(t 1=14)$ & -0.004 & $(0.019)$ & -0.009 & $(0.015)$ \\
\hline$I(t 1=15)$ & -0.031 & $(0.023)$ & -0.022 & $(0.017)$ \\
\hline$I(t 1=16)$ & -0.009 & $(0.016)$ & -0.014 & $(0.016)$ \\
\hline$I(t 1=17)$ & -0.012 & $(0.018)$ & -0.004 & $(0.015)$ \\
\hline$I(t 1=18)$ & -0.030 & $(0.019)$ & -0.009 & $(0.015)$ \\
\hline$I(t 1=19)$ & -0.022 & $(0.018)$ & -0.017 & $(0.015)$ \\
\hline$I(t 1=20)$ & -0.017 & $(0.018)$ & -0.021 & $(0.016)$ \\
\hline$I(t 1=21)$ & -0.018 & $(0.017)$ & -0.007 & $(0.015)$ \\
\hline$I(t 1=22)$ & 0.000 & $(0.017)$ & -0.015 & $(0.016)$ \\
\hline$I(t 1=23)$ & -0.015 & $(0.018)$ & -0.033 & $(0.017)$ \\
\hline$I(t 1=24)$ & -0.020 & $(0.018)$ & -0.031 & $(0.017)$ \\
\hline$I(t 1=25)$ & -0.010 & $(0.017)$ & -0.017 & $(0.016)$ \\
\hline$I(t 1=26)$ & -0.005 & $(0.017)$ & -0.011 & $(0.016)$ \\
\hline$I(t 1=27)$ & -0.028 & $(0.020)$ & -0.016 & $(0.016)$ \\
\hline$I(t 1=28)$ & -0.005 & $(0.018)$ & -0.013 & $(0.016)$ \\
\hline$I(t 1=29)$ & -0.011 & $(0.018)$ & -0.013 & $(0.016)$ \\
\hline$I(t 1=30)$ & -0.024 & $(0.018)$ & -0.019 & $(0.016)$ \\
\hline
\end{tabular}


Table 7: Coefficient estimates $<$ continued $>$

\begin{tabular}{|c|c|c|c|c|}
\hline \multirow{2}{*}{$\begin{array}{l}\text { Start of Evaluation: } \\
\text { Variable }\end{array}$} & \multicolumn{2}{|c|}{$\begin{array}{l}\text { Two Month after } \\
\text { Start Month }\end{array}$} & \multicolumn{2}{|c|}{$\begin{array}{l}\text { Two Month after } \\
\text { End }\end{array}$} \\
\hline & Coef. & (s.e.) & Coef. & (s.e.) \\
\hline$I(t 1=31)$ & 0.001 & $(0.017)$ & -0.016 & $(0.016)$ \\
\hline$I(t 1=32)$ & -0.010 & $(0.018)$ & -0.007 & $(0.016)$ \\
\hline$I(t 1=33)$ & -0.010 & $(0.018)$ & -0.011 & $(0.016)$ \\
\hline$I(t 1=34)$ & -0.020 & $(0.019)$ & -0.008 & $(0.015)$ \\
\hline$I(t 1=35)$ & -0.028 & $(0.021)$ & -0.011 & $(0.016)$ \\
\hline$I(t 1=36)$ & -0.010 & $(0.019)$ & -0.014 & $(0.016)$ \\
\hline $\mathrm{AD}: \tau$ & $1.27 \mathrm{E}-04$ & ( $1.66 \mathrm{E}-03)$ & 2.62E-04 & $(1.67 \mathrm{E}-03)$ \\
\hline $\mathrm{AD}: \tau^{2}$ & $-8.62 \mathrm{E}-06$ & $(1.38 \mathrm{E}-05)$ & $-1.06 \mathrm{E}-05$ & $(1.38 \mathrm{E}-05)$ \\
\hline $\mathrm{PO}: \tau$ & $1.67 \mathrm{E}-03$ & ( $1.00 \mathrm{E}-03)$ & $1.95 \mathrm{E}-03$ & $(8.69 \mathrm{E}-04)$ \\
\hline $\mathrm{PO}: \tau^{2}$ & $-8.36 \mathrm{E}-06$ & $(9.53 \mathrm{E}-06)$ & $-1.15 \mathrm{E}-05$ & ( 8.49E-06) \\
\hline \multicolumn{5}{|c|}{ Variables as deviation from their mean value over all treated: } \\
\hline Age $35-44$ & $-3.48 \mathrm{E}-03$ & $(9.25 \mathrm{E}-03)$ & $-6.46 \mathrm{E}-03$ & $(8.75 \mathrm{E}-03)$ \\
\hline Age $45-50$ & $2.68 \mathrm{E}-02$ & $(2.66 \mathrm{E}-02)$ & $2.41 \mathrm{E}-02$ & $(2.21 \mathrm{E}-02)$ \\
\hline Halberstadt & $2.14 \mathrm{E}-02$ & ( $1.99 \mathrm{E}-02)$ & $1.81 \mathrm{E}-02$ & $(1.79 \mathrm{E}-02)$ \\
\hline Halle & $2.78 \mathrm{E}-02$ & $(2.55 \mathrm{E}-02)$ & $2.27 \mathrm{E}-02$ & $(2.05 \mathrm{E}-02)$ \\
\hline Magdeburg & $1.29 \mathrm{E}-02$ & $(1.48 \mathrm{E}-02)$ & $1.05 \mathrm{E}-02$ & $(1.22 \mathrm{E}-02)$ \\
\hline Merseburg & $2.01 \mathrm{E}-02$ & ( $1.54 \mathrm{E}-02)$ & $3.12 \mathrm{E}-02$ & $(1.44 \mathrm{E}-02)$ \\
\hline Sangerhausen & $9.00 \mathrm{E}-03$ & ( $1.60 \mathrm{E}-02)$ & $5.61 \mathrm{E}-03$ & $(1.39 \mathrm{E}-02)$ \\
\hline Stendal & $1.61 \mathrm{E}-02$ & ( $1.73 \mathrm{E}-02)$ & $1.52 \mathrm{E}-02$ & $(1.81 \mathrm{E}-02)$ \\
\hline Wittenberg & 8.23E-03 & ( $1.97 \mathrm{E}-02)$ & $5.98 \mathrm{E}-03$ & $(1.68 \mathrm{E}-02)$ \\
\hline Skilled Worker & $-3.27 \mathrm{E}-02$ & ( $3.50 \mathrm{E}-02)$ & $-1.22 \mathrm{E}-02$ & $(3.92 \mathrm{E}-02)$ \\
\hline Craftsman & $-2.92 \mathrm{E}-02$ & ( $3.61 \mathrm{E}-02)$ & $-1.65 \mathrm{E}-02$ & $(3.95 \mathrm{E}-02)$ \\
\hline Technical college & $-3.31 \mathrm{E}-02$ & $(3.57 \mathrm{E}-02)$ & $-2.07 \mathrm{E}-03$ & $(4.08 \mathrm{E}-02)$ \\
\hline University education & $-3.84 \mathrm{E}-02$ & $(3.43 \mathrm{E}-02)$ & $-2.12 \mathrm{E}-02$ & $(3.89 \mathrm{E}-02)$ \\
\hline Female skilled worker & $4.50 \mathrm{E}-04$ & $(1.84 \mathrm{E}-02)$ & $-2.71 \mathrm{E}-04$ & $(1.55 \mathrm{E}-02)$ \\
\hline Craftswoman & $-2.15 \mathrm{E}-02$ & ( $3.59 \mathrm{E}-02)$ & $-2.87 \mathrm{E}-03$ & $(2.85 \mathrm{E}-02)$ \\
\hline Female and technical college & $-2.11 \mathrm{E}-03$ & ( $2.15 \mathrm{E}-02)$ & $-8.30 \mathrm{E}-03$ & $(2.28 \mathrm{E}-02)$ \\
\hline Female and university education & $2.12 \mathrm{E}-03$ & ( $1.64 \mathrm{E}-02)$ & 7.07E-03 & $(1.40 \mathrm{E}-02)$ \\
\hline
\end{tabular}


Table 8: Coefficient estimates for CDiDHR - TR-TR nonemployment in Previous Month

\begin{tabular}{|c|c|c|c|c|}
\hline \multirow{2}{*}{$\begin{array}{l}\text { Start of Evaluation: } \\
\text { Variable }\end{array}$} & \multicolumn{2}{|c|}{$\begin{array}{c}\text { Combined Effect } \\
\text { One Month after } \\
\text { Start Month of Sequence }\end{array}$} & \multicolumn{2}{|c|}{$\begin{array}{c}\text { Incremental Effect of Second TR } \\
\text { One Month after } \\
\text { Start Month of Second TR }\end{array}$} \\
\hline & Coef. & (s.e.) & Coef. & (s.e.) \\
\hline \multicolumn{5}{|c|}{ Long-run preprogram difference } \\
\hline Const & -0.066 & $(0.037)$ & -0.011 & $(0.029)$ \\
\hline$t$ & $1.62 \mathrm{E}-03$ & $(1.46 \mathrm{E}-03)$ & $-5.12 \mathrm{E}-04$ & $(7.82 \mathrm{E}-04)$ \\
\hline$t^{2}$ & $-1.28 \mathrm{E}-05$ & ( $1.31 \mathrm{E}-05)$ & $5.53 \mathrm{E}-06$ & $(5.35 \mathrm{E}-06)$ \\
\hline \multicolumn{5}{|l|}{ Outcome-Equation } \\
\hline $\bar{I}(t 1=-6)$ & 0.013 & (0.067) & -0.062 & (0.059) \\
\hline$I(t 1=-5)$ & 0.008 & $(0.066)$ & -0.052 & $(0.059)$ \\
\hline$I(t 1=-4)$ & 0.013 & $(0.066)$ & -0.043 & $(0.059)$ \\
\hline$I(t 1=-3)$ & 0.012 & $(0.065)$ & -0.059 & $(0.058)$ \\
\hline$I(t 1=-2)$ & 0.009 & $(0.065)$ & -0.060 & $(0.058)$ \\
\hline$I(t 1=-1)$ & -0.003 & $(0.068)$ & -0.069 & $(0.061)$ \\
\hline$I(t 1=1)$ & -0.017 & $(0.089)$ & -0.235 & $(0.204)$ \\
\hline$I(t 1=2)$ & -0.015 & $(0.088)$ & -0.232 & $(0.204)$ \\
\hline$I(t 1=3)$ & -0.017 & $(0.089)$ & -0.234 & $(0.206)$ \\
\hline$I(t 1=4)$ & -0.020 & $(0.089)$ & -0.211 & $(0.206)$ \\
\hline$I(t 1=5)$ & -0.014 & $(0.089)$ & -0.225 & $(0.207)$ \\
\hline$I(t 1=6)$ & -0.015 & $(0.089)$ & -0.244 & $(0.208)$ \\
\hline$I(t 1=7)$ & -0.019 & $(0.089)$ & -0.232 & $(0.208)$ \\
\hline$I(t 1=8)$ & 0.014 & $(0.090)$ & -0.232 & $(0.207)$ \\
\hline$I(t 1=9)$ & -0.013 & $(0.089)$ & -0.230 & $(0.207)$ \\
\hline$I(t 1=10)$ & 0.018 & $(0.093)$ & -0.230 & $(0.207)$ \\
\hline$I(t 1=11)$ & -0.015 & $(0.089)$ & -0.222 & $(0.208)$ \\
\hline$I(t 1=12)$ & -0.018 & $(0.089)$ & -0.215 & $(0.208)$ \\
\hline$I(t 1=13)$ & 0.002 & $(0.093)$ & -0.211 & $(0.208)$ \\
\hline$I(t 1=14)$ & -0.011 & $(0.090)$ & -0.229 & $(0.209)$ \\
\hline$I(t 1=15)$ & 0.019 & $(0.098)$ & -0.237 & $(0.209)$ \\
\hline$I(t 1=16)$ & 0.014 & $(0.096)$ & -0.208 & $(0.209)$ \\
\hline$I(t 1=17)$ & 0.021 & $(0.094)$ & -0.228 & $(0.209)$ \\
\hline$I(t 1=18)$ & -0.014 & $(0.091)$ & -0.216 & $(0.209)$ \\
\hline$I(t 1=19)$ & -0.013 & $(0.091)$ & -0.203 & $(0.208)$ \\
\hline$I(t 1=20)$ & -0.010 & $(0.090)$ & -0.214 & $(0.206)$ \\
\hline$I(t 1=21)$ & -0.009 & $(0.090)$ & -0.210 & $(0.207)$ \\
\hline$I(t 1=22)$ & -0.010 & $(0.090)$ & -0.237 & $(0.208)$ \\
\hline$I(t 1=23)$ & -0.010 & $(0.090)$ & -0.223 & $(0.208)$ \\
\hline$I(t 1=24)$ & 0.022 & $(0.090)$ & -0.195 & $(0.209)$ \\
\hline$I(t 1=25)$ & -0.012 & $(0.090)$ & -0.210 & $(0.211)$ \\
\hline$I(t 1=26)$ & 0.025 & $(0.099)$ & -0.237 & $(0.210)$ \\
\hline$I(t 1=27)$ & -0.012 & $(0.090)$ & -0.224 & $(0.211)$ \\
\hline$I(t 1=28)$ & 0.005 & $(0.092)$ & -0.224 & $(0.211)$ \\
\hline
\end{tabular}

$<$ continued on next page $>$ 
Table 8: Coefficient estimates $<$ continued $>$

\begin{tabular}{|c|c|c|c|c|}
\hline \multirow[b]{2}{*}{ Start of Evaluation: } & \multicolumn{2}{|c|}{ Combined Effect } & \multicolumn{2}{|c|}{ Incremental Effect of Second TR } \\
\hline & \multicolumn{2}{|c|}{$\begin{array}{c}\text { One Month after } \\
\text { Start Month of Sequence }\end{array}$} & \multicolumn{2}{|c|}{$\begin{array}{l}\text { One Month after } \\
\text { Start Month of Second TR }\end{array}$} \\
\hline Variable & Coef. & (s.e.) & Coef. & (s.e.) \\
\hline$I(t 1=29)$ & 0.026 & $(0.097)$ & -0.223 & $(0.212)$ \\
\hline$I(t 1=30)$ & 0.009 & $(0.092)$ & -0.237 & $(0.209)$ \\
\hline$I(t 1=31)$ & -0.010 & $(0.089)$ & -0.223 & $(0.210)$ \\
\hline$I(t 1=32)$ & -0.007 & $(0.089)$ & -0.206 & $(0.211)$ \\
\hline$I(t 1=33)$ & 0.012 & $(0.093)$ & -0.220 & $(0.210)$ \\
\hline$I(t 1=34)$ & -0.005 & $(0.089)$ & -0.221 & $(0.213)$ \\
\hline$I(t 1=35)$ & -0.008 & $(0.089)$ & -0.241 & $(0.211)$ \\
\hline$I(t 1=36)$ & -0.013 & $(0.089)$ & -0.223 & $(0.210)$ \\
\hline $\mathrm{AD}: \tau$ & $1.34 \mathrm{E}-05$ & $(2.95 \mathrm{E}-03)$ & $1.82 \mathrm{E}-03$ & $(1.57 \mathrm{E}-03)$ \\
\hline $\mathrm{AD}: \tau^{2}$ & $-2.12 \mathrm{E}-06$ & $(2.80 \mathrm{E}-05)$ & $-1.28 \mathrm{E}-05$ & $(1.03 \mathrm{E}-05)$ \\
\hline $\mathrm{PO}: \tau$ & $3.62 \mathrm{E}-04$ & $(3.68 \mathrm{E}-03)$ & $6.61 \mathrm{E}-03$ & $(5.77 \mathrm{E}-03)$ \\
\hline $\mathrm{PO}: \tau^{2}$ & $-3.23 \mathrm{E}-06$ & $(3.36 \mathrm{E}-05)$ & $-4.39 \mathrm{E}-05$ & $(3.84 \mathrm{E}-05)$ \\
\hline \multicolumn{5}{|c|}{ Variables as deviation from their mean value over all treated: } \\
\hline Age $35-44$ & $-1.56 \mathrm{E}-02$ & $(4.56 \mathrm{E}-02)$ & $-1.29 \mathrm{E}-02$ & $(2.32 \mathrm{E}-02)$ \\
\hline Age $45-50$ & $5.54 \mathrm{E}-03$ & $(5.43 \mathrm{E}-02)$ & $8.92 \mathrm{E}-03$ & $(2.95 \mathrm{E}-02)$ \\
\hline Halberstadt & $3.16 \mathrm{E}-02$ & $(4.70 \mathrm{E}-02)$ & $5.70 \mathrm{E}-02$ & $(5.30 \mathrm{E}-02)$ \\
\hline Halle & $2.90 \mathrm{E}-02$ & $(4.80 \mathrm{E}-02)$ & $3.84 \mathrm{E}-02$ & $(4.32 \mathrm{E}-02)$ \\
\hline Magdeburg & $3.22 \mathrm{E}-02$ & $(4.53 \mathrm{E}-02)$ & $4.28 \mathrm{E}-02$ & $(5.30 \mathrm{E}-02)$ \\
\hline Merseburg & $2.60 \mathrm{E}-02$ & $(4.53 \mathrm{E}-02)$ & $5.02 \mathrm{E}-02$ & $(5.05 \mathrm{E}-02)$ \\
\hline Sangerhausen & $2.95 \mathrm{E}-02$ & $(5.16 \mathrm{E}-02)$ & $5.49 \mathrm{E}-02$ & $(4.33 \mathrm{E}-02)$ \\
\hline Stendal & $2.79 \mathrm{E}-02$ & $(4.62 \mathrm{E}-02)$ & $3.58 \mathrm{E}-02$ & $(5.61 \mathrm{E}-02)$ \\
\hline Wittenberg & $-1.74 \mathrm{E}-01$ & $(2.02 \mathrm{E}-01)$ & $2.84 \mathrm{E}-02$ & $(3.81 \mathrm{E}-02)$ \\
\hline Skilled Worker & - & $(-)$ & - & $(-)$ \\
\hline Craftsman & $-8.01 \mathrm{E}-02$ & $(1.34 \mathrm{E}-01)$ & $-1.52 \mathrm{E}-02$ & $(5.37 \mathrm{E}-02)$ \\
\hline Technical college & $-7.34 \mathrm{E}-02$ & $(1.19 \mathrm{E}-01)$ & $-4.57 \mathrm{E}-02$ & $(5.38 \mathrm{E}-02)$ \\
\hline University education & $-7.28 \mathrm{E}-02$ & $(1.24 \mathrm{E}-01)$ & $-1.35 \mathrm{E}-01$ & $(9.07 \mathrm{E}-02)$ \\
\hline Female skilled worker & - & $(-)$ & $-3.95 \mathrm{E}-02$ & $(3.19 \mathrm{E}-02)$ \\
\hline Craftswoman & - & $(-)$ & $-7.93 \mathrm{E}-03$ & $(5.48 \mathrm{E}-02)$ \\
\hline Female and technical college & $-9.49 \mathrm{E}-02$ & $(1.26 \mathrm{E}-01)$ & $9.53 \mathrm{E}-03$ & $(3.35 \mathrm{E}-02)$ \\
\hline Female and university education & $3.06 \mathrm{E}-02$ & $(6.58 \mathrm{E}-02)$ & $1.20 \mathrm{E}-01$ & ( $6.71 \mathrm{E}-02)$ \\
\hline
\end{tabular}

AD: Ashenfelter's Dip $\equiv I(-a d(\tau) \leq t 1<0)$

PO: After end of program $\equiv I(t 1>0)$ 
Table 9: Coefficient estimates for CDiDHR - TR-TR - Employment in Previous Month

\begin{tabular}{|c|c|c|c|c|}
\hline \multirow{2}{*}{$\begin{array}{l}\text { Start of Evaluation: } \\
\text { Variable }\end{array}$} & \multicolumn{2}{|c|}{$\begin{array}{c}\text { Combined Effect } \\
\text { Two Month after } \\
\text { Start Month of Sequence }\end{array}$} & \multicolumn{2}{|c|}{$\begin{array}{c}\text { Incremental Effect of Second TR } \\
\text { Two Month after } \\
\text { Start Month of Second TR }\end{array}$} \\
\hline & Coef. & (s.e.) & Coef. & (s.e.) \\
\hline \multicolumn{5}{|c|}{ Long-run preprogram difference } \\
\hline Const & 0.000 & $(0.017)$ & -0.159 & (0.055) \\
\hline$t$ & $-1.19 \mathrm{E}-03$ & $(7.88 \mathrm{E}-04)$ & $1.58 \mathrm{E}-03$ & $(2.02 \mathrm{E}-03)$ \\
\hline$t^{2}$ & $9.24 \mathrm{E}-06$ & $(8.27 \mathrm{E}-06)$ & $-7.81 \mathrm{E}-06$ & $(1.61 \mathrm{E}-05)$ \\
\hline \multicolumn{5}{|l|}{ Outcome-Equation } \\
\hline $\bar{I} I(t 1=-6)$ & 0.134 & $(0.179)$ & -0.280 & (1.371) \\
\hline$I(t 1=-5)$ & 0.111 & $(0.184)$ & -0.374 & $(1.368)$ \\
\hline$I(t 1=-4)$ & 0.027 & $(0.169)$ & -0.350 & $(1.367)$ \\
\hline$I(t 1=-3)$ & 0.011 & $(0.157)$ & -0.257 & $(1.364)$ \\
\hline$I(t 1=-2)$ & -0.106 & $(0.146)$ & -0.331 & $(1.343)$ \\
\hline$I(t 1=-1)$ & -0.058 & $(0.137)$ & -0.351 & $(1.364)$ \\
\hline$I(t 1=1)$ & 0.111 & $(0.130)$ & 0.207 & $(0.442)$ \\
\hline$I(t 1=2)$ & 0.108 & $(0.125)$ & 0.257 & $(0.443)$ \\
\hline$I(t 1=3)$ & -0.147 & $(0.233)$ & 0.243 & $(0.442)$ \\
\hline$I(t 1=4)$ & 0.075 & $(0.109)$ & 0.254 & $(0.439)$ \\
\hline$I(t 1=5)$ & 0.039 & $(0.103)$ & 0.283 & $(0.440)$ \\
\hline$I(t 1=6)$ & 0.028 & $(0.103)$ & 0.278 & $(0.440)$ \\
\hline$I(t 1=7)$ & 0.034 & $(0.101)$ & 0.180 & $(0.449)$ \\
\hline$I(t 1=8)$ & 0.032 & $(0.102)$ & 0.279 & $(0.446)$ \\
\hline$I(t 1=9)$ & 0.030 & $(0.101)$ & 0.184 & $(0.460)$ \\
\hline$I(t 1=10)$ & 0.056 & $(0.104)$ & 0.278 & $(0.451)$ \\
\hline$I(t 1=11)$ & -0.004 & $(0.107)$ & 0.288 & $(0.452)$ \\
\hline$I(t 1=12)$ & -0.058 & $(0.129)$ & 0.291 & $(0.446)$ \\
\hline$I(t 1=13)$ & -0.103 & $(0.131)$ & 0.366 & $(0.447)$ \\
\hline$I(t 1=14)$ & 0.030 & $(0.102)$ & 0.241 & $(0.454)$ \\
\hline$I(t 1=15)$ & 0.030 & $(0.103)$ & 0.324 & $(0.441)$ \\
\hline$I(t 1=16)$ & -0.019 & $(0.102)$ & 0.298 & $(0.431)$ \\
\hline$I(t 1=17)$ & 0.064 & $(0.102)$ & 0.286 & $(0.427)$ \\
\hline$I(t 1=18)$ & -0.005 & $(0.110)$ & 0.351 & $(0.434)$ \\
\hline$I(t 1=19)$ & -0.050 & $(0.108)$ & 0.344 & $(0.435)$ \\
\hline$I(t 1=20)$ & 0.012 & $(0.106)$ & 0.345 & $(0.436)$ \\
\hline$I(t 1=21)$ & 0.014 & $(0.105)$ & 0.345 & $(0.436)$ \\
\hline$I(t 1=22)$ & 0.004 & ( 0.109 ) & 0.345 & $(0.436)$ \\
\hline$I(t 1=23)$ & 0.006 & $(0.095)$ & 0.336 & $(0.437)$ \\
\hline$I(t 1=24)$ & -0.113 & $(0.119)$ & 0.275 & $(0.436)$ \\
\hline$I(t 1=25)$ & 0.033 & $(0.098)$ & 0.332 & $(0.434)$ \\
\hline$I(t 1=26)$ & -0.025 & $(0.109)$ & 0.333 & $(0.435)$ \\
\hline$I(t 1=27)$ & 0.042 & $(0.102)$ & 0.330 & $(0.433)$ \\
\hline$I(t 1=28)$ & 0.048 & $(0.102)$ & 0.377 & $(0.448)$ \\
\hline
\end{tabular}

$<$ continued on next page $>$ 
Table 9: Coefficient estimates $<$ continued $>$

\begin{tabular}{|c|c|c|c|c|}
\hline \multirow{3}{*}{ Start of Evaluation: } & \multicolumn{2}{|c|}{ Combined Effect } & \multicolumn{2}{|c|}{ Incremental Effect of Second TR } \\
\hline & \multicolumn{2}{|c|}{$\begin{array}{c}\text { Two Month after } \\
\text { Start Month of Sequence }\end{array}$} & \multicolumn{2}{|c|}{$\begin{array}{l}\text { Two Month after } \\
\text { Start Month of Second TR }\end{array}$} \\
\hline & Coef. & (s.e.) & Coef. & (s.e.) \\
\hline$I(t 1=29)$ & 0.005 & $(0.110)$ & 0.402 & $(0.447)$ \\
\hline$I(t 1=30)$ & -0.016 & $(0.112)$ & 0.405 & $(0.448)$ \\
\hline$I(t 1=31)$ & 0.066 & $(0.103)$ & 0.397 & $(0.445)$ \\
\hline$I(t 1=32)$ & 0.007 & $(0.106)$ & 0.330 & $(0.462)$ \\
\hline$I(t 1=33)$ & -0.027 & $(0.111)$ & 0.391 & $(0.443)$ \\
\hline$I(t 1=34)$ & -0.041 & $(0.109)$ & 0.390 & $(0.443)$ \\
\hline$I(t 1=35)$ & -0.033 & $(0.119)$ & 0.395 & $(0.443)$ \\
\hline$I(t 1=36)$ & -0.031 & $(0.117)$ & 0.392 & $(0.448)$ \\
\hline $\mathrm{AD}: \tau$ & $-4.09 \mathrm{E}-03$ & $(6.84 \mathrm{E}-03)$ & $6.09 \mathrm{E}-03$ & $(3.77 \mathrm{E}-02)$ \\
\hline $\mathrm{AD}: \tau^{2}$ & $1.04 \mathrm{E}-05$ & $(6.51 \mathrm{E}-05)$ & $-2.41 \mathrm{E}-05$ & $(2.40 \mathrm{E}-04)$ \\
\hline $\mathrm{PO}: \tau$ & $-1.40 \mathrm{E}-03$ & $(5.62 \mathrm{E}-03)$ & $-4.71 \mathrm{E}-03$ & $(1.35 \mathrm{E}-02)$ \\
\hline $\mathrm{PO}: \tau^{2}$ & $2.49 \mathrm{E}-05$ & $(6.86 \mathrm{E}-05)$ & $4.54 \mathrm{E}-05$ & $(1.02 \mathrm{E}-04)$ \\
\hline \multicolumn{5}{|c|}{ Variables as deviation from their mean value over all treated: } \\
\hline Age $35-44$ & $1.83 \mathrm{E}-02$ & $(4.14 \mathrm{E}-02)$ & $-7.00 \mathrm{E}-02$ & $(1.77 \mathrm{E}-01)$ \\
\hline Age $45-50$ & $2.07 \mathrm{E}-01$ & $(1.94 \mathrm{E}-01)$ & - & $(-)$ \\
\hline Halberstadt & 3.78E-02 & $(8.53 \mathrm{E}-02)$ & $-4.41 \mathrm{E}-01$ & $(6.82 \mathrm{E}-01)$ \\
\hline Halle & $1.75 \mathrm{E}-01$ & $(1.07 \mathrm{E}-01)$ & $-3.28 \mathrm{E}-01$ & $(6.53 \mathrm{E}-01)$ \\
\hline Magdeburg & $2.40 \mathrm{E}-02$ & $(6.62 \mathrm{E}-02)$ & $-1.88 \mathrm{E}-01$ & ( $6.70 \mathrm{E}-01)$ \\
\hline Merseburg & $4.97 \mathrm{E}-02$ & $(7.21 \mathrm{E}-02)$ & $-3.11 \mathrm{E}-01$ & (6.69E-01) \\
\hline Sangerhausen & $-1.47 \mathrm{E}-02$ & $(7.70 \mathrm{E}-02)$ & $-3.23 \mathrm{E}-01$ & $(6.57 \mathrm{E}-01)$ \\
\hline Stendal & $-1.17 \mathrm{E}-02$ & $(1.06 \mathrm{E}-01)$ & $-4.14 \mathrm{E}-01$ & ( $6.63 \mathrm{E}-01)$ \\
\hline Wittenberg & $1.51 \mathrm{E}-01$ & $(1.78 \mathrm{E}-01)$ & $-4.84 \mathrm{E}-01$ & $(7.57 \mathrm{E}-01)$ \\
\hline Skilled Worker & - & $(-)$ & - & $(-)$ \\
\hline Craftsman & $-7.76 \mathrm{E}-02$ & $(1.12 \mathrm{E}-01)$ & - & $(-)$ \\
\hline Technical college & $-1.96 \mathrm{E}-01$ & $(2.16 \mathrm{E}-01)$ & - & $(-)$ \\
\hline University education & $-2.74 \mathrm{E}-01$ & $(1.67 \mathrm{E}-01)$ & 3.53E-01 & $(3.29 \mathrm{E}-01)$ \\
\hline Female skilled worker & $-1.05 \mathrm{E}-01$ & $(7.43 \mathrm{E}-02)$ & $2.11 \mathrm{E}-01$ & $(1.65 \mathrm{E}-01)$ \\
\hline Craftswoman & $-1.11 \mathrm{E}-01$ & $(1.00 \mathrm{E}-01)$ & - & $(-)$ \\
\hline Female and technical college & $1.21 \mathrm{E}-01$ & $(1.55 \mathrm{E}-01)$ & $1.07 \mathrm{E}-01$ & $(1.66 \mathrm{E}-01)$ \\
\hline Female and university education & $1.72 \mathrm{E}-01$ & $(1.07 \mathrm{E}-01)$ & $-1.51 \mathrm{E}-01$ & ( $3.64 \mathrm{E}-01)$ \\
\hline
\end{tabular}

AD: Ashenfelter's Dip $\equiv I(-a d(\tau) \leq t 1<0)$

PO: After end of program $\equiv I(t 1>0)$ 
Table 10: Coefficient estimates for CDiDHR - TR-JC nonemployment in Previous Month

\begin{tabular}{|c|c|c|c|c|}
\hline \multirow{2}{*}{$\begin{array}{l}\text { Start of Evaluation: } \\
\text { Variable }\end{array}$} & \multicolumn{2}{|c|}{$\begin{array}{c}\text { Combined Effect } \\
\text { One Month after } \\
\text { Start Month of Sequence }\end{array}$} & \multicolumn{2}{|c|}{$\begin{array}{c}\text { Incremental Effect of JC } \\
\text { One Month after } \\
\text { Start Month of JC }\end{array}$} \\
\hline & Coef. & (s.e.) & Coef. & (s.e.) \\
\hline \multicolumn{5}{|c|}{ Long-run preprogram difference } \\
\hline Const & -0.050 & $(0.048)$ & -0.008 & $(0.031)$ \\
\hline$t$ & $8.72 \mathrm{E}-04$ & $(1.74 \mathrm{E}-03)$ & $-5.70 \mathrm{E}-04$ & $(9.03 \mathrm{E}-04)$ \\
\hline$t^{2}$ & $-5.37 \mathrm{E}-06$ & $(1.44 \mathrm{E}-05)$ & $4.76 \mathrm{E}-06$ & $(6.27 \mathrm{E}-06)$ \\
\hline \multicolumn{5}{|l|}{ Outcome-Equation } \\
\hline$I(t 1=-9)$ & - & $(-)$ & -0.013 & $(0.049)$ \\
\hline$I(t 1=-8)$ & - & $(-)$ & -0.025 & $(0.049)$ \\
\hline$I(t 1=-7)$ & - & $(-)$ & -0.032 & $(0.048)$ \\
\hline$I(t 1=-6)$ & 0.007 & $(0.080)$ & -0.027 & $(0.049)$ \\
\hline$I(t 1=-5)$ & -0.003 & $(0.081)$ & -0.028 & $(0.047)$ \\
\hline$I(t 1=-4)$ & -0.036 & $(0.079)$ & -0.029 & $(0.048)$ \\
\hline$I(t 1=-3)$ & -0.023 & $(0.081)$ & -0.029 & $(0.048)$ \\
\hline$I(t 1=-2)$ & -0.025 & $(0.081)$ & -0.030 & $(0.047)$ \\
\hline$I(t 1=-1)$ & -0.031 & $(0.081)$ & -0.028 & $(0.047)$ \\
\hline$I(t 1=1)$ & -0.041 & $(0.084)$ & -0.007 & $(0.053)$ \\
\hline$I(t 1=2)$ & -0.042 & $(0.085)$ & 0.005 & $(0.052)$ \\
\hline$I(t 1=3)$ & -0.046 & $(0.085)$ & 0.003 & $(0.052)$ \\
\hline$I(t 1=4)$ & -0.051 & $(0.085)$ & 0.013 & $(0.052)$ \\
\hline$I(t 1=5)$ & -0.043 & $(0.084)$ & 0.002 & $(0.052)$ \\
\hline$I(t 1=6)$ & -0.039 & $(0.084)$ & 0.003 & $(0.053)$ \\
\hline$I(t 1=7)$ & -0.062 & $(0.086)$ & 0.006 & $(0.054)$ \\
\hline$I(t 1=8)$ & -0.040 & $(0.086)$ & 0.002 & $(0.053)$ \\
\hline$I(t 1=9)$ & -0.039 & $(0.084)$ & 0.010 & $(0.054)$ \\
\hline$I(t 1=10)$ & -0.040 & $(0.085)$ & 0.009 & $(0.053)$ \\
\hline$I(t 1=11)$ & -0.039 & $(0.085)$ & 0.006 & $(0.055)$ \\
\hline$I(t 1=12)$ & -0.050 & $(0.085)$ & 0.031 & $(0.057)$ \\
\hline$I(t 1=13)$ & -0.024 & $(0.087)$ & -0.007 & $(0.052)$ \\
\hline$I(t 1=14)$ & -0.037 & $(0.085)$ & 0.008 & $(0.052)$ \\
\hline$I(t 1=15)$ & -0.041 & $(0.084)$ & 0.007 & $(0.055)$ \\
\hline$I(t 1=16)$ & -0.045 & $(0.085)$ & 0.008 & $(0.055)$ \\
\hline$I(t 1=17)$ & -0.005 & $(0.089)$ & 0.014 & $(0.055)$ \\
\hline$I(t 1=18)$ & -0.034 & $(0.085)$ & 0.003 & $(0.054)$ \\
\hline$I(t 1=19)$ & -0.040 & $(0.085)$ & 0.014 & $(0.054)$ \\
\hline$I(t 1=20)$ & -0.029 & $(0.087)$ & 0.003 & $(0.055)$ \\
\hline$I(t 1=21)$ & -0.033 & $(0.085)$ & 0.008 & $(0.052)$ \\
\hline$I(t 1=22)$ & -0.037 & $(0.084)$ & 0.003 & $(0.053)$ \\
\hline$I(t 1=23)$ & -0.037 & $(0.084)$ & -0.003 & $(0.052)$ \\
\hline$I(t 1=24)$ & -0.030 & $(0.085)$ & 0.059 & $(0.060)$ \\
\hline$I(t 1=25)$ & -0.025 & $(0.086)$ & 0.019 & $(0.057)$ \\
\hline
\end{tabular}

$<$ continued on next page $>$ 
Table 10: Coefficient estimates $<$ continued $>$

\begin{tabular}{|c|c|c|c|c|}
\hline \multirow{3}{*}{$\begin{array}{l}\text { Start of Evaluation: } \\
\text { Variable }\end{array}$} & \multirow{2}{*}{\multicolumn{2}{|c|}{\begin{tabular}{|c|} 
Combined Effect \\
One Month after \\
Start Month of Sequence
\end{tabular}}} & \multirow{2}{*}{\multicolumn{2}{|c|}{$\begin{array}{c}\text { Incremental Effect of JC } \\
\text { One Month after } \\
\text { Start Month of JC }\end{array}$}} \\
\hline & & & & \\
\hline & Coef. & (s.e.) & Coef. & (s.e.) \\
\hline$I(t 1=26)$ & -0.042 & $(0.085)$ & 0.019 & $(0.055)$ \\
\hline$I(t 1=27)$ & -0.030 & $(0.086)$ & 0.010 & $(0.054)$ \\
\hline$I(t 1=28)$ & -0.016 & $(0.091)$ & 0.018 & $(0.055)$ \\
\hline$I(t 1=29)$ & -0.036 & $(0.085)$ & 0.020 & $(0.056)$ \\
\hline$I(t 1=30)$ & -0.021 & $(0.088)$ & 0.024 & $(0.056)$ \\
\hline$I(t 1=31)$ & -0.048 & $(0.086)$ & 0.004 & $(0.054)$ \\
\hline$I(t 1=32)$ & -0.030 & $(0.087)$ & 0.006 & $(0.053)$ \\
\hline$I(t 1=33)$ & -0.026 & $(0.086)$ & 0.003 & $(0.054)$ \\
\hline$I(t 1=34)$ & -0.041 & $(0.086)$ & 0.004 & $(0.053)$ \\
\hline$I(t 1=35)$ & -0.031 & $(0.086)$ & 0.004 & $(0.053)$ \\
\hline$I(t 1=36)$ & -0.049 & $(0.085)$ & 0.035 & $(0.058)$ \\
\hline $\mathrm{AD}: \tau$ & $2.07 \mathrm{E}-04$ & $(2.96 \mathrm{E}-03)$ & $7.82 \mathrm{E}-04$ & ( $1.39 \mathrm{E}-03)$ \\
\hline $\mathrm{AD}: \tau^{2}$ & $-1.96 \mathrm{E}-06$ & ( $2.63 \mathrm{E}-05)$ & $-6.50 \mathrm{E}-06$ & $(9.68 \mathrm{E}-06)$ \\
\hline $\mathrm{PO}: \tau$ & $1.16 \mathrm{E}-03$ & ( $3.25 \mathrm{E}-03)$ & $1.53 \mathrm{E}-04$ & ( $1.62 \mathrm{E}-03)$ \\
\hline $\mathrm{PO}: \tau^{2}$ & $-1.31 \mathrm{E}-05$ & (3.00E-05) & $-1.98 \mathrm{E}-06$ & $(1.16 \mathrm{E}-05)$ \\
\hline
\end{tabular}

Variables as deviation from their mean value over all treated:

\begin{tabular}{l|cc|cc}
\hline Age 35-44 & $-1.96 \mathrm{E}-03$ & $(3.09 \mathrm{E}-02)$ & $-1.85 \mathrm{E}-02$ & $(1.33 \mathrm{E}-02)$ \\
Age 45-50 & $-3.19 \mathrm{E}-02$ & $(3.97 \mathrm{E}-02)$ & $3.59 \mathrm{E}-03$ & $(1.78 \mathrm{E}-02)$ \\
Halberstadt & $-5.33 \mathrm{E}-02$ & $(4.62 \mathrm{E}-02)$ & $5.34 \mathrm{E}-03$ & $(2.69 \mathrm{E}-02)$ \\
Halle & $-1.63 \mathrm{E}-01$ & $(1.47 \mathrm{E}-01)$ & $-4.34 \mathrm{E}-03$ & $(1.97 \mathrm{E}-02)$ \\
Magdeburg & $-5.78 \mathrm{E}-02$ & $(4.96 \mathrm{E}-02)$ & $-2.13 \mathrm{E}-02$ & $(2.54 \mathrm{E}-02)$ \\
Merseburg & $-7.08 \mathrm{E}-02$ & $(5.43 \mathrm{E}-02)$ & $-1.21 \mathrm{E}-02$ & $(2.18 \mathrm{E}-02)$ \\
Sangerhausen & $-6.33 \mathrm{E}-02$ & $(4.99 \mathrm{E}-02)$ & $1.08 \mathrm{E}-03$ & $(1.79 \mathrm{E}-02)$ \\
Stendal & $-3.89 \mathrm{E}-02$ & $(5.44 \mathrm{E}-02)$ & $1.63 \mathrm{E}-02$ & $(3.07 \mathrm{E}-02)$ \\
Wittenberg & $-1.09 \mathrm{E}-01$ & $(7.63 \mathrm{E}-02)$ & $2.36 \mathrm{E}-02$ & $(3.27 \mathrm{E}-02)$ \\
Skilled Worker & $1.98 \mathrm{E}-02$ & $(6.64 \mathrm{E}-02)$ & $1.24 \mathrm{E}-02$ & $(1.96 \mathrm{E}-02)$ \\
Craftsman & $7.19 \mathrm{E}-02$ & $(9.11 \mathrm{E}-02)$ & $2.55 \mathrm{E}-02$ & $(4.87 \mathrm{E}-02)$ \\
Technical college & $-6.51 \mathrm{E}-02$ & $(8.33 \mathrm{E}-02)$ & $-1.71 \mathrm{E}-01$ & $(1.75 \mathrm{E}-01)$ \\
University education & $-1.21 \mathrm{E}-01$ & $(1.22 \mathrm{E}-01)$ & $9.95 \mathrm{E}-03$ & $(1.98 \mathrm{E}-02)$ \\
Female skilled worker & $-2.02 \mathrm{E}-02$ & $(6.82 \mathrm{E}-02)$ & $-1.39 \mathrm{E}-02$ & $(1.53 \mathrm{E}-02)$ \\
Craftswoman & $-7.82 \mathrm{E}-02$ & $(1.07 \mathrm{E}-01)$ & $-1.68 \mathrm{E}-02$ & $(4.82 \mathrm{E}-02)$ \\
Female and technical college & $7.32 \mathrm{E}-02$ & $(8.06 \mathrm{E}-02)$ & $1.69 \mathrm{E}-01$ & $(1.74 \mathrm{E}-01)$ \\
Female and university education & $1.10 \mathrm{E}-01$ & $(1.09 \mathrm{E}-01)$ & $2.40 \mathrm{E}-03$ & $(1.33 \mathrm{E}-02)$ \\
\hline AD: Ashenfter's Dip
\end{tabular}

AD: Ashenfelter's Dip $\equiv I(-a d(\tau) \leq t 1<0)$

PO: After end of program $\equiv I(t 1>0)$ 
Table 11: Coefficient estimates for CDiDHR - TR-JC - Employment in Previous Month

\begin{tabular}{|c|c|c|c|c|}
\hline \multirow{2}{*}{$\begin{array}{l}\text { Start of Evaluation: } \\
\text { Variable }\end{array}$} & \multicolumn{2}{|c|}{$\begin{array}{c}\text { Combined Effect } \\
\text { Two Month after } \\
\text { Start Month of Sequence }\end{array}$} & \multicolumn{2}{|c|}{$\begin{array}{c}\text { Incremental Effect of JC } \\
\text { Two Month after } \\
\text { Start Month of JC }\end{array}$} \\
\hline & Coef. & (s.e.) & Coef. & (s.e.) \\
\hline \multicolumn{5}{|c|}{ Long-run preprogram difference } \\
\hline Const & 0.021 & $(0.016)$ & -0.031 & $(0.026)$ \\
\hline$t$ & $-2.03 \mathrm{E}-03$ & $(8.81 \mathrm{E}-04)$ & $-2.23 \mathrm{E}-03$ & $(1.18 \mathrm{E}-03)$ \\
\hline$t^{2}$ & $1.24 \mathrm{E}-05$ & $(9.29 \mathrm{E}-06)$ & $1.34 \mathrm{E}-05$ & $(9.27 \mathrm{E}-06)$ \\
\hline \multicolumn{5}{|l|}{ Outcome-Equation } \\
\hline $\bar{I}(t 1=-9)$ & - & $(-)$ & 1.194 & $(0.639)$ \\
\hline$I(t 1=-8)$ & - & $(-)$ & 1.234 & $(0.590)$ \\
\hline$I(t 1=-7)$ & - & $(-)$ & 1.160 & $(0.571)$ \\
\hline$I(t 1=-6)$ & 0.170 & $(0.138)$ & 1.261 & $(0.568)$ \\
\hline$I(t 1=-5)$ & -0.025 & $(0.150)$ & 0.858 & $(0.597)$ \\
\hline$I(t 1=-4)$ & 0.031 & $(0.127)$ & 0.883 & $(0.366)$ \\
\hline$I(t 1=-3)$ & -0.053 & $(0.110)$ & 0.635 & $(0.423)$ \\
\hline$I(t 1=-2)$ & -0.040 & $(0.090)$ & -0.106 & $(0.337)$ \\
\hline$I(t 1=-1)$ & -0.116 & $(0.107)$ & - & $(-)$ \\
\hline$I(t 1=1)$ & 0.076 & $(0.118)$ & -0.468 & $(0.162)$ \\
\hline$I(t 1=2)$ & 0.075 & $(0.118)$ & -0.594 & $(0.208)$ \\
\hline$I(t 1=3)$ & 0.073 & $(0.118)$ & -0.569 & $(0.176)$ \\
\hline$I(t 1=4)$ & 0.059 & $(0.114)$ & -0.449 & $(0.190)$ \\
\hline$I(t 1=5)$ & 0.057 & $(0.114)$ & -0.464 & $(0.177)$ \\
\hline$I(t 1=6)$ & 0.075 & $(0.114)$ & -0.476 & $(0.172)$ \\
\hline$I(t 1=7)$ & 0.059 & $(0.110)$ & -0.510 & $(0.167)$ \\
\hline$I(t 1=8)$ & 0.065 & $(0.116)$ & -0.512 & $(0.163)$ \\
\hline$I(t 1=9)$ & 0.062 & $(0.112)$ & -0.535 & $(0.159)$ \\
\hline$I(t 1=10)$ & 0.060 & $(0.112)$ & -0.536 & $(0.159)$ \\
\hline$I(t 1=11)$ & -0.074 & $(0.149)$ & -0.634 & $(0.159)$ \\
\hline$I(t 1=12)$ & 0.055 & $(0.107)$ & -0.589 & $(0.154)$ \\
\hline$I(t 1=13)$ & -0.019 & $(0.111)$ & -0.588 & $(0.154)$ \\
\hline$I(t 1=14)$ & 0.081 & $(0.104)$ & -0.572 & $(0.153)$ \\
\hline$I(t 1=15)$ & -0.078 & $(0.149)$ & -0.581 & $(0.153)$ \\
\hline$I(t 1=16)$ & 0.079 & $(0.103)$ & -0.581 & $(0.153)$ \\
\hline$I(t 1=17)$ & -0.054 & $(0.125)$ & -0.580 & $(0.154)$ \\
\hline$I(t 1=18)$ & -0.062 & $(0.149)$ & -0.652 & $(0.165)$ \\
\hline$I(t 1=19)$ & 0.063 & $(0.108)$ & -0.584 & $(0.152)$ \\
\hline$I(t 1=20)$ & 0.007 & $(0.127)$ & -0.575 & $(0.152)$ \\
\hline$I(t 1=21)$ & 0.058 & $(0.108)$ & -0.576 & $(0.152)$ \\
\hline$I(t 1=22)$ & 0.053 & $(0.107)$ & -0.577 & $(0.152)$ \\
\hline$I(t 1=23)$ & 0.006 & $(0.108)$ & -0.571 & $(0.152)$ \\
\hline$I(t 1=24)$ & 0.003 & $(0.120)$ & -0.535 & $(0.153)$ \\
\hline$I(t 1=25)$ & 0.011 & $(0.114)$ & -0.533 & $(0.153)$ \\
\hline
\end{tabular}


Table 11: Coefficient estimates <continued $>$

\begin{tabular}{l|cc|cc}
\hline \multirow{2}{*}{ Start of Evaluation: } & \multicolumn{3}{|c|}{ Combined Effect } & \multicolumn{2}{c}{ Incremental Effect of JC } \\
& \multicolumn{2}{|c}{ Two Month after } & \multicolumn{2}{c}{ Two Month after } \\
Start Month of Sequence & \multicolumn{2}{c}{ Start Month of JC } \\
Variable & Coef. & (s.e. $)$ & Coef. & $($ s.e. $)$ \\
\hline$I(t 1=26)$ & 0.014 & $(0.118)$ & -0.537 & $(0.154)$ \\
$I(t 1=27)$ & -0.035 & $(0.121)$ & -0.537 & $(0.153)$ \\
$I(t 1=28)$ & 0.058 & $(0.109)$ & -0.538 & $(0.154)$ \\
$I(t 1=29)$ & 0.061 & $(0.109)$ & -0.537 & $(0.154)$ \\
$I(t 1=30)$ & -0.058 & $(0.133)$ & -0.538 & $(0.154)$ \\
$I(t 1=31)$ & 0.063 & $(0.107)$ & -0.610 & $(0.165)$ \\
$I(t 1=32)$ & 0.066 & $(0.110)$ & -0.539 & $(0.156)$ \\
$I(t 1=33)$ & 0.064 & $(0.109)$ & -0.626 & $(0.158)$ \\
$I(t 1=34)$ & -0.028 & $(0.121)$ & -0.594 & $(0.154)$ \\
$I(t 1=35)$ & 0.012 & $(0.115)$ & -0.598 & $(0.155)$ \\
$I(t 1=36)$ & 0.050 & $(0.108)$ & -0.615 & $(0.156)$ \\
$\mathrm{AD}: \tau$ & $-1.04 \mathrm{E}-03$ & $(4.97 \mathrm{E}-03)$ & $-4.16 \mathrm{E}-02$ & $(1.61 \mathrm{E}-02)$ \\
$\mathrm{AD}: \tau^{2}$ & $-3.15 \mathrm{E}-05$ & $(5.08 \mathrm{E}-05)$ & $2.65 \mathrm{E}-04$ & $(1.04 \mathrm{E}-04)$ \\
$\mathrm{PO}: \tau$ & $-1.33 \mathrm{E}-03$ & $(6.70 \mathrm{E}-03)$ & $2.92 \mathrm{E}-02$ & $(7.02 \mathrm{E}-03)$ \\
$\mathrm{PO}: \tau^{2}$ & $1.04 \mathrm{E}-05$ & $(7.64 \mathrm{E}-05)$ & $-2.27 \mathrm{E}-01$ & $(3.602536 \mathrm{E}-04)$ \\
\hline
\end{tabular}

Variables as deviation from their mean value over all treated:

\begin{tabular}{l|cc|cc}
\hline Age 35-44 & $-3.26 \mathrm{E}-02$ & $(4.70 \mathrm{E}-02)$ & - & $(-)$ \\
Age 45-50 & $-1.31 \mathrm{E}-02$ & $(5.81 \mathrm{E}-02)$ & $-2.13 \mathrm{E}-01$ & $(8.14 \mathrm{E}-02)$ \\
Halberstadt & $-5.15 \mathrm{E}-02$ & $(7.68 \mathrm{E}-02)$ & $4.53 \mathrm{E}-01$ & $(1.11 \mathrm{E}-01)$ \\
Halle & $-5.17 \mathrm{E}-02$ & $(1.16 \mathrm{E}-01)$ & $4.29 \mathrm{E}-01$ & $(1.37 \mathrm{E}-01)$ \\
Magdeburg & $-2.09 \mathrm{E}-02$ & $(4.68 \mathrm{E}-02)$ & $3.89 \mathrm{E}-01$ & $(8.11 \mathrm{E}-02)$ \\
Merseburg & $-7.97 \mathrm{E}-02$ & $(6.90 \mathrm{E}-02)$ & $1.61 \mathrm{E}-01$ & $(7.59 \mathrm{E}-02)$ \\
Sangerhausen & $-4.35 \mathrm{E}-03$ & $(5.11 \mathrm{E}-02)$ & $3.15 \mathrm{E}-01$ & $(7.61 \mathrm{E}-02)$ \\
Stendal & $-8.06 \mathrm{E}-02$ & $(8.23 \mathrm{E}-02)$ & $3.47 \mathrm{E}-01$ & $(1.56 \mathrm{E}-01)$ \\
Wittenberg & $-9.75 \mathrm{E}-02$ & $(7.19 \mathrm{E}-02)$ & $5.02 \mathrm{E}-01$ & $(1.14 \mathrm{E}-01)$ \\
Skilled Worker & $-1.34 \mathrm{E}-01$ & $(7.43 \mathrm{E}-02)$ & $-4.80 \mathrm{E}-01$ & $(1.09 \mathrm{E}-01)$ \\
Craftsman & $-9.86 \mathrm{E}-02$ & $(1.25 \mathrm{E}-01)$ & - & $(-)$ \\
Technical college & $-2.07 \mathrm{E}-01$ & $(1.12 \mathrm{E}-01)$ & - & $(-)$ \\
University education & $-1.29 \mathrm{E}-01$ & $(8.24 \mathrm{E}-02)$ & - & $(-)$ \\
Female skilled worker & $-3.71 \mathrm{E}-02$ & $(5.94 \mathrm{E}-02)$ & $5.56 \mathrm{E}-01$ & $(1.50 \mathrm{E}-01)$ \\
Craftswoman & - & $(-)$ & - & $(-)$ \\
Female and technical college & $-2.24 \mathrm{E}-03$ & $(9.76 \mathrm{E}-02)$ & - & $(-)$ \\
Female and university education & $-5.84 \mathrm{E}-03$ & $(5.37 \mathrm{E}-02)$ & $-1.29 \mathrm{E}-01$ & $(5.93 \mathrm{E}-02)$ \\
\hline
\end{tabular}

Incremental Effect of JC with conventional, heteroscedasticity consistent standard errors due to insufficient number of observations.

AD: Ashenfelter's Dip $\equiv I(-a d(\tau) \leq t 1<0)$

PO: After end of program $\equiv I(t 1>0)$ 